\title{
Nanostructured Inorganic Materials at Work in Electrochemical Sensing and Biofuel Cells
}

\author{
Yaovi Holade ${ }^{1, *}$, Sophie Tingry ${ }^{1}$, Karine Servat ${ }^{2}$, Teko W. Napporn ${ }^{2}$, David Cornu ${ }^{1}$ \\ and Kouakou Boniface Kokoh ${ }^{2}$ \\ 1 Institut Européen des Membranes, IEM UMR 5635, CNRS-UM-ENSCM, Place Eugène Bataillon, \\ 34095 Montpellier CEDEX 5, France; sophie.tingry@univ-montp2.fr (S.T.); david.cornu@enscm.fr (D.C.) \\ 2 UMR 7285 CNRS, “Équipe SAMCat”, Université de Poitiers, 4 rue Michel Brunet, B27, TSA 51106, \\ 86073 Poitiers CEDEX 09, France; karine.servat@univ-poitiers.fr (K.S.); \\ teko.napporn@univ-poitiers.fr (T.W.N.); boniface.kokoh@univ-poitiers.fr (K.B.K.) \\ * Correspondence: yaovi.holade@enscm.fr; Tel.: +33-467-14-91-14
}

Academic Editor: Angeliki A. Lemonidou

Received: 30 November 2016; Accepted: 11 January 2017; Published: 18 January 2017

\begin{abstract}
The future of analytical devices, namely (bio)sensors, which are currently impacting our everyday life, relies on several metrics such as low cost, high sensitivity, good selectivity, rapid response, real-time monitoring, high-throughput, easy-to-make and easy-to-handle properties. Fortunately, they can be readily fulfilled by electrochemical methods. For decades, electrochemical sensors and biofuel cells operating in physiological conditions have concerned biomolecular science where enzymes act as biocatalysts. However, immobilizing them on a conducting substrate is tedious and the resulting bioelectrodes suffer from stability. In this contribution, we provide a comprehensive, authoritative, critical, and readable review of general interest that surveys interdisciplinary research involving materials science and (bio)electrocatalysis. Specifically, it recounts recent developments focused on the introduction of nanostructured metallic and carbon-based materials as robust "abiotic catalysts" or scaffolds in bioelectrochemistry to boost and increase the current and readout signals as well as the lifetime. Compared to biocatalysts, abiotic catalysts are in a better position to efficiently cope with fluctuations of temperature and $\mathrm{pH}$ since they possess high intrinsic thermal stability, exceptional chemical resistance and long-term stability, already highlighted in classical electrocatalysis. We also diagnosed their intrinsic bottlenecks and highlighted opportunities of unifying the materials science and bioelectrochemistry fields to design hybrid platforms with improved performance.
\end{abstract}

Keywords: nanomaterials; electrocatalysis; bioelectrocatalysis; electroanalysis; non-enzymatic sensing; glucose; sensor; biosensor; electrochemical sensing; biofuel cells

\section{Introduction}

The field of biosensors, analytical devices which are used to determine the presence and amount of specific analytes in a biological matrix, has attracted much attention within the last quarter century because of the fundamental questions and the potentially practical applications in our everyday life. With the buzzword "bioelectronics", which aims to highlight that the world of electronics can be combined with biology and biotechnology [1,2], our daily life is impacted by various specific biosensors developed for clinical diagnosis such as glucose monitoring in diabetic patients (the historical market driver), detection of pathogens, food analysis (level of specific species such as sugar), determination of drug residues in food such as antibiotics and growth promoters (particularly meat and honey), environmental applications (detection of pesticides and river water contaminants such as heavy metal ions), homeland security (remote sensing of airborne bacteria such as in counter-bioterrorist 
activities), determination of levels of toxic substances before and after bioremediation, detection and determination of organophosphate, routine analytical measurement of folic acid, biotin, vitamin B12 and pantothenic acid as an alternative to microbiological assay, drug discovery and evaluation of biological activity of new compounds, protein engineering, detection of toxic metabolites such as mycotoxins, and so on. The most important basic characteristics of a biosensor are: (i) linearity, because the detection of a high substrate concentration requires the maximum linear value of the sensor calibration curve; (ii) sensitivity, because the value of the electrode response per substrate concentration should be significantly high, i.e., capable of detecting trace quantity; (iii) selectivity, because any interference of other chemical species within the analyzed sample must be minimized for obtaining the correct result; (iv) response time, because the sampling time, i.e., the necessary time for having $95 \%$ of the response, should be as small as possible.

By an amperometric biosensor, one understands a self-containing integrated device based on the measurement of an electrochemical signal, i.e., the current resulting from the oxidation or reduction of an electroactive biological element (biomolecule) providing specific quantitative analytical information. Basically, a biosensor is a device that uses specific biochemical reactions mediated by isolated enzymes, immune systems, tissues, organelles or whole cells to detect chemical compounds usually by electrical, thermal or optical signals [3-5]. Thus, the derived name of "sensor" mostly focuses on the targeted analyte rather than the catalyst that performs the reaction. Currently, electroanalytical devices operating in the tremendous electrochemical integrated biosensors work in dual directions: (i) the electrochemical event alters the interfacial properties of the electronic element, thus enabling the readout of the catalytic reaction by monitoring the performance of the process (readout current, potential, impedance, charge transfer); (ii) the sensor system uses the electronic units to activate the biomaterial toward a desired function [1]. Thus, it is important to understand the core fundamental process underlying the performance of the sensor that is the catalytic reaction. The majority of developed sensors aim at tracking glucose levels in either blood or food. Basically, blood glucose monitoring is a way of checking the glucose concentration in the blood using a sensor called a glucometer. The purpose of this great interest is to provide a quick and real-time response to check if the sugar level is high or low, indicating a change in diet, exercise or insulin since glucose is the main physiological carbohydrate. Furthermore, the monitoring of blood glucose is very important to reduce and anticipate the risk of developing complications with diabetes. Practically, a daily checking of the glucose level allows diabetics and physicians to have a powerful tool to see whether the insulin and other administrated medications work or not. Overall, the approach should prevent hypoglycemia or hyperglycemia. Glucose oxidation is not only useful for blood glucose monitoring but may also be applied to other areas such as industrial processes (e.g., the food industry), and the development of fuel cells and batteries. In these cases, assays should be extended to other carbohydrates of interest such as lactose, maltose, etc.

Furthermore, several proof-of-concept investigations have shown that other non-invasive electrochemical sensors can be readily developed to track the progress of biochemical reactions through some indicators such as hydrogen peroxide $\left(\mathrm{H}_{2} \mathrm{O}_{2}\right)$, ascorbic acid, dopamine, DNA, etc. [6-13]. Given the low analyte-level measurements in a relatively complex matrix, the screening and development of high-performing electrode materials that provide better sensitivity and selectivity is essential. For instance, $\mathrm{H}_{2} \mathrm{O}_{2}$ is produced by most oxidases in mitochondria and diffuses out through the membranes toward various cellular compartments. Since it is the major cellular reactive oxygen species (ROS) in living organisms, its precise quantification should enable a better understanding of the clinical consequences of their concentration enhancement. Currently, electrode materials can be made from enzymes (enzymatic) or carbon-metallic species (abiotic). The overall aim of the review is not to oppose enzymatic catalysis to abiotic catalysis, but to discuss how nanostructured inorganic materials can boost the field of sensors (restricted to glucose and hydrogen peroxide, given their paramount importance in biochemical reactions) and fuel cells utilizing molecules that can be vastly found in biological systems. Given the multivariate approaches involved in the fabrication of glucose-sensing 
electrodes, the different mechanisms involving enzymatic electrodes will be firstly examined before moving to abiotic ones.

\section{From Enzymatically to Abiotically Assisted Sensing}

The rich and diverse research in the field of glucose biosensors has released three main types of so-called "enzymatic glucose biosensors" and classified them in terms of first, second, and third generation as shown in Figure 1. Herein, we introduce the name of "fourth generation" for non-enzymatic glucose biosensors, which bypass the use of an enzyme as a catalyst to perform the oxidation of the biomolecule, i.e., glucose. For the first generation, the normal product of the reaction diffuses to the transducer and causes an electrical response, while the second generation involves specific mediators between the reaction and transducer to generate an improved response, and the third generation concerns the reaction itself that causes the response. The core component of these systems is the biocatalyst that is not a conductor while it must transfer electrons. Hence, with the use of a solid electronic conductor, bioelectrocatalysts typically operate at lower temperatures and milder conditions than traditional electrocatalysis, because most biological catalysts have evolved to be most stable and active at relatively low temperature and near-neutral $\mathrm{pH}$ [14].

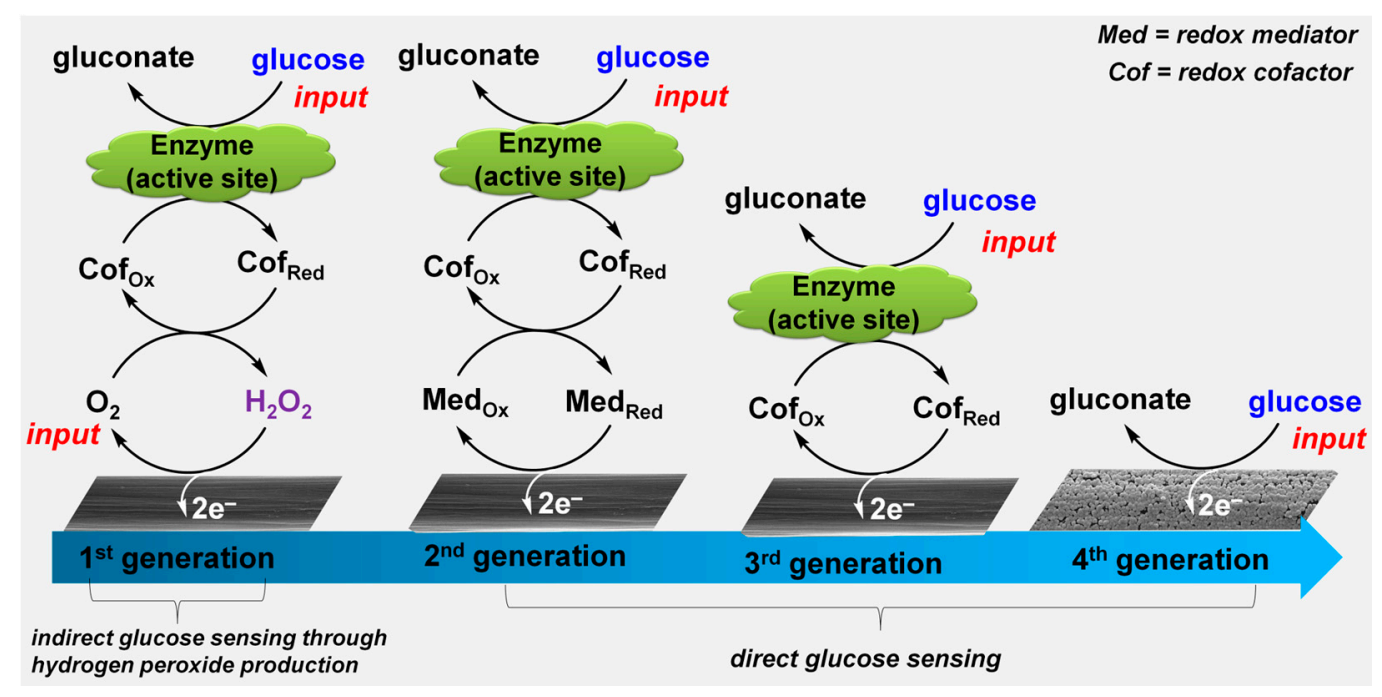

Figure 1. Summary of glucose electrooxidation mechanisms: presented as enzymatic (first-, secondand third-generation sensors) and non-enzymatic (so-called herein "fourth-generation" sensors).

\subsection{First-Generation Glucose-Sensing Bioelectrocatalysis}

First-generation glucose biosensors (reported in 1962, a Clark electrode coated with GOx separated by a dialysis membrane) mostly estimate the glucose concentration in the sample based on $\mathrm{H}_{2} \mathrm{O}_{2}$ production by GOx utilizing dissolved oxygen $\left(\mathrm{O}_{2 \mathrm{~d}}\right)[15,16]$. GOx is a flavin adenine dinucleotide (FAD)-containing enzyme which selectively oxidizes $\beta$-D-glucose to glucono-1,5-lactone. During the reaction, the FAD cofactor (oxidized form, Cof $\mathrm{Ox}_{\text {) }}$ is reduced to $\mathrm{FADH}_{2}$ (reduced state, $\mathrm{Cof}_{\text {Red }}$ ) which further reacts with $\mathrm{O}_{2 \mathrm{~d}}$ to be oxidized back to FAD and $\mathrm{H}_{2} \mathrm{O}_{2}$ is produced, as in Equations (1) and (2) [17-20].

$$
\begin{gathered}
\beta \text {-D-glucose }+ \text { yellow } \mathrm{GOx}(\mathrm{FAD}) \rightarrow \text { glucono- } \delta \text {-lactone }+ \text { colorlessGOx }\left(\mathrm{FADH}_{2}\right) \\
\text { colorlessGOx }\left(\mathrm{FADH}_{2}\right)+\mathrm{O}_{2} \rightarrow \text { yellow } \mathrm{GOx}(\mathrm{FAD})+\mathrm{H}_{2} \mathrm{O}_{2} \\
\mathrm{H}_{2} \mathrm{O}_{2} \rightarrow \mathrm{O}_{2}+2 \mathrm{H}^{+}+2 \mathrm{e}^{-}
\end{gathered}
$$


This reaction leads to a decrease in $\mathrm{O}_{2 \mathrm{~d}}$ and an increase in $\mathrm{H}_{2} \mathrm{O}_{2}$ concentrations near the electrode, which cause a variation (decrease or increase, depending on the electrode potential window) in the measured current proportional to the glucose amount that is oxidized, allowing its detection. It can be presumed that this category of biosensors operates through the indirect glucose measurement by either recording the $\mathrm{O}_{2 \mathrm{~d}}$ depletion near the electrode or detecting the produced electrochemically reactive $\mathrm{H}_{2} \mathrm{O}_{2}$ (oxidation reaction current, Equation (3)). The first generation faces several drawbacks, which in turn limit their widespread application. To get high selectivity, the amperometric measurement of $\mathrm{H}_{2} \mathrm{O}_{2}$ requires a high operating potential (typically $0.6 \mathrm{~V}$ vs. $\mathrm{Ag}|\mathrm{AgCl}| \mathrm{KCl}_{\text {sat }}$ ) at the commonly used $\mathrm{Pt}$ electrode to insure bioelectrocatalyst regeneration at the electrode. Thereafter, such Pt electrodes can be fouled by components of the sample to be tested and other components may also be electroactive (presence of electroactive interference species in the blood). One logical solution for preventing the above issues is to use a coating, which limits the exposure of the electrode surface to these chemicals. Unfortunately, the strategy rapidly results in the restricted solubility of oxygen in biological fluids, which produces fluctuations in the oxygen tension while the device requires a stable oxygen concentration when the assays focus on the $\mathrm{H}_{2} \mathrm{O}_{2}$ detection. In practice, any concentration fluctuations not due to the $\mathrm{H}_{2} \mathrm{O}_{2}$ generation will result in a current change and give inaccurate results. Other serious disadvantages are the deactivation of the enzyme GOx due to the production of $\mathrm{H}_{2} \mathrm{O}_{2}$ (inhibitor of the enzyme itself), and the use of an expensive Pt metal for the fabrication of electrodes restricts the biosensor to clinical laboratories only.

Furthermore, as a non-diffusional cofactor, the FAD redox center is deep within the three-dimensional (3D) enzyme structure and protected by a thick protein layer [21-23]. As a matter of fact, electron transfer to the active center is a major limiting factor, which causes complicated electron transfer mechanisms. It should be noticed that other alternatives of reducing undesired reactions by decreasing the required potential for $\mathrm{H}_{2} \mathrm{O}_{2}$ detection at about $0 \mathrm{~V}$ vs. $\mathrm{Ag}|\mathrm{AgCl}| \mathrm{KCl}_{\text {sat }}$, where fewer non-target species will be oxidized, lead to incorporating metallic species (Prussian blue, Rh or $\mathrm{Ru}$ ) at the electrode surface $[3,24,25]$. Alternatively, horseradish peroxidase (HRP) enzyme [26-28] which oxidizes $\mathrm{H}_{2} \mathrm{O}_{2}$ electrocatalytically at lower potentials without oxidizing any other components of the sample can be incorporated. Hence, finding elegant ways to, firstly, remove the oxygen dependence and, secondly, facilitate electron transfer from the substrate to the active center imbedded in the enzyme molecular network led to the development of second-generation biosensors.

\subsection{Second-Generation Glucose-Sensing Bioelectrocatalysis}

A second-generation glucose biosensor utilizes a redox mediator to transfer electrons from the active center of the enzyme to the working electrode surface, i.e., it replaces $\mathrm{O}_{2 \mathrm{~d}}$ in a first-generation biosensor (thus overcoming the drawback of observed dependence on oxygen pressure) with redox active species capable of transferring electrons from the biocatalyst active site to the electrode surface. It is called mediated electron transfer (MET) bioelectrocatalysis $[20,29,30]$. This strategy is used when the active site of the enzyme is physically inaccessible to the electrode surface and an artificial intermediate redox species is solicited to shuttle electrons between the enzyme and electrode. In such configuration, the electron mediator reacts with the cofactor of the biocatalyst and is reduced while the cofactor is oxidized to its initial state. The oxidation of the mediator by the electrode produces a current proportional to the concentration of the glucose input. Alongside the FAD-GOx, the pyrroloquinoline quinone-dependent glucose dehydrogenase (PQQ-GDH) is another alternative that seems to catalyze also other sugars, leading to an overestimation of the total "glucose concentration". Other strategies are based on the use of nicotinamide adenine dinucleotide (NAD) as a cofactor to combine $\mathrm{O}_{2}$ independence and specificity toward glucose only [31]. It should be expressively stated that $\mathrm{NAD}^{+}$is a diffusional cofactor; hence, its diffusion capability is another challenge of paramount importance. For an efficient and accurate sensing capability, the mediator must possess a number of essential attributes that idealize it for enzymatic glucose analysis, including a low molecular weight and an insoluble nature so as to effectively diffuse without complexing, reversible 
or quasi-reversible properties (excellent electron-acceptor and electron-donor properties), a suitably lower redox potential to avoid oxidation of interfering species, high stability and resistance to forming side compounds, and low toxicity (particularly where in vivo use would be required) [32]. A variety of redox mediators, such as derivates of ferrocene, ferricyanide, quinone, methylene blue, transition-metal complexes, etc., were used to improve sensor performance [29,33-40]. For a given species to be an excellent redox mediator, its electrochemical potential $\left(E_{m}^{0}\right)$ which determines the operational potential of the biocatalytic electrode must be such that it provides a necessary thermodynamic driving force to facilitate electron transfer with the enzyme. For an enzymatic oxidation reaction, $E_{m}^{0}$ must be higher than the redox potential of the enzyme $\left(E_{e n}^{0}\right)$ whereas the reverse is true for an enzymatic reduction reaction; $\Delta E_{e l}=\left|E_{m}^{0}-E_{e n}^{0}\right|$ is defined as the mediator-induced overpotential which is the potential required for electron transfer to occur between the enzyme and mediator [14]. Experimentally, $\Delta E_{\mathrm{el}}=200-400 \mathrm{mV}$ is suggested to provide the minimum overpotential needed to reach the maximum enzyme-mediator electron transfer rate [14,41-43]. With a judicious choice of the redox mediator, enhanced electron transfer between the redox center of enzyme and the electrode surface occurs at a relatively lower electrode potential where interference from another electroactive species might be negligible. Far from being a simple strategy, the effectiveness of the second-generation bioelectrocatalysis mostly relies on the different mediator immobilization strategies such as adsorption or electrodeposition onto the surface, tethering to a polymer backbone, or binding directly to the biocatalyst. Among the long list of major drawbacks of second-generation glucose biosensors, there is the competition between the redox mediator and oxygen, the interference of other electroactive species with the mediator which could lead to false and inaccurate results, and the small size and highly diffusive nature of mediators which cause issues of leaching of mediator from the intermediate region between the enzyme and electrode surface. Overall, using an artificial redox mediator introduces an additional layer of complexity to the design of the electrodes, which rarely leads to a thorough understanding of the fundamental phenomena and a technological break in the field.

A proof-of-concept of a dual-integrated sensor array measuring glucose and lactate levels simultaneously and selectively in sweat metabolites is presented within Figure 2 [3]. Indeed, wearable electronics are a class of sensors, devices that can be worn or mated with human skin to continuously and closely monitor an individual's activities without interrupting or limiting the user's motions and are designed for real-time continuous monitoring of collective or individual physiological biomarkers [3]. Developed by Javey and co-workers, this mechanically flexible and fully integrated sensor array (FISA) for multiplexed in situ perspiration analysis (no external analysis is needed) enables the simultaneous and selective measurement of sweat metabolites (glucose and lactate) and electrolytes (sodium $\left(\mathrm{Na}^{+}\right)$and potassium $\left(\mathrm{K}^{+}\right)$ions), as well as the skin temperature (to calibrate the response of the sensors) [3]. Figure 2a displays the schematic illustration of the multiplexed sensor array (where each electrode has a $3 \mathrm{~mm}$ diameter) for sweat analysis by four biomarkers: glucose, lactate, $\mathrm{Na}^{+}$and $\mathrm{K}^{+}$. Cations $\mathrm{Na}^{+}$and $\mathrm{K}^{+}$are secreted in their native form; thus, the measurement of their levels is only facilitated through the use of ion-selective electrodes (ISEs). However, assays of glucose and lactate require catalysts that have the intrinsic ability of performing their selective oxidation. To these ends, amperometric glucose and lactate sensors (with current output) are based on GOx and lactate oxidase (LOx) which are immobilized within a permeable film of a linear polysaccharide chitosan. To enhance the sensitivity of the multiplexed bioelectrodes, either a GOx solution is mixed thoroughly with a chitosan/carbon nanotubes one or a LOx layer is sandwiched between two layers of chitosan/carbon nanotubes at $\mathrm{pH}$ 7.2. The mixture stands on a thinner Prussian blue layer mediator that has been preliminary electrodeposited on a bare Au electrode (promotes better immobilization $[19,44-46]$ ). In such a configuration, the input will be the substrate (glucose, lactate) and the output current (between the working electrode and the counter-electrode) of the sensor can be converted to a voltage through a transimpedance amplifier. Hence, the calibration curve can be set as the current or voltage. However, one should keep in mind that adding a new step to a process is accompanied by another layer of complexity in the design. Thus, it is very 
important to note that this current-voltage conversion should be used only if the device suffers from sensitivity issues coming from the magnitude of the produced current. Prior to their practical implementation, the conducted ex situ assays revealed linear relationships between the current and analyte concentration with sensitivities of $2.35 \mathrm{nA} \cdot \mu \mathrm{M}^{-1}$ for glucose sensors and $220 \mathrm{nA} \cdot \mathrm{mM}^{-1}$ for lactate sensors [3]. These enzymatic sensors autonomously generate current signals proportional to the abundance of the corresponding metabolites between the working and the $\mathrm{Ag}|\mathrm{AgCl}| \mathrm{KCl}_{\text {sat }}$ electrodes (serves as a shared reference electrode and counter-electrode) where glucose is oxidized to gluconic acid (a two-electron process) and lactate to pyruvate (a one-electron process). For the autonomous operation, a sensor needs energy to conduct the electrochemical oxidation reaction. To this end, FISA is powered by a single rechargeable lithium-ion polymer battery with a nominal voltage of $3.7 \mathrm{~V}$ of a desired capacity of $105 \mathrm{mAh}$. The designed collective sensor can be comfortably worn on various body parts, including the forehead, wrists and arms as illustrated in Figure $2 b$ where a human subject wears two FISAs, packaged as a "smart wristband" and a "smart headband", allowing for real-time perspiration monitoring on the wrist and forehead simultaneously during stationary leg cycling. This on-body, real-time perspiration analysis during a stationary or operating exercise has been made practical by a custom-developed mobile application for data display and aggregation as shown in Figure 2c (the four targeted biomarkers). It is obvious that this work bridges the technological gap between signal transduction, conditioning (amplification and filtering), processing and wireless transmission in wearable biosensors by merging plastic-based sensors. However, several questions remain unresolved among which is the sensitivity of the biocatalyst GOx with $\mathrm{O}_{2}$, whose concentration in biofluids is relatively important (about $200 \mu \mathrm{M}$ ). Indeed, as it has been shown in Section 2.1, GOx is capable of reacting with $\mathrm{O}_{2}$ to produce $\mathrm{H}_{2} \mathrm{O}_{2}$ so that the assays will have a "false positive result". Since $\mathrm{H}_{2} \mathrm{O}_{2}$ is an inhibitor of GOx, the sensor will be also gradually deteriorated.

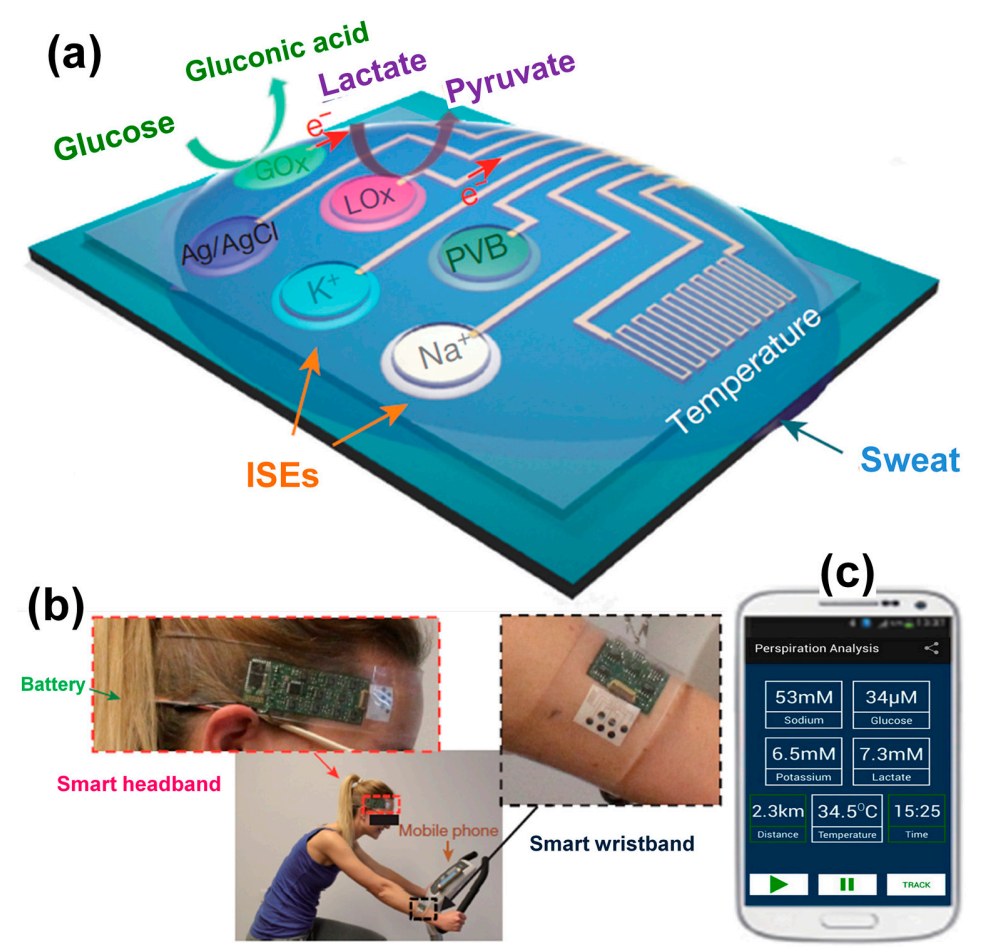

Figure 2. (a) Schematic illustration of the sensor array (including glucose, lactate, sodium, potassium and temperature sensors) for multiplexed perspiration analysis including: ion-selective electrodes (ISEs), polyvinyl butyral (PVB), glucose oxidase (GOx) and lactate oxidase (LOx); (b) Photographs of a subject wearing a "smart headband" and a "smart wristband" during stationary cycling; (c) Real-time data display of sweat analyte levels as well as skin temperature during exercise. Reprinted and Adapted with permission from Reference [3]. Copyright Macmillan Publishers Limited, 2016. 


\subsection{Third-Generation Glucose-Sensing Bioelectrocatalysis}

Researchers have come up with the third-generation glucose biosensors on the basis of the direct electron transfer (DET) between the active center of the enzyme and the electrode, provided the distance is close enough $[19,20,47]$, thus bypassing the simultaneous use of a redox mediator and oxygen interference. It is an ambitious type of enzymatic bioelectrocatalysis. In this elegant and attractive approach, termed DET or direct bioelectrocatalysis, electrons are transferred directly from the active site of the biocatalyst to the conducting electrode (in the case of an oxidation reaction) which acts as an "electron source or sink" with respect to the electrochemical reaction or external circuit. In practice, this is the ideal design for an electrochemical sensor because it reduces the number of necessary components for the proper operation of the analytical device. As mentioned previously, the biggest difficulty in achieving DET between the electrode and enzyme is the thick protein in which the redox active center is embedded. Cofactor $\mathrm{NAD}^{+} / \mathrm{NADH}$ and glucose molecules access this center by means of diffusion and penetration of the 3D molecular network. Besides, the intrinsic barrier to electron flow in the case of GOx-based bioanodes is its globular structure in which the active site contains fixed $\mathrm{FAD} / \mathrm{FADH}_{2}$ redox cofactor and is buried deep inside a cavity of ca. $13 \AA$ (a major hindrance for DET). To make DET happen, there are two minimal prerequisites that must be accommodated $[14,17,47,48]$ : (i) the distance between the electron donor and acceptor, i.e., a cofactor and an electrode undergoing heterogeneous electron transfer, should not exceed $2 \mathrm{~nm}(20 \AA)$ since greater distances lead to negligible rates of electron transfer; (ii) the cofactor must be orientated towards the electrode to keep the electron tunneling distance below $2 \mathrm{~nm}$ in the case of an enzyme possessing a cofactor which is of a sufficient proximal location. By offering an electrode surface that entraps and encompasses the enzyme, mesoporous electrode materials are of particular interest, as well as carbon nanotubes which provide suitable orientation for enzyme immobilization and establish a connection between the electrode surface and the deeply buried active site of the enzyme. It should be noted that rigorous and deep experimental results by series of blank and control tests must be performed before any claim of a DET mechanism. GOx is the prototypic example where, in the majority of cases, DET by GOx is often the result of misinterpretation [14]; the discussion of fundamentals and strategies for enzymatic DET is beyond the scope of this review.

\subsection{Towards a Fourth-Generation Glucose-Sensing Electrocatalysis}

Over 50 years of intense research in bioelectrocatalysis, enzymatic glucose sensors have remained a balance of advantages versus disadvantages, both of which are significant. Although dominating the glucose sensor industry, enzymatic systems have a number of critical flaws. The first-generation sensors suffer from a high oxygen dependency (therefore they are immediately unsuitable for practical and reliable analytical use). The ability of the second generation is highly impacted by the presence of other electroactive interferences in the sample as well as the complicated mass production of a reproducible sensor. The third-generation sensors, which are still in their infancy, have to deal with appropriate 3D orientation, low electron tunneling distances to guarantee successful DET and substrate accessibility of the enzyme by glucose [32]. Ensuring the stability is a key aspect for the commercialization of analytical devices and this issue which surrounds enzymatic systems in all fields of science seriously influences the portion of electrochemical sensors on the market of analytical devices. The use of non-enzymatic electrodes as glucose sensors potentially promises a "fourth generation" for analytical glucose oxidation where the active metal nanoparticles (NPs) undergo an oxidation step that forms a hydrous oxide layer, $\mathrm{OH}_{\mathrm{ads}}$, which mediates the oxidation of the adsorbed species. These non-enzymatic materials are abiotic catalysts, which are expected to find suitable usage in the food industry and in the development of fuel cells and batteries operating in close-biological conditions. Indeed, industrial processes for quality control of food and drink products are essential, and measuring the quantity of various sugars to validate the quality, maturity, authenticity and nutritional value of the product is of considerable importance. Although they have a potential use in the blood glucose industry, non-enzymatic sensors are possibly of greater use in non-physiological situations. This is 
primarily due to their lower selectivity as industrial systems have a greater opportunity to impose selectivity via chromatographic methods, or indeed they may involve "clean" systems which do not contain interference species. Furthermore, the intrinsic thermal stability, chemical resistance and long-term durability observed in non-enzymatic systems place them in a better position for experimentally extreme environments while the high electrocatalytic activity of abiotic electrodes vastly outweighs that of their enzymatic counterparts, and as such, they are potentially useful in the fuel cell industry [32].

\section{Non-Enzymatic Electrochemical Sensors for Biomedical and Non-Biomedical Applications}

\subsection{Clarifying the Requirements of Electrochemical Sensors for Biomedical and Non-Physiological Situations}

Within the last 10 years, the number of publications related to electrochemical sensors has become exponentially massive, where glucose concentrates the most attention. However, the literature review in the case of non-enzymatic sensors is often the most daunting part. Indeed, the electrochemical performance is performed mostly in a strong alkaline medium ( $\mathrm{pH}$ about 13) and the conclusions are extrapolated to physiological or natural conditions ( $\mathrm{pH}$ about 7$)$. Within the two main and distinguished application fields of electrochemical sensors, i.e., biomedical or non-physiological situations, the motivation should be clearly stated and supported by results obtained in appropriate experimental conditions. To be as systematic as possible when completing this gargantuan task of reports, we have found it helpful to provided herein the minimum requirements of a viable electrochemical sensor in which enzymatic or abiotic electrocatalysis occur.

\subsubsection{Which Type of Electrochemical Sensor?}

The research should clearly indicate whether the electrode material is catalyzing the reaction for a design operating in physiological conditions or not. The second item is whether the sensor will be operating in vivo or in vitro. This clarification helps to narrowly choose the $\mathrm{pH}$ range and the most suitable interferences to be examined. For instance, screening glucose content in a blood sample either in vivo or in vitro does not require the same experimental set up as for searching in a food or drink.

\subsubsection{Which Precision for Which Goal?}

Let us take an example of designing electrode materials for glucose detection in blood where the normal concentration range is $64-128 \mathrm{mg} \cdot \mathrm{dL}^{-1}$, i.e., $3.5-7.1 \mathrm{mM}$ ( $\mathrm{pH}$ of about 7.7). Hence, there is no interest to be out of the 1-20 $\mathrm{mM}$ range during the assays; running tests to detect a concentration lower than $1 \mathrm{mM}$ or higher than $30 \mathrm{mM}$ is of no scientific interest. Of course, if the goal were the search for glucose contamination in the food industry, such assays would be welcome. The use of very acidic or alkaline solutions as electrolytes and injecting human serum samples during the calibration curve evaluation should be avoided. In summary, the main characteristics of the targeted application should be rigorously determined in order to prepare a supporting electrolyte that mimics the real conditions and the electrode must be selective enough to the target only, with minimum of interference from erroneous sources.

\subsubsection{Reliability of Tests: Addressing our Experimental Needs}

A reliable screening begins with the blank and control tests. For a blank result, the assay should be performed in the presence of the catalyst and the absence of the targeted analyte, for example glucose. Such a test helps to determine whether the catalyst can perform the reaction or not. In the case of a control test, the experiment is run in electrolyte containing the substrate and in the absence of the active component of the catalyst. This type of experiments determines the overall performance descriptors. For example, if the electrode material is AuNPs supported on a carbon paper electrode, the latter will only constitute the working electrode during the experiment to ensure that the catalytic activity comes from AuNPs, not from carbon paper. The overall requirements are: 
(i) the catalyst must be selective to the target only; (ii) the signal-to-noise $(\mathrm{S} / \mathrm{N})$ should be high enough (at least 3); (iii) the amperometric sensitivity, i.e., the limit of detection, should be as low as possible $\left(10^{-n} \mathrm{~mol} \cdot \mathrm{L}^{-1}\right.$ where $\mathrm{n}$ is a natural integer $)$ and the specific sensitivity $\left(\mu \mathrm{A} \cdot \mathrm{mM}^{-1}\right.$ or $\left.\mu \mathrm{A} \cdot \mathrm{mM}^{-1} \cdot \mathrm{cm}^{-2}\right)$ should be as high as possible; (iv) there should be no oxygen dependency since a reliance on $\mathrm{O}_{2}$ possesses major fundamental (possible parasite reaction) and technical (in real analysis, removing $\mathrm{O}_{2}$ from the sample is impossible) problems meaning that the experiments should not be run in a nitrogenor argon-saturated $\left(\mathrm{O}_{2}\right.$-free) solution; $(\mathrm{v})$ the catalyst should be stable enough during application and have a long lifetime (months for glucose sensors); (vi) accuracy and precision, which means "must meet International Organization for Standardization (ISO) standards of within 20\% error", and at least three independent measurements should be performed (reproducibility); (vii) the biocompatibility property should be met, particularly for in vivo use due to biological components and immune response; (viii) low fabrication and running costs must be lower than those of the enzymatic systems; (ix) fabrication should be easier than screen-printed enzymatic electrode strips [32].

\subsubsection{Current Methods: Running the Electrochemical Assays Experimentally}

The widely used and most reliable experimental tool to perform the tests is the amperometric method in a three-electrode electrochemical configuration. The electrochemical cell has a working electrode (where the catalyst is immobilized), a counter-electrode that should not be electrochemically active (electron collection and distribution) and an appropriate reference electrode that is stable in the investigated medium (to regulate the potential of the working electrode). Basically, to overcome interfering processes such as passivation and deactivation, which can occur during the current measurement, the counter-electrode must be substantially larger than that of the working electrode. The entire electrochemical experiment should be performed using an electrolyte containing $\mathrm{O}_{2}$ in equilibrium with air in order to mimic the real situations: the electrolyte should have the same chemical composition and $\mathrm{pH}$ as the real sample. In preliminary experiments, it is strongly advised to perform cyclic voltammetry $(\mathrm{CV})$ in a relatively large electrode potential range using the as-prepared electrolyte and to conduct the aforementioned blank and control tests. This is essential to find the suitable electrode potential ( $E_{\text {applied }}$ ) for the amperometric test. When the $C V$ curve for the target displays a peak current at an electrode potential $E_{\text {peak }}$, the $E_{\text {applied }}$ should be ca. $20-50 \mathrm{mV}$ lower or higher than the $E_{\text {peak }}$. It should be noted that choosing $E_{\text {peak }}<E_{\text {applied }}$ is preferred due to the possible electron transfer limiting phenomena before the peak current. Then, in a potentiostatic mode (fixed potential), the medium is progressively spiked with a high-concentration solution of the analyte initially prepared in the same supporting electrolyte. For instance, when the investigation aims for a glucose search within a blood sample, a stock solution of $0.5-1 \mathrm{M}$ should be fine. The aliquot to be added depends exclusively on the initial volume and the medium could be slightly stirred (keeping it constant) during the entire experiment using either a stir bar or a rotation disc electrode (RDE) when possible, even if it does not reflect reality, for example blood glucose monitoring. A relatively steady-state operation should be reached between the two successively added aliquots.

\subsubsection{Screening Electroactive Interferences and Electrode Fouling in the Case of Glucose Sensors}

The main specification of a sensor is to give the real analyte concentration without any overestimation or underestimation due to the undesired reaction of reduction or oxidation happening simultaneously at $E_{\text {applied }}$. Hence, the two major problems of the amperometric sensing are the presence of other electroactive interferences in the real sample and electrode fouling. Currently, the moderately high anodic potential used to oxidize glucose in the case of non-platinum electrodes also oxidizes other biomolecules within the blood, thus giving an amperometric current that overestimates or underestimates the blood glucose value. This is a typical specificity of non-enzymatic glucose sensors, in which the kinetics is enhanced but the selectivity is sometimes less than ideal. It should be noted that an inaccurate estimation of blood glucose levels due to parasite reactions during an assay might have life-threatening consequences, as hypoglycemia can be masked or even be induced 
by the inappropriate administration of insulin, thus leading to a hypoglycemic coma or even death. A number of compounds found in human blood that can interfere with the glucose determination are listed in Table 1 and their chemical structures are shown in Scheme 1.

In order to get the most rational idea about the electrode response in a real sample, two approaches can be experimentally adopted during the electrolytic solution preparation: (i) preparation of a supporting electrolyte that has a similar $\mathrm{pH}$ with the above interfering chemicals added during the electrochemical tests to evaluate their influence; (ii) preparation of a supporting electrolyte that mimics the real sample, i.e., has a similar $\mathrm{pH}$ and contains the above interfering chemicals at appropriate concentrations. To date, researchers prefer the first approach which is easy to implement in a laboratory. To this end, different kinds of buffers are used, mostly based on citrate/phosphate buffer ( $\mathrm{pH}$ slightly acidic or neutral), phosphate buffer (neutral $\mathrm{pH}$ ), and Tris-buffer (slightly alkaline buffering capacity in the $\mathrm{pH}=7-9$ range). In some cases, chloride ions at a concentration of 100-150 mM are directly integrated to the buffer. It should be noted that: (i) phosphate anions have a somewhat interfering effect, mostly on platinum electrodes; (ii) for electrode materials based on noble metals ( $\mathrm{Au}, \mathrm{Pt}$, etc.), Tris-buffer should be avoided since the Tris or tris(hydroxymethyl)aminomethane is an organic compound, $\left(\mathrm{HOCH}_{2}\right)_{3} \mathrm{CNH}_{2}$, which can be readily oxidized in the same potential window as glucose. Overall, both Tris-buffer and citrate-based buffers contain a carbon source so that the reaction products cannot be accurately analyzed if the nature of the reaction product needs to be known. All these possible interferences should be taken into account when choosing a supporting electrolyte for non-enzymatic electrodes.

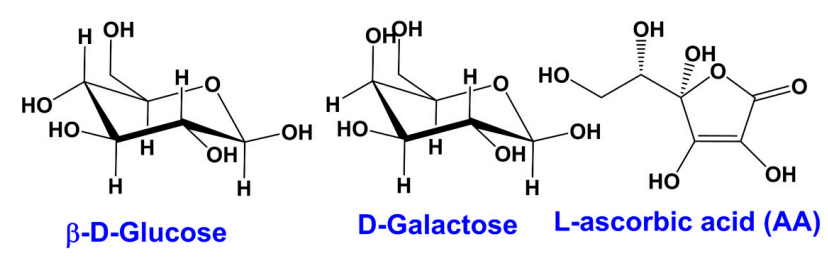<smiles>NCCc1ccc(O)c(O)c1</smiles><smiles>CC(=O)Oc1ccc(OC(C)(C)C(C)(C)C(C)(Cl)Cl)c(C(=O)O)c1</smiles>

Scheme 1. Chemical structures of various known electroactive interference species for glucose sensing.

Table 1. Possible interfering electrochemical responses to electrochemical glucose sensors, collected from References [32,49-57].

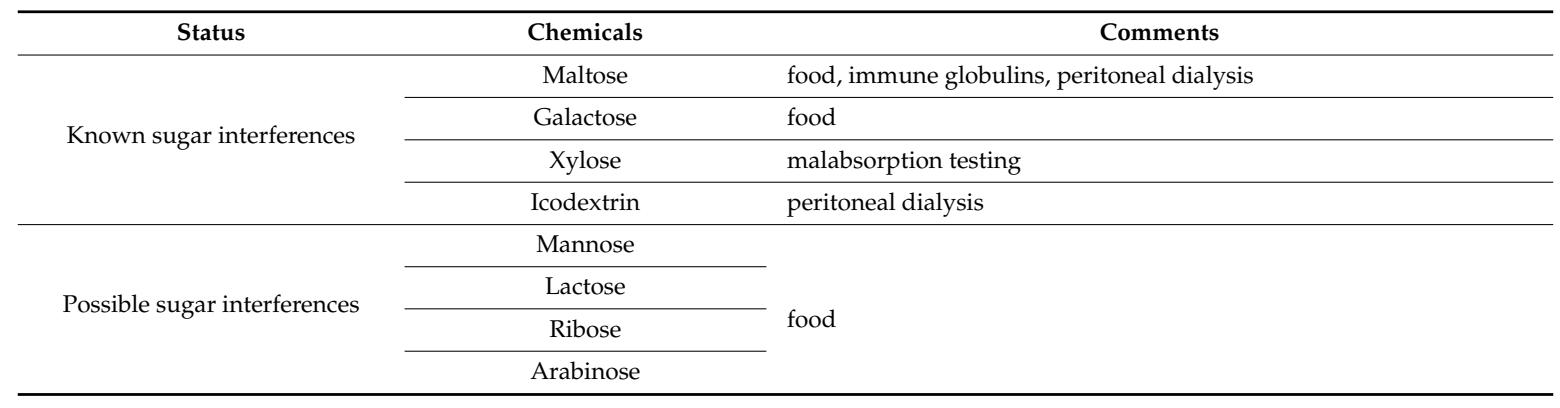


Table 1. Cont.

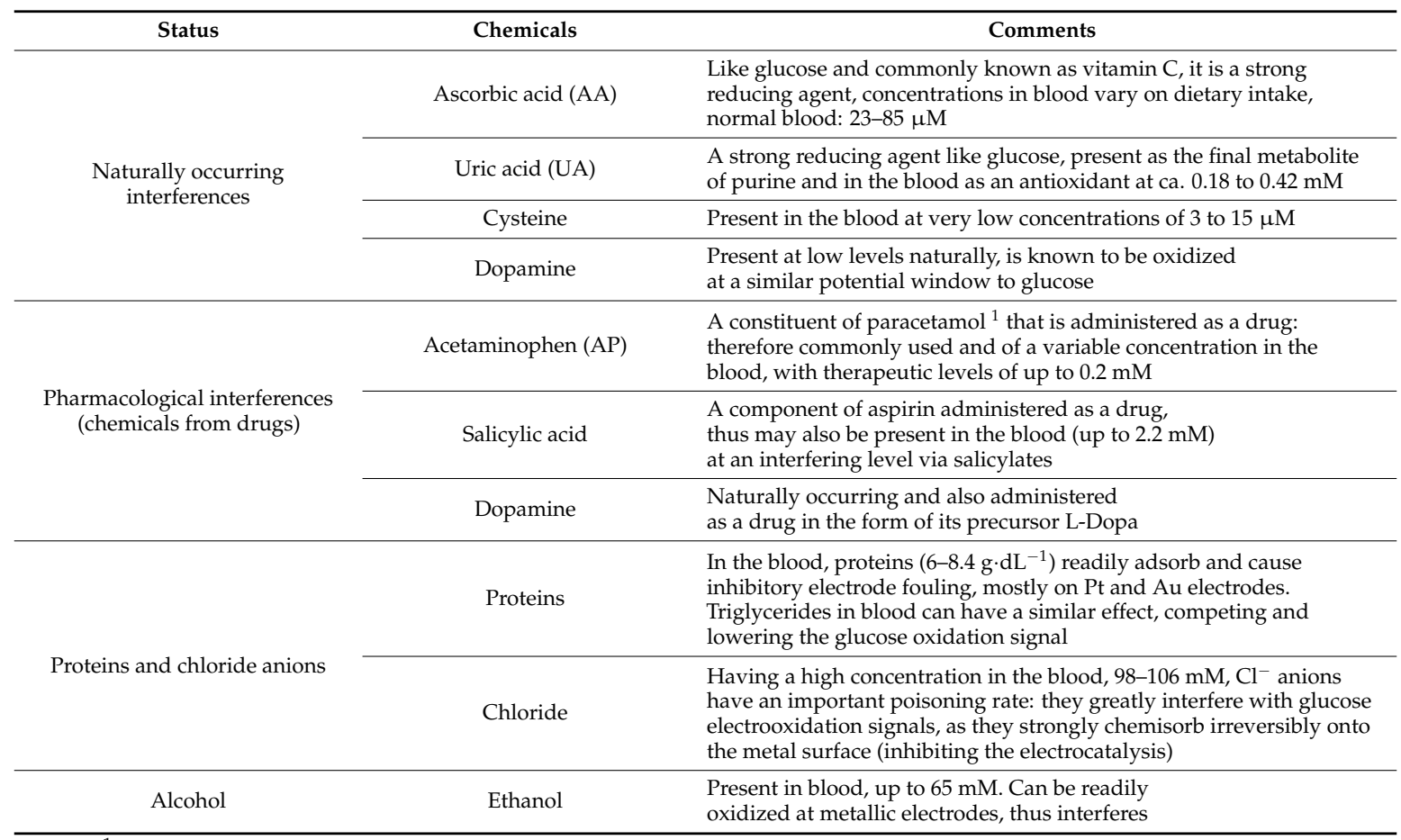

${ }^{1}$ An antipyretic and analgesic drug: An effective and safe agent that is applied to reduce fever, relieve coughing, colds, and pain including muscular aches, chronic pain, migraine headache, backache, and toothache.

\subsection{Nanomaterials for Sensors Based on Glucose Monitoring for Biomedical and Food Industry Targets}

\subsubsection{Nanostructured Metals: Porous and Non-Porous Materials}

An ideal catalytic material should have a high dispersion of the active sites, a controllable surface structure and morphology, and minimal metal loading which allow for optimizing the activity, selectivity, and durability [58]. For platinum group metals (PGMs), the old and most widely used approach of optimizing electrochemical performances towards organic molecules, electrooxidation relies on engineering materials with a tunable surface structure and composition, namely nanoalloys and core-shell materials with fascinating and exceptional properties. Strategically, alloying agents are chosen to allow the d-orbital occupancy of one metal lower than that of the host metal [59-61]. From this perspective, the main driving force results from the synergistic effect involving the d-band center of the metal, the binding energy of which is more stabilized. Considering gold-platinum nanoalloys, the electronic exchanges between the $5 \mathrm{~d}$ orbitals of $\mathrm{Au}$ (full: $5 \mathrm{~d}^{10}$ ) and Pt (unfilled: $5 \mathrm{~d}^{9}$ ) induce the modification of their valence band energy [62-64]. Thereafter, more hydroxyl species (the main descriptors of oxidation reactions) may be formed at the catalyst surface, leading to more active sites. Finally, the electronic effect induced by both metals is capable of efficiently triggering the oxidation reaction. The second method is to partially or completely remove a sacrificial component in alloys, leading to nanocages or nanoframes with well-defined and controllable facets and distinguished catalytic performances. Indeed, owing to their extraordinarily high surface areas, large pore volumes and low metal content per surface area, nanoporous materials offer many opportunities in glucose electrocatalysis such as high sensitivity, lower detection limit and high selectivity. For electrodes comprising inorganic materials within their composition, their activity is often considered in terms of their roughness factor, in which the greater the surface roughness, the greater the electrochemical activity. In a recent attempt to grow electrocatalytic metal nanoparticles directly onto a carbon paper electrode employing halide anions as regulators, Holade et al. demonstrated that flower-like rough surfaces exhibited higher catalytic activity than featureless smooth surfaces, about one order of magnitude greater [58]. Fundamentally, solid porous materials are classified according to their pore 
sizes (diameter) in three main categories which are macroporous ( $>50 \mathrm{~nm})$, mesoporous $(2-50 \mathrm{~nm})$ and microporous $(<2 \mathrm{~nm})[65,66]$. These are termed nanoporous materials, the pore sizes of which are less than $100 \mathrm{~nm}$, thus including the microporous and mesoporous categories, and a part of the macroporous category. Given the size of the investigated molecules and the mass transport phenomena in electrocatalysis, the pore diameter should be neither too large nor too small. Therefore, the best compromise is the mesoporous metallic materials, which have exceptional properties, including ultrahigh surface areas, tunable pore sizes (from 2 to $50 \mathrm{~nm}$ ) and shapes, and they exhibit nanoscale defects in their channels and on their pore walls, which is of particular interest for most applications in electrocatalysis. For instance, a high surface area increases the proportion of atoms exposed on the surface and subsequently should provide a large number of reaction or interaction sites for surface or interface-related processes. These essential characteristics enable improving the electrode performances by significantly enhancing their utilization efficiency and optimizing the specific activity. The utilization efficiency (UE) is the ratio between the active surface area and the projected geometric area of the entire NPs $\left(\mathrm{UE}=S_{\text {active }} / S_{\text {geomectric }}=\mathrm{ECSA} /\right.$ Geometric, $\mathrm{ECSA}=$ electrochemical active surface area).

\subsubsection{Noble Metal (Gold and Platinum)-Based Electrodes}

The above nanostructuration can be intelligently used for a drastic increase of both the sluggish kinetics of the electrooxidation of glucose and the stability in non-enzymatic glucose sensors. One of the strategic methods of minimizing the oxidation of other biomolecules within the real sample is the decrease of the oxidation overpotential, given the experimental fact that most metal and metal oxide electrodes oxidize glucose at potentials of 0.4 to $0.7 \mathrm{~V}$ vs. saturated calomel electrode (SCE), high enough to provoke the oxidation of a number of available chemical species. By employing the method of under-potential deposition (UPD), Taniguchi and coworkers conducted systematic studies about the electrocatalytic oxidation of sugars on $\mathrm{Au}(111)$ single-crystal electrodes modified with various ad-metals $(\mathrm{Cu}, \mathrm{Ag}, \mathrm{Ru}, \mathrm{Pt}, \mathrm{Pd}$ and $\mathrm{Cd})$ in alkaline solutions $[67,68]$. Their outcomes indicated that $\mathrm{Ag}$ ad-atoms of one-third monolayer (ML) onto the $\mathrm{Au}(111)$ surface showed the highest catalytic activity for glucose oxidation. Full coverage of Ag ad-atoms, however, led to a decrease in the peak current with no marked shift in the potential for glucose oxidation, but suppressed the oxidation significantly $[67,68]$. Taken together, these results demonstrated that the presence of $\mathrm{Au}$ atoms at the surface is crucial for better efficiency and the best cooperative interaction is obtained in the case of the Au-Ag heterogeneous catalytic surface. The onset potential ( $E_{\text {onset }}$ ) of glucose electrooxidation was $-0.55 \mathrm{~V}$ vs. $\mathrm{Ag}|\mathrm{AgCl}| \mathrm{KCl}_{\text {sat }}$ on a bare $\mathrm{Au}(111)$ electrode and this potential shifted to around $-0.65 \mathrm{~V}$ vs. $\mathrm{Ag}|\mathrm{AgCl}| \mathrm{KCl}_{\text {sat }}$ at an $\mathrm{Ag} 1 / 3 \mathrm{ML}$ ad-atom-modified electrode, meaning a $100 \mathrm{mV}$ gain in terms of electrode kinetics. Theoretically, at $\mathrm{pH} 13$, the reaction should start at $E_{\text {onset }}=-1.03 \mathrm{~V}$ vs. standard hydrogen electrode (SHE) $=-1.23 \mathrm{~V}$ vs. $\mathrm{Ag}|\mathrm{AgCl}| \mathrm{KCl}_{\text {sat }}=-1.27 \mathrm{~V}$ vs. $\mathrm{SCE}=-0.25 \mathrm{~V}$ vs. reversible hydrogen electrode (RHE) [69]. Note: $\mathrm{RHE}=-0.06 \times \mathrm{pH}$ vs. SHE, in volt. $\mathrm{E}(\mathrm{SCE})=0.24 \mathrm{~V}$ vs. SHE; $\mathrm{E}^{\circ}\left(\mathrm{Ag}|\mathrm{AgCl}| \mathrm{KCl}_{\text {sat }}\right)=0.20 \mathrm{~V}$ vs. SHE. Otherwise, the overpotential for $E_{\text {onset }}$ was $\eta=680$ and $580 \mathrm{mV}$ for the pristine $\mathrm{Au}(111)$ electrode and the Ag-modified one, respectively. Interestingly, the oxidation peak potential $\left(E_{\text {peak }}\right)$ for glucose oxidation to gluconolactone (two-electron oxidation) also shifted from ca. -0.27 to ca. $-0.40 \mathrm{~V}$ vs. $\mathrm{Ag}|\mathrm{AgCl}| \mathrm{KCl}_{\text {sat }}$, i.e., about $130 \mathrm{mV}$ lower. When the $\mathrm{Au}(100)$ electrode was used, a similar suggested catalytic effect of the Ag ad-layer [70] was observed experimentally for the glucose oxidation reaction [68]. The peak potential for the oxidation of glucose was ca. $-0.5 \mathrm{~V}$ vs. $\mathrm{Ag}|\mathrm{AgCl}| \mathrm{KCl}_{\text {sat }}$ at the $\mathrm{Ag}$ ad-layer-modified $\mathrm{Au}(100)$ electrodes, which was slightly more negative than at $\mathrm{Ag}$ ad-layer-modified $\mathrm{Au}(111)$ electrodes. Hence, the oxidation potential of glucose on gold-based electrodes has been successfully lowered by modification with partial monolayers of ad-atoms. The main performance descriptor for the glucose oxidation reaction has been unanimously identifies to be $\mathrm{Au}(\mathrm{OH})_{\mathrm{x}}$ species. Thus, the possible explanation of the superior catalytic activity of Ag ad-layer-modified Au electrodes is that the change in the electronic structure of Au upon Ag deposition allowed the facile formation of hydroxyl species 
$(\mathrm{M}-\mathrm{OH}, \mathrm{M}=\mathrm{Au})$ at more negative potentials than at a bare Au electrode. These fundamental works highlight two distinguished effects: the crystallographic structure for $\mathrm{Au}(\mathrm{hkl})$ and the electronic interaction between silver and gold atoms. Recent experimental data confirmed the cornerstone role of the crystallographic structure of AuNPs on the reactivity of glucose [71-74]. For low indexes, the reactivity of glucose over Au(hkl) surfaces increases in the order $(111)<(110)<(100)$. Other studies have pointed out the likely role of higher crystallographic (hkl) facets such as (200) or $(220)[58,64,75]$. This plausible contribution needs a fundamental investigation using single crystals. Even the experiments mentioned above were conducted in alkaline electrolyte $(0.1 \mathrm{M} \mathrm{NaOH})$; such seminal works provide key information on the reactivity of glucose molecules. In 2008, Chen's group combined both characteristics of nanoporosity and nanoalloys to design nanoporous $\mathrm{PtPb}$ electrodes exhibiting highly enhanced resistance toward poisoning by chloride ions and capable of amperometric glucose detection (in a solution of $0.1 \mathrm{M}$ phosphate buffer $(\mathrm{pH} 7.4)+0.15 \mathrm{M} \mathrm{NaCl}$ ) at a very low potential of $-0.08 \mathrm{~V}$ vs. $\mathrm{Ag}|\mathrm{AgCl}| \mathrm{KCl}_{\text {sat }}$ where the interference from the oxidation of common interfering species, such as ascorbic acid, acetamidophenol, and uric acid, was effectively avoided [76]. However, it should be noted that such PtPb bimetallic nano-networks directly deposited on Ti substrates using a one-step hydrothermal method with excellent electrocatalytic performance cannot be integrated into a device for in vivo operation because of the severe toxicity issues of lead, but they are fine for non-physiological uses.

\subsubsection{Platinum and Gold-Free Electrodes: Earth-Abundant Transition Metals}

In another experimental attempt to exploit nanoporosity on 3D surfaces, nanostructured metal oxides that possess interesting nanomorphology, multiple oxidation states, and good biological compatibility were examined. Compared to metals, metal oxides have lower electronic conductivity, which greatly restricts their wide applications in electrochemistry such as the design of electrochemical sensors with superior performance. Consequently, one of the logical solutions to boost their electronic conductivity is to construct composite materials by hybridizing them with noble metal nanoparticles [77,78]. For instance, a kind of dealloyed nanoporous gold (NPG) modified by ultrathin $\mathrm{CuO}$ film (obtained by electrodeposition) demonstrated a good performance as a non-enzymatic electrode for a glucose sensor, exhibiting a high sensitivity of $374.0 \mu \mathrm{A} \cdot \mathrm{mM}^{-1} \cdot \mathrm{cm}^{-2}$ in a wide linear range up to $12 \mathrm{mM}$ glucose and good anti-interference ability [78]. Contrary to the claims in the paper (promising glucose sensing in food and human blood), it is important to note that the obtained data are insufficient to support the conclusion since the experiments were conducted in a highly strong alkaline solution $(0.1 \mathrm{M} \mathrm{NaOH}, \mathrm{pH} 13)$, which makes the experimental conditions very different from reality. Experimental conditions do not support the claims even if "the NPG/CuO electrode has been applied to detect glucose in human serum samples with a 100-fold dilution in $0.1 \mathrm{M}$ $\mathrm{NaOH}$ solution to verify its applicability in real sample analysis" as stated [78]. Among various non-enzymatic metal oxide-based glucose sensors, nanostructured copper oxides $\left(\mathrm{Cu}_{2} \mathrm{O}\right.$ and $\left.\mathrm{CuO}\right)$ attract much attention owing to their outstanding electronic conductivity, electrochemical activity, low cost, and ease of synthesis [79-83]. Kong et al. [82] reported a synthesized hollow $\mathrm{CuO}$ polyhedron (about $5 \mu \mathrm{m}$ diameter and $120 \mathrm{~nm}$ thickness) that exhibits a high sensitivity of $1112 \mu \mathrm{A} \cdot \mathrm{mM}^{-1} \cdot \mathrm{cm}^{-2}$ with a glucose detection limit of $0.33 \mu \mathrm{M}(\mathrm{S} / \mathrm{N}=3)$ at $+0.55 \mathrm{~V}$ vs. $\mathrm{Ag}|\mathrm{AgCl}| \mathrm{KCl}_{\text {sat }}$, with a linear range up to $4 \mathrm{mM}$, and a high resistance to the interference from interfering species such as $\mathrm{Cl}^{-}, \mathrm{AA}$ and UA. Although this hollow $\mathrm{CuO}$ polyhedron-modified electrode exhibits good electrocatalytic activity with a fast sensing response of about $2 \mathrm{~s}$, its potentiality for non-enzymatic detection of glucose in real samples is not obvious since the experiments were conducted in a relatively high $\mathrm{pH}(0.1 \mathrm{mM} \mathrm{KOH})$. On the same road of copper-based electrodes, Dong et al. [79] reported a 3D Cu foam-supported mesoporous $\mathrm{Cu}_{2} \mathrm{O}$ nanothorn array electrode, fabricated through a two-step facile electrochemical route for the two-electron oxidation of glucose to gluconate, as shown by the sketch in Figure 3a. First, $\mathrm{Cu}$ foam-supported $\mathrm{Cu}_{2} \mathrm{O}$ was prepared by anodization using a two-electrode system $(\mathrm{Cu}$ foam as the anode and a graphite slab as the cathode) at room temperature, with $0.4 \mathrm{M} \mathrm{H}_{2} \mathrm{C}_{2} \mathrm{O}_{4}$ aqueous solution 
with a small amount of HF employed as an electrolyte. Second, the electrooxidation was performed in a $1 \mathrm{M} \mathrm{KOH}$ aqueous solution by $\mathrm{CV}$ in a three-electrode configuration ( $\mathrm{Pt}$ foil as the counter-electrode and $\mathrm{Ag}|\mathrm{AgCl}| \mathrm{KCl}_{\text {sat }}$ as the reference electrode). Figure $3 \mathrm{~b}$ shows the scanning electron microscopy (SEM) image of the as-obtained hybrid electrode highlighting a 3D continuous skeleton while the high magnification (Figure 3c) indicates that $\mathrm{Cu}_{2} \mathrm{O}$ has a particular (nanothorn-like) morphology; this $\mathrm{Cu}_{2} \mathrm{O}$ material was grown in situ on the surface of skeletons of the $\mathrm{Cu}$ substrate, and its surface roughness was remarkably enhanced. Deep characterizations by transmission electron microscope (TEM), selected-area electron diffraction (SAED), and X-ray diffraction (XRD) show that the nanothorns have widths of $\sim 20-40 \mathrm{~nm}$, lengths of several micrometers and they grow along the specific direction of [011]. High-resolution TEM indicates the nanoporous character of the nanothorn surface with a pore size (diameter) of 2-6 nm, expected to enhance the surface area of the nanothorns. It is worth noting that in an alkaline electrolytic solution, the glucose oxidation occurs in the potential range of 0.40 to $0.8 \mathrm{~V}$ vs. $\mathrm{Ag}|\mathrm{AgCl}| \mathrm{KCl}_{\text {sat }}$, where the oxidation wave for $\mathrm{Cu}(\mathrm{II}) / \mathrm{Cu}(\mathrm{III})$ is reported [84-87]. It was experimentally shown ( $\mathrm{pH}$ 13.3) that the redox reaction associated with the couple $\mathrm{Cu}(\mathrm{III}) / \mathrm{Cu}$ (II) is a quasi-reversible process with one electron transferred and the determined formal electrode potential is $0.37 \mathrm{~V}$ vs. SCE $[88,89]$, that is about $0.41 \mathrm{~V}$ vs. $\mathrm{Ag}|\mathrm{AgCl}| \mathrm{KCl}_{\text {sat }}$. Thus, a CV of the copper electrode in alkaline medium should display anodic peaks at $-0.34,-0.1$ and $0.41 \mathrm{~V}$ vs. $\mathrm{Ag}|\mathrm{AgCl}| \mathrm{KCl}_{\text {sat }}$ for the conversion of $\mathrm{Cu}(0)$ to $\mathrm{Cu}(\mathrm{I})$, of $\mathrm{Cu}(\mathrm{I})$ to $\mathrm{Cu}$ (II) and of $\mathrm{Cu}$ (II) to $\mathrm{Cu}(\mathrm{III})$, respectively. Although the exact mechanism for the glucose oxidation in alkaline media at $\mathrm{Cu}$ electrodes or $\mathrm{Cu}$-modified electrodes is still not known with certainty, it has been proposed that $\mathrm{Cu}(\mathrm{III})$ species, rather than $\mathrm{Cu}(\mathrm{I})$ or $\mathrm{Cu}(\mathrm{II})$, serve as the mediators for electron transfer $[79,90,91]$. Thus, the efficiency relies mostly on the ability of the electrodes to provide available $\mathrm{Cu}$ (III) species at a low electrode potential. The situation could be worst at a neutral $\mathrm{pH}$ where the sensor is expected to operate. The performance of the above $\mathrm{Cu}$ foam-supported $\mathrm{Cu}_{2} \mathrm{O}$ nanothorn array electrode in a $0.1 \mathrm{M} \mathrm{NaOH}$ solution demonstrates that such a hybrid electrode was able to trigger the detection of ultralow-concentration glucose (an ultrahigh sensitivity of $97.9 \mathrm{~mA} \cdot \mathrm{mM}^{-1} \cdot \mathrm{cm}^{-2}$ and an ultralow detection limit of $5 \mathrm{nM}$ ) at $0.55 \mathrm{~V}$ vs. $\mathrm{Ag}|\mathrm{AgCl}| \mathrm{KCl}_{\text {sat }}$. This remarkable sensing performance was attributed to the synergistic effect of the dramatically enhanced surface area of the electrocatalytic material $\left(\mathrm{Cu}_{2} \mathrm{O}\right)$, the perfect architecture in which mesoporous $\mathrm{Cu}_{2} \mathrm{O}$ nanothorn arrays grow in situ on the $\mathrm{Cu}$ substrate surface, and the estimated catalytic rate constant $\left(K_{\text {cat }}\right)$ of $2.1 \times 10^{7} \mathrm{~cm}^{3} \cdot \mathrm{mol}^{-1} \cdot \mathrm{s}^{-1}$, which indicates a fast catalytic rate of the hybrid electrode [79]. The anti-interference performance of the $\mathrm{Cu}$ foam-supported $\mathrm{Cu}_{2} \mathrm{O}$ electrode shown within Figure $3 \mathrm{~d}$ indicates negligible current responses from the interference of other biomolecules. For the long-term stability $\left(0.1 \mathrm{M} \mathrm{NaOH}, 1 \mathrm{mM}\right.$ glucose, $0.55 \mathrm{~V}$ vs. $\left.\mathrm{Ag}|\mathrm{AgCl}| \mathrm{KCl}_{\text {sat }}\right)$, the amperometric response was approximately $98.7 \%$ of the original value after 15 days, suggesting excellent stability of the hybrid electrode. To screen the glucose level in human serum samples, the authors employed the method of injecting $100 \mu \mathrm{L}$ of human serum into $20 \mathrm{~mL}$ of $0.1 \mathrm{M} \mathrm{NaOH}$ solution, and the measurement was conducted at $0.55 \mathrm{~V}$ vs. $\mathrm{Ag}|\mathrm{AgCl}| \mathrm{KCl}_{\text {sat }}$ with stirring. According to the authors, the obtained data were consistent with those from the biochemical analyzer in the hospital, indicating the reliability for glucose determination in real systems [79]. The question raised by such methodology is the reactivity of glucose on the design electrode in a real physiological system at a $\mathrm{pH}$ of 7.7 and in the presence of many other biomolecules at high concentrations. Indeed, adding $100 \mu \mathrm{L}$ of human serum into $20 \mathrm{~mL}$ of $0.1 \mathrm{M} \mathrm{NaOH}$ solution means that the concentration of interference species is diluted by a factor of 200 before the analysis and the $\mathrm{pH}$ is still 13. So, could the electrode give the same result if the solution was exclusively composed of a human serum sample where the $\mathrm{pH}$ is ca. 7.7, and there is a large amount of interference biomolecules? 

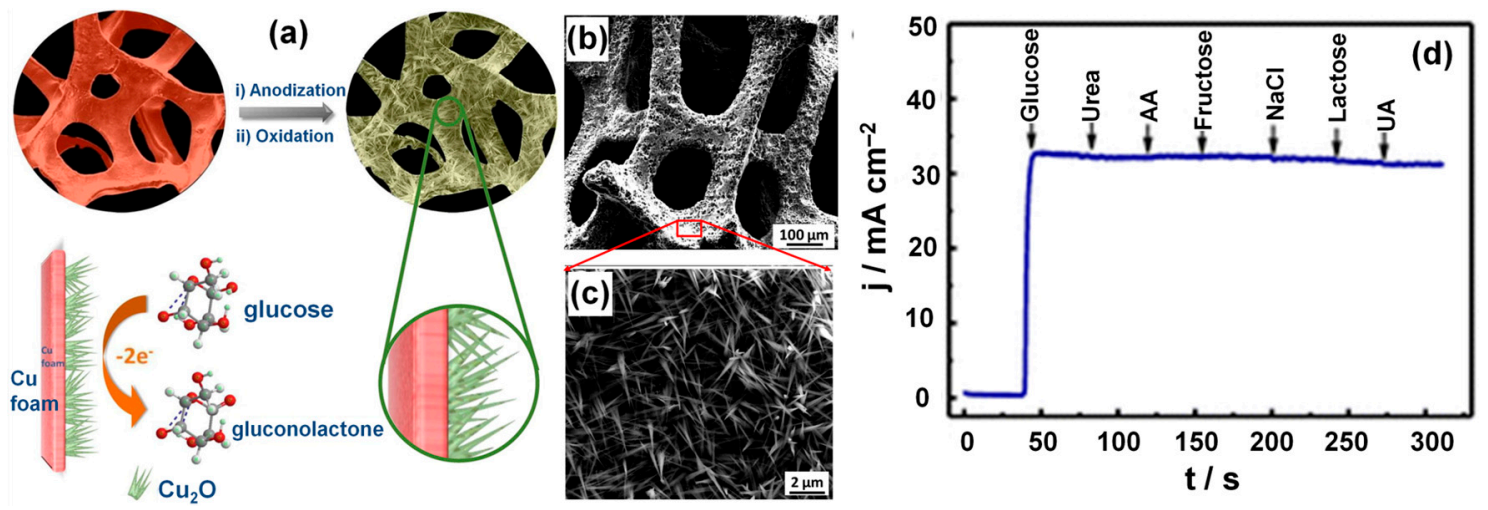

Figure 3. (a) Schematic illustration showing the fabrication of the 3D Cu foam-supported mesoporous $\mathrm{Cu}_{2} \mathrm{O}$ nanothorn array electrode and its function in the electrocatalytic oxidation of glucose; (b) Typical low- and (c) high-magnification SEM images of the $\mathrm{Cu}$ foam-supported $\mathrm{Cu}_{2} \mathrm{O}$ nanothorn array electrode; (d) Amperometric response of the $\mathrm{Cu}$ foam-supported $\mathrm{Cu}_{2} \mathrm{O}$ nanothorn array electrode toward the addition of $1 \mathrm{mM}$ glucose and various $0.02 \mathrm{mM}$ interfering species in the $0.1 \mathrm{M} \mathrm{NaOH}$ solution at $0.55 \mathrm{~V}$ vs. $\mathrm{Ag}|\mathrm{AgCl}| \mathrm{KCl}_{\text {sat }}$. Reprinted and adapted with permission from Reference [79].

Copyright American Chemical Society, 2015.

\subsubsection{Heterogeneous Electrode Materials: $\mathrm{Au}$ - and $\mathrm{Cu}$-Based Hydroxide or Oxide Interfaces}

Owing to its excellent electronic conductivity, $\mathrm{Cu}$ can replace $\mathrm{Au}$ as the support in the design of electrocatalysts. It also exhibits electroactivity properties, and is the most promising candidate for a carbon dioxide reduction reaction. In 2015, Li et al. [92] reported the first attempt in combining a $\mathrm{Cu}$ metal oxide and noble metal in a binder-free style for fabricating non-enzymatic glucose sensors. As is well discussed in Reference [58], the majority of existing synthetic methodologies require materials to be stabilized in a liquid or dispersed in a powder before using a binder, such as Nafion, to immobilize the NPs on a substrate (i.e., glassy carbon, carbon paper) prior to use. While the use of a Nafion ionomer contributes to the proton transport within the electrode materials, the use of such binders adds a layer of complexity to the fabrication process, and the degradation of binders results in the undesired loss of NPs and a subsequent decrease in the catalytic performance [58]. The preparation procedure for $\mathrm{Au} / \mathrm{CuO}$ nanocauliflower is illustrated in Figure 4a. In a typical synthetic procedure, a copper foil was first electrochemically anodized in a conventional three-electrode system to form $\mathrm{Cu}(\mathrm{OH})_{2}$ nanowire arrays (at $25^{\circ} \mathrm{C}$ in $3 \mathrm{M} \mathrm{NaOH}$ for 30 min under $10 \mathrm{~mA} \cdot \mathrm{cm}^{-2}$ ) and then annealed at $180{ }^{\circ} \mathrm{C}$ for $1 \mathrm{~h}$ to convert $\mathrm{Cu}(\mathrm{OH})_{2}$ to $\mathrm{CuO}$. Subsequently, the obtained nanowire arrays were dipped into $\mathrm{HAuCl}_{4}$ solution $(\mathrm{pH}=6.0)$ under simulated solar light irradiation $\left(100 \mathrm{~mW} \cdot \mathrm{cm}^{-2}\right)$ for $30 \mathrm{~min}$ for the direct photocatalytic reduction of $\mathrm{Au}(\mathrm{III})$, forming a unique nanocauliflower structure of $\mathrm{Au} / \mathrm{CuO}$. The SEM micrographs in Figure $4 \mathrm{~b}$ show a dense layer of the $\mathrm{Cu}(\mathrm{OH})_{2}$ nanowires covering the $\mathrm{Cu}$ foil substrate after anodization. After annealing, the length of the $\mathrm{CuO}$ nanowires was about 8-10 $\mu \mathrm{m}$ [92]. Figure $4 \mathrm{c}$ depicts SEM images of the $\mathrm{Au} / \mathrm{CuO}$ composite material where $\mathrm{Au}$ fully covers the entire $\mathrm{CuO}$ nanowire surface which may be ascribed to the rough $\mathrm{CuO}$ nanowire surface being an active $\mathrm{Au}$ loading site. The $\mathrm{pH}$ of the aqueous $\mathrm{HAuCl}_{4}$ solution has a critical role in the synthesis efficiency for Au deposition and an optimized $\mathrm{pH}$ value of 6.5 was used in both $\mathrm{Au} / \mathrm{Cu}(\mathrm{OH})_{2}$ and $\mathrm{Au} / \mathrm{CuO}$ cases: a lower $\mathrm{pH}$ value would result in the removal of the nanowires from the copper foil substrate, while a higher $\mathrm{pH}$ value would fail to deposit $\mathrm{Au}$ on the nanowires [92]. 
(a)
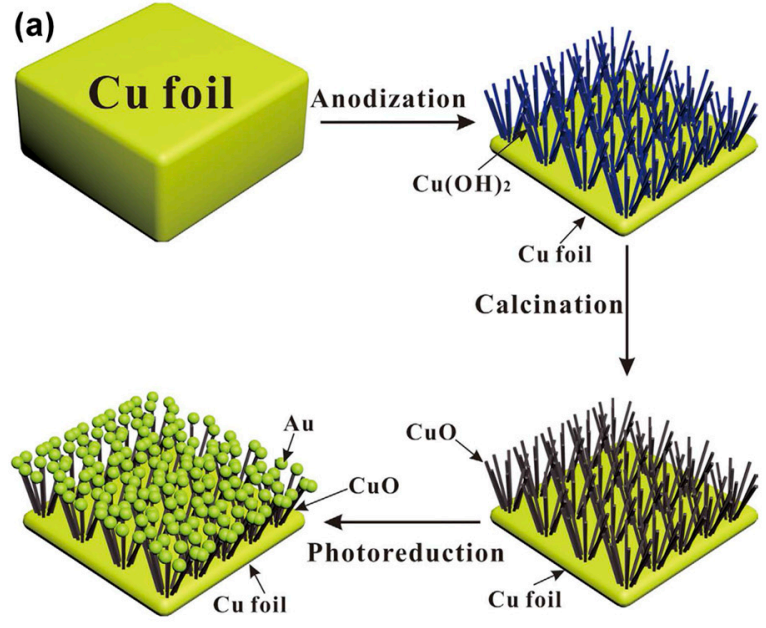
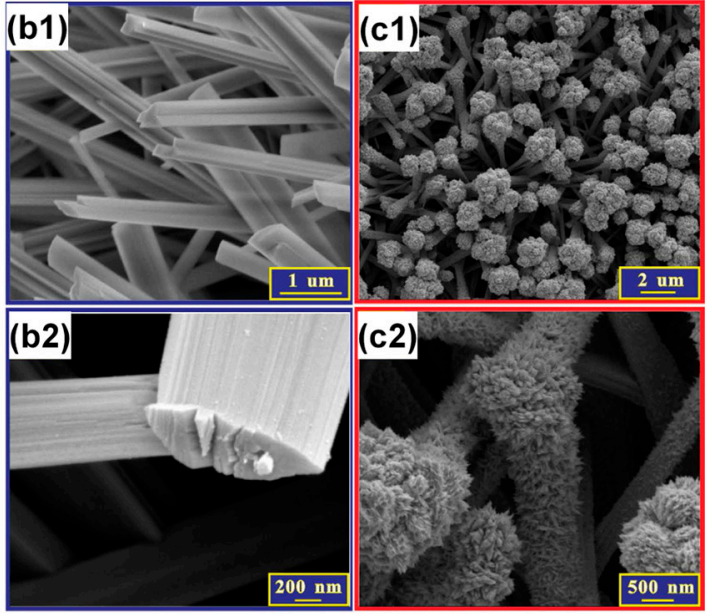

Figure 4. (a) Schematic illustration of the preparation of $\mathrm{Au} / \mathrm{CuO}$ nanocauliflower composites; scanning electron microscopy (SEM) (b1, c1) and high resolution SEM (b2, c2) micrographs of (b) $\mathrm{Cu}(\mathrm{OH})_{2}$ nanowires and (c) $\mathrm{Au} / \mathrm{CuO}$ nanocauliflowers. Reprinted and adapted with permission from Reference [92]. Copyright Macmillan Publishers Limited, 2016.

The electrochemical properties of the $\mathrm{Cu}(\mathrm{OH})_{2}, \mathrm{Au} / \mathrm{Cu}(\mathrm{OH})_{2}, \mathrm{CuO}$ and $\mathrm{Au} / \mathrm{CuO}$ samples were examined by $\mathrm{CV}$ in $1.0 \mathrm{M} \mathrm{NaOH}$ solution (Figure $5 \mathrm{a}$ ). As discussed above, the oxidation wave in the potential range of 0.3 to $0.5 \mathrm{~V}$ vs. $\mathrm{Ag}|\mathrm{AgCl}| \mathrm{KCl}_{\text {sat }}$ for all the samples belongs to the conversion of $\mathrm{Cu}$ (II) to $\mathrm{Cu}$ (III) which, once formed, may then act as electron transfer media for the oxidation of glucose. Among all samples, $\mathrm{Au} / \mathrm{CuO}$ displayed the highest anodic current and may suggest better electronic conductivity, resulting from the ensemble effect of Au nanostructures and $\mathrm{CuO}$ nanowires. To probe such a hypothesis, electrochemical impedance spectroscopy (EIS) measurements were conducted. Indeed, EIS is a powerful tool for studying the electronic properties on the electrode interface through the determination of the charge transfer resistance $\left(R_{\mathrm{ct}}\right)$. The metric of $R_{\mathrm{ct}}$ is correlated with the number of electrons that are transferred from the catalytic surface to the reactant(s) as well as intermediate(s) formation inside the double layer. Thus, $R_{\mathrm{ct}}$ is desired to be as small as possible for faster electrochemical kinetics. Experimentally, $R_{\mathrm{ct}}$ can be determined separately using the EIS spectrum, at the intersection between the Nyquist curve and $X$-axis at high frequencies. As depicted in Figure $5 \mathrm{~b}$, the $\mathrm{Au} / \mathrm{CuO}$ sample exhibits the smallest semicircular diameter $\left(R_{\mathrm{ct}}\right)$, thereby confirming the accelerated electron transfer in the presence of the $\mathrm{Au}$ nanostructures as the $\mathrm{Au} / \mathrm{CuO}$ exhibited the lowest resistance among all the samples. As a general rule, metals are better conductors than oxides, which are better than hydroxides. Having the lowest $R_{\mathrm{ct}}$, the $\mathrm{Au} / \mathrm{CuO}$ material was expected to be the best-performing catalyst. A typical current-time curve of the $\mathrm{Au} / \mathrm{CuO}$ electrode during the amperometric assay at $0.35 \mathrm{~V}$ vs. $\mathrm{Ag}|\mathrm{AgCl}| \mathrm{KCl}_{\text {sat }}$ is presented in Figure $5 \mathrm{c}$, which shows an excellent amperometric response with a short dwell-time of less than $2 \mathrm{~s}$ in response to the addition of glucose at different concentrations. Calibration curves within the insets of Figure $5 \mathrm{c}$ indicate a high sensitivity of $708.7 \mu \mathrm{A} \cdot \mathrm{mM}^{-1} \cdot \mathrm{cm}^{-2}$ in a wide linear range of $1 \mu \mathrm{M}$ to $30 \mathrm{mM}$, and a low detection limit of $0.3 \mu \mathrm{M}$ $(\mathrm{S} / \mathrm{N}=3)$. For $\mathrm{Cu}(\mathrm{OH})_{2}, \mathrm{Au} / \mathrm{Cu}(\mathrm{OH})_{2}$ and $\mathrm{CuO}$ samples, the sensitivities were $334.7 \mu \mathrm{A} \cdot \mathrm{mM}^{-1} \cdot \mathrm{cm}^{-2}$ (24 $\mu \mathrm{M}-30 \mathrm{mM}$, low detection limit of $8.3 \mu \mathrm{M}), 390.2 \mu \mathrm{A} \mathrm{mM}^{-1} \cdot \mathrm{cm}^{-2}(14 \mu \mathrm{M}-30 \mathrm{mM}$, low detection limit of $8.0 \mu \mathrm{M})$ and $442.0 \mu \mathrm{A} \cdot \mathrm{mM}^{-1} \cdot \mathrm{cm}^{-2}(8.0 \mu \mathrm{M}-30 \mathrm{mM}$, low detection limit of $6.2 \mu \mathrm{M})$, respectively. The superior performance of the $\mathrm{Au} / \mathrm{CuO}$ electrode material results from the intelligent combination of a noble metal and a metal-oxide within a suitable nano-framework towards an excellent electron transfer rate. Again, the authors employed a non-physiological medium $(0.1 \mathrm{M} \mathrm{NaOH}, \mathrm{pH} 13)$ to examine the anti-interference property, shown in Figure 5d. The outcomes do not show any significant interference upon the addition of uric acid, ascorbic acid, dopamine (at $0.1 \mathrm{mM}$ ), and saccharides 
$(0.05 \mathrm{mM})$ such as sucrose, lactose, and maltose. Even if the tests are encouraging, they do not guarantee any reliability of $\mathrm{Au} / \mathrm{CuO}$ in real biological conditions.
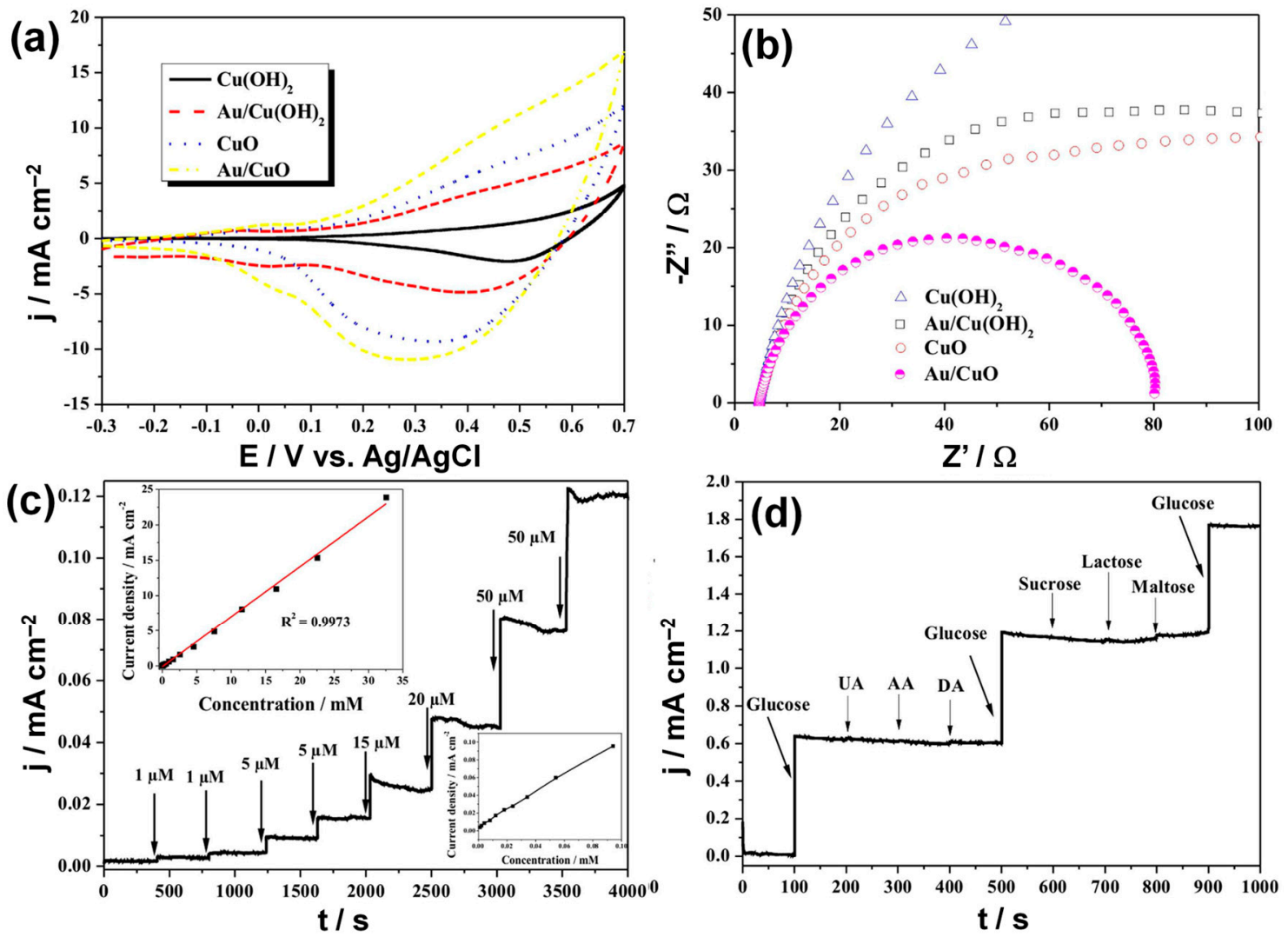

Figure 5. (a) Cyclic voltammograms of the $\mathrm{Cu}(\mathrm{OH})_{2}, \mathrm{Au} / \mathrm{Cu}(\mathrm{OH})_{2}, \mathrm{CuO}$ and $\mathrm{Au} / \mathrm{CuO}$ electrode materials in $1.0 \mathrm{M} \mathrm{NaOH}$ with a scan rate of $50 \mathrm{mV} \cdot \mathrm{s}^{-1}$; (b) EIS: Nyquist plots of $\mathrm{Cu}(\mathrm{OH})_{2}$, $\mathrm{Au} / \mathrm{Cu}(\mathrm{OH})_{2}, \mathrm{CuO}$, and $\mathrm{Au} / \mathrm{CuO}$ samples collected at open circuit potential; (c) Amperometric responses of the $\mathrm{Au} / \mathrm{CuO}$ electrode with successive addition of glucose at $0.35 \mathrm{~V}$ vs. $\mathrm{Ag}|\mathrm{AgCl}| \mathrm{KCl}_{\text {sat }}$, the top-left inset is the calibration curve at a high glucose concentration, and the bottom-right inset is the calibration curve at a low glucose concentration; (d) Anti-interference property of the $\mathrm{Au} / \mathrm{CuO}$ electrode with initial addition of $1.0 \mathrm{mM}$ glucose and $0.05 \mathrm{mM}$ of UA, AA, and DA, and then again $1.0 \mathrm{mM}$ glucose, followed by addition of $0.02 \mathrm{mM}$ sucrose, lactose, and maltose, and final addition of $1.0 \mathrm{mM}$ glucose at $0.35 \mathrm{~V}$ vs. $\mathrm{Ag}|\mathrm{AgCl}| \mathrm{KCl}_{\text {sat }}$. Reprinted and adapted with permission from Reference [92]. Copyright Macmillan Publishers Limited, 2016.

\subsubsection{Heterogeneous Electrode Materials: Au- and Co-Based Hydroxide or Oxide Interfaces}

As an alternative to noble metals, cobalt ( $\mathrm{Co}$ ) is another promising candidate as an electrocatalyst. $\mathrm{Su}$ et al. [93] combined the electrodeposition method and galvanic replacement reaction to design a controllable cobalt oxide/Au hierarchically nanostructured electrode that has glucose-sensing ability with a wide linear range from $0.2 \mu \mathrm{M}$ to $20 \mathrm{mM}$ and a low detection limit of $0.1 \mu \mathrm{M}(\mathrm{S} / \mathrm{N}=3)$. Typically, the galvanic replacement is a simple and well-established chemical way to fabricate metal (especially noble metal) nanostructures [94-96]. For instance, through a galvanic replacement reaction between a cobalt sacrificial template and gold ions, hollow gold nanostructures can be synthesized [97]. In a typical procedure, a fluorine-doped tin oxide-coated glass slide (FTO) is preliminarily washed with acetone, ethanol, and twice-distilled water for $10 \mathrm{~min}$ in an ultrasonic cleaner. The electrolytic solution for the electrodeposition is a buffer constituted by $0.025 \mathrm{M} \mathrm{H}_{3} \mathrm{BO}_{3}$ at $\mathrm{pH}=5.4$ and employing an aqueous solution of $0.1 \mathrm{M} \mathrm{CoSO}_{4}$ as a cobalt source. The entire media is maintained under nitrogen atmosphere before and during the electrolysis. Then, cobalt electrodeposition 
(Equation (4)) is performed by applying $\mathrm{CV}$ in the potential range of -0.2 to $-1.2 \mathrm{~V}$ vs. $\mathrm{Ag}|\mathrm{AgCl}| \mathrm{KCl}_{\text {sat }}$ at $20 \mathrm{mV} \cdot \mathrm{s}^{-1}$ for 20 cycles [93]. Afterwards, the electrode is rinsed with water and then immersed in $1.0 \mathrm{mM} \mathrm{HAuCl}_{4}$ solution for $30 \mathrm{~min}$ at $50^{\circ} \mathrm{C}$ to accomplish the galvanic replacement between $\mathrm{Co}(0)$ and $\mathrm{Au}(\mathrm{III})$. Indeed, $E^{\circ}\left(\mathrm{AuCl}_{4}{ }^{-} / \mathrm{Au}\right)=1.00 \mathrm{~V}$ vs. SHE and $E^{\circ}\left(\mathrm{Co}^{2+} / \mathrm{Co}\right)=-0.28 \mathrm{~V} \mathrm{vs}$. SHE; thus, $\mathrm{Au}(\mathrm{III})$ can be reduced by $\mathrm{Co}(0)$ species (Equation (5)). The electrode fabrication strategy is illustrated in Figure 6a where the cobalt particles were first deposited onto a FTO glass surface by the $\mathrm{CV}$ method and cobalt oxide/Au hierarchical nanostructures were subsequently prepared using the reaction of $\mathrm{HAuCl}_{4}$ aqueous solution with the cobalt particles. By controlling the introduced amount of $\mathrm{Co}$ and $\mathrm{Au}$ precursors, it is possible to obtain a heterogeneous catalytic surface composed of $\mathrm{Au}$ and $\mathrm{Co}_{3} \mathrm{O}_{4}$ NPs. Figure $6 \mathrm{~b}$ shows a typical TEM micrograph of cobalt oxide/Au. Deep characterizations reveal that NPs with a lattice spacing of about $0.23 \mathrm{~nm}$ correspond to the (111) planes of $\mathrm{Au}$, whereas those with a lattice spacing of $0.26 \mathrm{~nm}$ correspond to the interspacing of the (311) planes of $\mathrm{Co}_{3} \mathrm{O}_{4}$, supported by energy-dispersive spectroscopy (EDS), Raman spectroscopy and X-ray photoelectron spectroscopy (XPS). In the high-resolution XPS spectrum of Co 2p, two characteristic peaks centered at the binding energy (BE) of 780.6 and $796.1 \mathrm{eV}$, corresponding to the $\mathrm{Co}_{2} 2 \mathrm{p}_{3 / 2}$ and $\mathrm{Co} 2 \mathrm{p}_{1 / 2}$ spin-orbit peaks of the $\mathrm{Co}_{3} \mathrm{O}_{4}$ phase, were clearly identified, while the $\mathrm{Au} 4 \mathrm{f}$ XPS spectrum showed two sets of $\mathrm{Au} 4 \mathrm{f}_{7 / 2}$ and $\mathrm{Au} 4 \mathrm{f}_{5 / 2}$ signals at $\mathrm{BE}=83.5$ and $87.2 \mathrm{eV}$ corresponding to metallic gold $\left(\mathrm{Au}^{\circ}\right)$.

$$
\begin{gathered}
\mathrm{Co}^{2+}+2 \mathrm{e}^{-} \rightarrow \mathrm{Co} \\
2 \mathrm{AuCl}_{4}^{-}+3 \mathrm{Co} \rightarrow 2 \mathrm{Au}+3 \mathrm{Co}^{2+}+8 \mathrm{Cl}^{-}
\end{gathered}
$$

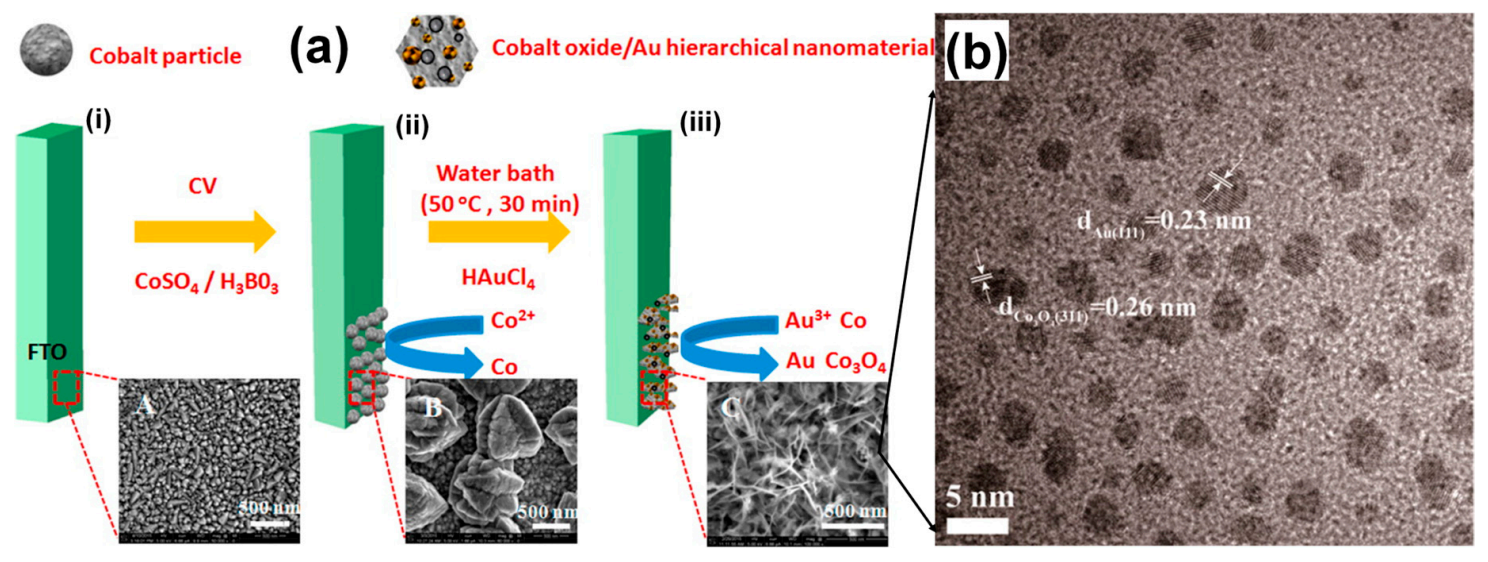

Figure 6. (a) Scheme for fabrication of cobalt oxide/Au hierarchically nanostructured electrode: (i) FTO; (ii) cobalt particles and (iii) $\mathrm{Co}_{3} \mathrm{O}_{4} / \mathrm{Au}$ hierarchically nanostructured material; (b) TEM images of $\mathrm{Co}_{3} \mathrm{O}_{4} / \mathrm{Au}$ hierarchically nanostructured material. Reprinted and adapted with permission from Reference [93]. Copyright American Chemical Society, 2016.

The CV experiments for the electrooxidation behavior of glucose at both cobalt oxide and cobalt oxide/ $\mathrm{Au}$ electrodes show that the oxidation of glucose starts at ca. 0.40 and $0.25 \mathrm{~V}$ vs. $\mathrm{Ag}|\mathrm{AgCl}| \mathrm{KCl}_{\text {sat }}$ on $\mathrm{CoO}_{\mathrm{x}} / \mathrm{FTO}$ and $\mathrm{Au} / \mathrm{Co}_{3} \mathrm{O}_{4} /$ FTO electrodes, respectively [93]. This significant negative shift of $E_{\text {onset }}$ towards the lower potential range is assigned to the presence of AuNPs tethered to $\mathrm{Co}_{3} \mathrm{O}_{4}$ within the material. According to the literature, the mechanism of the electrochemical oxidation of glucose catalyzed by $\mathrm{Co}_{3} \mathrm{O}_{4}$ has been proposed to be that $\mathrm{Co}_{3} \mathrm{O}_{4}$ is oxidized to $\mathrm{CoOOH}$, and then $\mathrm{CoOOH}$ is further oxidized to $\mathrm{CoO}_{2}$, which finally oxidizes glucose to generate gluconolactone and $\mathrm{CoOOH}$ (Equations (6)-(8)) [93,97]. Based on this mechanism, the performance mostly depends on the reversibility of the $\mathrm{CoO}_{2} / \mathrm{CoOOH}$ redox couple as an electron transfer agent. However, the entire efficiency depends on the first step where water molecules are split (Equation (6)). Thus, one can assume that a likely key role of $\mathrm{Au}$ as a co-catalyst is to promote this step at a low potential 
window. Amperometric measurements carried out at $0.60 \mathrm{~V}$ vs. $\mathrm{Ag}|\mathrm{AgCl}| \mathrm{KCl}_{\text {sat }}$ on $\mathrm{CoO}_{X} / \mathrm{FTO}$ and $0.30 \mathrm{~V}$ on $\mathrm{Au} / \mathrm{Co}_{3} \mathrm{O}_{4} / \mathrm{FTO}$ by the successive injection of glucose into $0.1 \mathrm{M} \mathrm{NaOH}$ under stirring are displayed within Figure 7. The low detection limit (LOD) is estimated to be $1 \mu \mathrm{M}(\mathrm{S} / \mathrm{N}=3)$ for the $\mathrm{CoO}_{\mathrm{X}} / \mathrm{FTO}$ electrode (linear ranges of $2 \mu \mathrm{M}$ to $0.2 \mathrm{mM}$, and $1 \mathrm{mM}$ to $20 \mathrm{mM}$ ), and $0.1 \mu \mathrm{M}$ for the $\mathrm{Au} / \mathrm{Co}_{3} \mathrm{O}_{4} / \mathrm{FTO}$ electrode (linear ranges of $0.2 \mu \mathrm{M}$ to $0.2 \mathrm{mM}$, and $0.5 \mathrm{mM}$ to $20 \mathrm{mM}$ ); the LOD was calculated as $\mathrm{LOD}=3 \mathrm{~s} / \mathrm{m}$ ( $\mathrm{s}$ is the standard deviation which was estimated from a small segment of the amperometric response curve obtained before the first addition of glucose, and $m$ is the slope of the calibration curve at low glucose concentrations) [93]. The comparison with other reported glucose sensors based on cobalt oxide and gold electrodes (see Table 1 of Reference [93]) indicates the good performance of $\mathrm{Au} / \mathrm{Co}_{3} \mathrm{O}_{4} / \mathrm{FTO}$ heterogeneous material, likely due to the excellent conductivity of gold and the synergistic electrocatalytic activity of gold and cobalt oxide. The presence of two different linear ranges may be presumably assigned to a change in the reaction mechanism depending on the glucose concentration which significantly affects the amount of active sites for $\mathrm{OH}^{-}$and $\mathrm{H}_{2} \mathrm{O}$ adsorption (Equation (6)).

$$
\begin{gathered}
\mathrm{Co}_{3} \mathrm{O}_{4}+\mathrm{OH}^{-}+\mathrm{H}_{2} \mathrm{O} \rightarrow 3 \mathrm{CoOOH}+\mathrm{e}^{-} \\
\mathrm{CoOOH}+\mathrm{OH}^{-} \rightarrow \mathrm{CoO}_{2}+\mathrm{H}_{2} \mathrm{O}+\mathrm{e}^{-} \\
2 \mathrm{CoO}_{2}+\mathrm{C}_{6} \mathrm{H}_{12} \mathrm{O}_{6} \rightarrow 2 \mathrm{CoOOH}+\mathrm{C}_{6} \mathrm{H}_{10} \mathrm{O}_{6}
\end{gathered}
$$

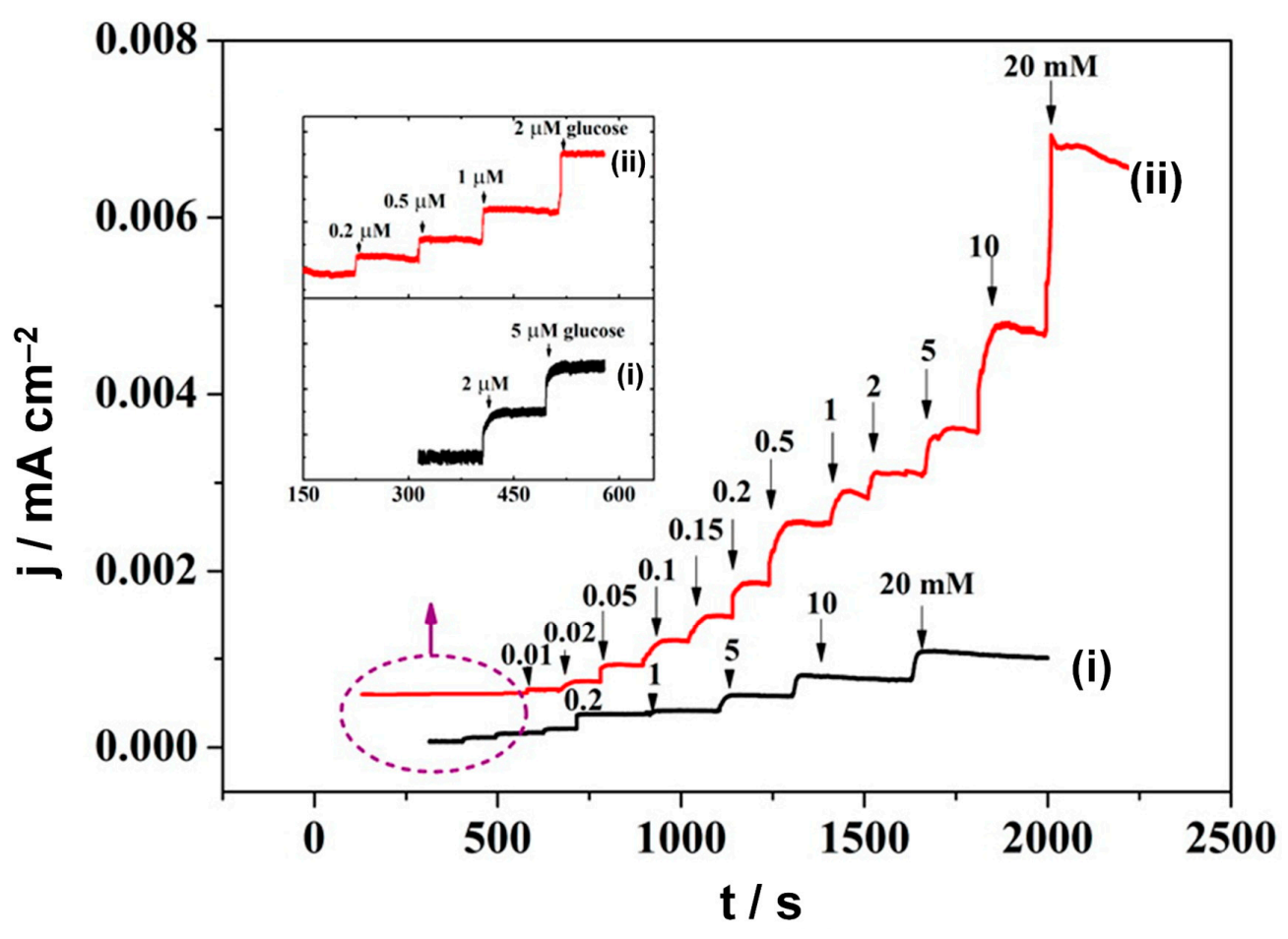

Figure 7. Amperometric response from the successive droppings of the glucose solution of different concentrations into $0.1 \mathrm{M} \mathrm{NaOH}$ solution of the cobalt oxide-modified FTO electrode: without $\mathrm{Au}$ (at $0.60 \mathrm{~V}$ vs. $\mathrm{Ag}|\mathrm{AgCl}| \mathrm{KCl}_{\text {sat }}$ on $\mathrm{CoO}_{\mathrm{X}} /$ FTO: plot (i)) and with $\mathrm{Au}\left(\right.$ at $0.30 \mathrm{~V}$ vs. $\mathrm{Ag}|\mathrm{AgCl}| \mathrm{KCl}_{\text {sat }}$ on $\mathrm{Au} / \mathrm{CoO}_{\mathrm{X}} /$ FTO: plot (ii)). Reprinted and adapted with permission from Reference [93]. Copyright American Chemical Society, 2016.

3.2.6. Heterogeneous Electrode Materials: Metallic $\mathrm{Ni}-$ and Ni-Based Hydroxide or Oxide Interfaces

From the above discussion, it was found that the main reaction descriptors are $\mathrm{Au}(\mathrm{OH})_{x}$ species in the case of gold electrodes and redox couples $\mathrm{Cu}(\mathrm{III}) / \mathrm{Cu}(\mathrm{II})$, and $\mathrm{Co}(\mathrm{IV}) / \mathrm{Co}(\mathrm{III})$ for non-noble metals. Furthermore, nickel electrodes have been extensively explored as catalysts of organic 
compound oxidation, mostly in an alkaline medium. Inspired by this trend, several prototypes of Ni-based materials have been explored as non-enzymatic electrodes for the electrocatalytic oxidation of glucose [98-104]. All research unanimously admitted that the catalytically active component is a $\mathrm{Ni}(\mathrm{III})$ oxyhydroxide species, involved in the $\mathrm{NiO}(\mathrm{OH}) / \mathrm{Ni}(\mathrm{OH})_{2}$ redox couple. A CV profile of the $\mathrm{Ni}$ electrode shows that a relatively high electrode potential of $\sim 1.4 \mathrm{~V}$ vs. RHE (about $0.4 \mathrm{~V}$ vs. SCE) is needed to produce $\mathrm{NiO}(\mathrm{OH})$ species $[105,106]$. To date, nickel electrodes have not been reported to function in close-physiological conditions. Indeed, they have several drawbacks that currently prevent their application to glucose sensing because of their inability to operate in physiological conditions ( $\mathrm{pH}$ about 7.7) since $\mathrm{NiO}(\mathrm{OH})$ catalysis is highly dependent of the concentrated presence of $\mathrm{OH}^{-}$anions. Contrary to many claims in the literature, Ni electrodes cannot be suitable for fuel cells since the oxidation takes place at a high anodic potential so that the cell voltage will be negligible (cell voltage $\left.=E_{\text {cathode }}-E_{\text {anode }}\right)$. Basically, since $E_{\text {cathode }}$ is about 0.8-1 V vs. RHE, $E_{\text {anode }}$ should not exceed $0.7 \mathrm{~V}$ vs. RHE for a good cell voltage, which is not possible in the case of Ni electrodes ( $E_{\text {anode }}>1 \mathrm{~V}$ vs. RHE). They could maybe find applicability in the food industry or in organic electrosynthesis. The only possibility to integrate $\mathrm{Ni}$ in electroanalysis would be its combination with other composite materials since a relatively high electrode potential could provoke several interference reactions during the sensing.

\subsubsection{Carbon-Based Nanomaterials}

The nomenclature of nanostructured carbon materials is diverse: carbon nanotubes (CNTs), multiwalled and single-walled carbon nanotubes (MWCNTs and SWCNTs), carbon nanofibers (CNFs), and graphene nanosheets (GNSs) resulting from graphene. Basically, these materials have high active surface area that is significantly greater than the geometric surface area, which is ideal for a kinetically controlled, surface-bound reaction such as glucose oxidation. Similar to earth-abundant transition metals $\mathrm{M}(\mathrm{M}=\mathrm{Ni}, \mathrm{Co}, \mathrm{Mn}, \mathrm{Cu}, \mathrm{Fe})$, carbon-based materials are not the best-performing electrodes for glucose sensors at low electrode potential (operating potential is typically $0.2-0.7 \mathrm{~V}$ vs. $\left.\mathrm{Ag}|\mathrm{AgCl}| \mathrm{KCl}_{\text {sat }}\right)[107,108]$. They can, however, be combined with metallic materials to promote the electron transport between active catalysts and current collectors, thus yielding to a surface rich in $\mathrm{M}^{n+}(n=2,3)$ that is capable of undergoing the $\mathrm{M}^{(n+1)+} / \mathrm{M}^{n+}$ redox shuttle at a given potential. Indeed, nanostructured metal oxides have two major weaknesses that impede their widespread applications, which are poor electronic conductivity and structure collapse. Therefore, loading metal-based nanostructures on excellent conductive supports such as CNTs, MWCNTs, CNFs, and GNSs is the ideal solution to alleviate the two problems and the strategy has proven its efficiency in numerous examples [90,109-116]. The other effective solution is the combination of nanostructured carbons or metals with enzymes to design hybrid electrode materials with enhanced catalytic properties in electroanalysis and fuel cells [39,117-127].

\subsection{Nanomaterials for the Electroanalysis of $\mathrm{H}_{2} \mathrm{O}_{2}$ : Tracing the Progress of Biochemical Reactions}

The major role of electroanalysis is to provide a suitable quantitative assay for rapid and accurate determination of a species intended to track the progress of biochemical reactions in biological systems, which is of practical importance in biology, biomedicine, food security, and environmental protection. For instance, the precise determination of cellular reactive oxygen species (ROS) should enable a better understanding of the clinical consequences of their concentration enhancement, and assisting in studies of the biological effect of ROS in cells including superoxide anions $\left(\mathrm{O}_{2}{ }^{\bullet-}\right)$, hydroxyl radicals $(\bullet \mathrm{OH}), \mathrm{H}_{2} \mathrm{O}_{2}$, hypochlorous acid $(\mathrm{HOCl})$, and peroxynitrite $\left(\mathrm{ONOO}^{-}\right)[128,129]$. Produced by most oxidases in mitochondria, $\mathrm{H}_{2} \mathrm{O}_{2}$ can reach various cellular compartments by diffusing out through the membranes. It is a major ROS in living organisms, which affects cell proliferation and cell death, leading to diverse downstream biological effects connected with lipid peroxidation, DNA damage, and tumor promotion (an excess of ROS can lead to different kinds of disorders in the body, such as Parkinson's/Alzheimer's diseases, atherosclerosis, heart attack, and cancer) [130-133]. Horseradish 
peroxidase (HRP) is a natural enzyme that enables the electrochemical assay through a catalytic reduction of $\mathrm{H}_{2} \mathrm{O}_{2}$. As in the case of glucose, an elegant solution would be to design non-enzymatic artificial biosensors where nanomaterials (metal, carbon and metal oxide/sulfide semiconductors) can serve as an electrode to track the progress of biochemical reactions indirectly through $\mathrm{H}_{2} \mathrm{O}_{2}$ since it is an unavoidable byproduct.

\subsubsection{Noble Metal (Gold)-Based Electrodes}

Devadoss and coworkers used AuNPs-Nafion nanofibers as a scaffold to immobilize HRP, thus leading to a reliable and sensitive electrochemical detection of $\mathrm{H}_{2} \mathrm{O}_{2}$ as low as $38 \mathrm{nM}$ (in $0.1 \mathrm{M}$ phosphate buffered solution ( $\mathrm{pH}$ 7.4) used as the supporting electrolyte) [134]. However, in such a hybrid catalytic electrode, it is not easy to precisely determine the role of gold since $\mathrm{H}_{2} \mathrm{O}_{2}$ can also be reduced there. However, as is typical for compromises, this approach can also bring the disadvantages from both kinds of components: the limited stability of the HRP and the limited selectivity of AuNPs. Therefore, fully abiotic catalysts composed of electrodes modified with inorganic electrocatalytic species might be more promising, particularly if appropriate catalytic materials demonstrating selectivity for the $\mathrm{H}_{2} \mathrm{O}_{2}$-to- $\mathrm{H}_{2} \mathrm{O}$ reduction or $\mathrm{H}_{2} \mathrm{O}_{2}$-to- $\mathrm{O}_{2}$ oxidation are found. The effect of both distinguished reaction products during potential applications should justify and direct the research area so that the result of the electrode material is practically meaningful. Thus, several enzyme-free systems have been constructed to examine the ability of nanostructured metals towards $\mathrm{H}_{2} \mathrm{O}_{2}$ electrochemical sensing. To date, two peroxidase mimetic systems (enzyme-free) have been reported: either $\mathrm{Fe}_{3} \mathrm{O}_{4}$ NPs or a co-reduction approach for noble metals (AgAu nanoboxes, branched AgPd nanocrystals, and porous AgPt nanospheres) with peroxidase-like activity $[135,136]$. Li et al. [137] reported a co-reduction synthesis of Ag-Au bimetallic nanostructures for electrochemical $\mathrm{H}_{2} \mathrm{O}_{2}$ sensing. Figure $8 \mathrm{a}$ shows a representative TEM image of Ag-Au bimetallic material $\left(\left[\mathrm{Ag}^{+}\right] /\left[\mathrm{Au}^{3+}\right]=1: 0.1\right.$, towards the objective of $\mathrm{Ag}_{91} \mathrm{Au}_{9}$ ) exhibiting a coarse surface (inset, HRTEM image depicts the coarse surface of bimetallic material of ca. $140 \mathrm{~nm}$ ) [137]. The recorded calibration curves in a $0.1 \mathrm{M}$ phosphate buffered solution (PBS, $\mathrm{pH}=7.4$ ) at $-0.5 \mathrm{~V}$ vs. $\mathrm{Ag}|\mathrm{AgCl}| \mathrm{KCl}_{\text {sat }}$ for monometallics and a representative bimetallic material (Figure $8 \mathrm{~b}$ ) indicate that $\mathrm{Ag}_{90.5} \mathrm{Au}_{9.5}$ exhibits a linear region ranging from 0.18 to $48 \mathrm{mM}$ with a low detection limit of $2 \mu \mathrm{M}(\mathrm{S} / \mathrm{N}=3)$ and a sensitivity of $374 \mathrm{~mA} \cdot \mathrm{mM}^{-1} \cdot \mathrm{cm}^{-2}$, higher than both $\mathrm{Ag}\left(192.3 \mathrm{~mA} \cdot \mathrm{mM}^{-1} \cdot \mathrm{cm}^{-2}\right)$ and $\mathrm{Au}\left(33.7 \mathrm{~mA} \cdot \mathrm{mM}^{-1} \cdot \mathrm{cm}^{-2}\right)$. The relationship between the sensitivity (left $Y$-axis) or low detection limit (right $Y$-axis) and the atomic percentage of $\mathrm{Au}$ is displayed in Figure $8 \mathrm{c}$. The best compromise in terms of the sensitivity and low detection limit is reached when the atomic percentage of $\mathrm{Au}$ is about $32.7 \%$ and the corresponding $\mathrm{Ag}_{67.3} \mathrm{Au}_{32.7}$ has the highest sensitivity of $600 \mathrm{~mA} \cdot \mathrm{mM}^{-1} \cdot \mathrm{cm}^{-2}$ (a low detection limit of $0.2 \mu \mathrm{M}$ ). This optimal composition is likely due to the fact that the heterogeneous structure enables a better compromise during the diffusion and adsorption processes since a large amount of gold at the surface can lead to an excessive strong adsorption of hydroxide intermediate, thus blocking the first step [138]. Indeed, a strong interaction between $\mathrm{Au}$ and $\mathrm{HO}_{2}{ }^{-}$(the stable chemical form of $\mathrm{H}_{2} \mathrm{O}_{2}$ when $\mathrm{pH} \geq 7$ ) makes the desorption process difficult, thus delaying the electron transfer and adsorption of new molecules (limiting thereafter the catalytic cycle). In catalysis, the interaction of adsorbed species with the catalyst surface should be neither too weak (no adsorption for electron transfer) nor too strong (no desorption, leading to the accumulation of the reaction intermediates: the active sites on the catalytic surface are always occupied by adsorbed species, hence poisoning the catalyst). 

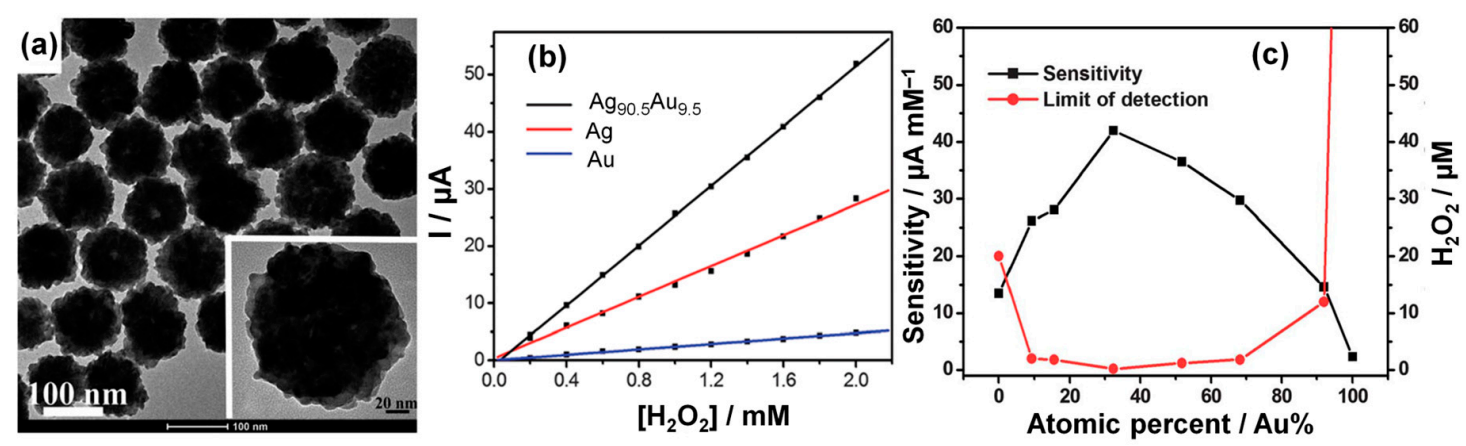

Figure 8. (a) TEM image of Ag-Au bimetallic material for the fixed ratio of $\left[\mathrm{Ag}^{+}\right] /\left[\mathrm{Au}^{\mathrm{III}}\right]=1: 0.1$ during the synthesis, the inset is a HRTEM micrograph; (b) Calibration curves from the amperometric responses of $\mathrm{Ag}_{90.5} \mathrm{Au}_{9.5^{-}}$(black), $\mathrm{Ag}$ - (red) and $\mathrm{Au}$ - (blue) modified GC electrodes at $E_{\text {applied }}=-0.5 \mathrm{~V}$ vs. $\mathrm{Ag}|\mathrm{AgCl}| \mathrm{KCl}_{\text {sat }}$ stirred in a $0.1 \mathrm{M}$ PBS; (c) Plots of the sensitivity (the black line) or the low detection limit (the red line) versus the atomic percentage of Au. Reprinted and adapted with permission from Reference [137]. Copyright The Royal Society of Chemistry, 2013.

\subsubsection{Heterogeneous Electrode Materials: Metal- and Carbon-Based Oxide Interfaces}

In 2014, a decisive advance was made when Maji et al. [129] developed a convenient synthetic approach to prepare a new generation of 2D nanohybrid systems of well-dispersed AuNPs over periodic mesoporous silica (PMS)-coated reduced graphene oxide (RGO), RGO-PMS@AuNPs, to act as an excellent platform for highly sensitive and selective detection of $\mathrm{H}_{2} \mathrm{O}_{2}$ at a nanomolar concentration level within biofluid (human urine or cancer cells). Figure 9a shows the synthesis procedure for immobilizing small $(\sim 3 \mathrm{~nm})$ AuNPs on a sandwich-like PMS-coated RGO (size range from $200 \mathrm{~nm}$ to $1 \mu \mathrm{m})$. PMS acts as a stabilizing agent to prevent the aggregation of individual RGO by weakening the $\pi-\pi$ stacking interaction between RGO nanosheets, and 3-aminopropyl triethoxysilane (APTES) was introduced to perform the surface modification from $-\mathrm{OH}$ to $-\mathrm{NH}_{2}$ on RGO-PMS prior to the reduction of $\mathrm{AuCl}_{4}{ }^{-}$[129]. The general scheme for the detection of either glucose (in human urine or blood) or hydrogen peroxide (from cancer cells) is displayed in Figure 9b.

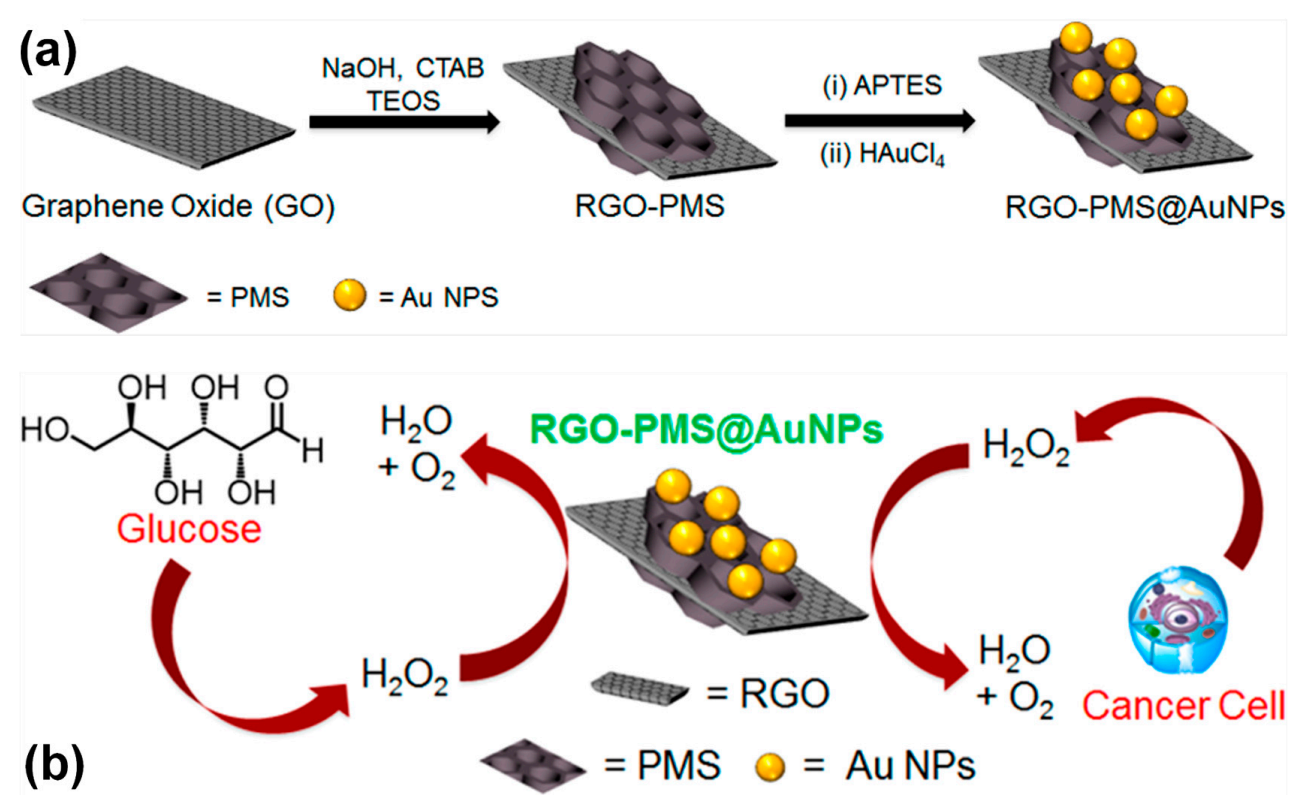

Figure 9. (a) Schematic illustration for the synthesis of RGO-PMS@AuNPs; (b) Schematic for in vitro detection of either glucose (left side) or $\mathrm{H}_{2} \mathrm{O}_{2}$ (right side). Reprinted and adapted with permission from Reference [129]. Copyright American Chemical Society, 2014. 
Typical CVs of the electrodes in $0.1 \mathrm{M}$ PBS $\left(\mathrm{pH} 7.4,30^{\circ} \mathrm{C}\right.$ ) are shown in Figure 10a for the bare glassy carbon (GC), RGO-PMS/GC, and RGO-PMS@AuNPs/GC electrodes. EIS results show that $R_{\mathrm{ct}}$ is significantly reduced from 522 to $125 \Omega$ for the RGOPMS@AuNPs/GC electrode as compared to the bare GC electrode, demonstrating the superior electron transfer capability of the hybrid material [129]. The CV profiles within Figure 10b indicate that RGO-PMS@AuNPs has the ability to oxidize $\left(0.65 \mathrm{~V}\right.$ vs. $\left.\mathrm{Ag}|\mathrm{AgCl}| \mathrm{KCl}_{\text {sat }}\right)$ or reduce $\left(-0.75 \mathrm{~V}\right.$ vs. $\left.\mathrm{Ag}|\mathrm{AgCl}| \mathrm{KCl}_{\text {sat }}\right) \mathrm{H}_{2} \mathrm{O}_{2}$ at $\mathrm{pH}=7.4$. The small AuNPs are responsible for the active catalytic reduction/oxidation processes. The oxidation or reduction process occurs at AuNPs and owing to its excellent electrical conductivity, RGO boosts the electron transfer capability within the hybrid, thus improving the electrocatalytic activity. $\mathrm{H}_{2} \mathrm{O}_{2}$ assays with the RGO-PMS@AuNPs/GC electrode carried out at $E_{\text {applied }}=-0.75 \mathrm{~V}$ vs. $\mathrm{Ag}|\mathrm{AgCl}| \mathrm{KCl}_{\text {sat }}$ demonstrated that the electrode could achieve $~ 95 \%$ in its steady-state current within $2 \mathrm{~s}$ for a linear detection range from $0.5 \mu \mathrm{M}$ to $50 \mathrm{mM}$ with a good anti-interference ability towards uric acid $(0.1 \mathrm{mM})$, ascorbic acid $(0.1 \mathrm{mM})$, L-cysteine $(0.05 \mathrm{mM})$, and glutathione $(1 \mathrm{mM})$. The performed in vitro cancer cell detection through the real-time detection of $\mathrm{H}_{2} \mathrm{O}_{2}$ released from living cells, including human embryonic kidney cells (HEK 293, a normal cell line), human cervical cancer cells (HeLa), and human hepatoma cancer cells (HepG2), demonstrated that the amount of $\mathrm{H}_{2} \mathrm{O}_{2}$ released from cancer cells can be efficiently monitored by measuring the current change. It opens a new, fruitful prospect for a sensitive and reliable probe for $\mathrm{H}_{2} \mathrm{O}_{2}$ released by any cancer cells [129].
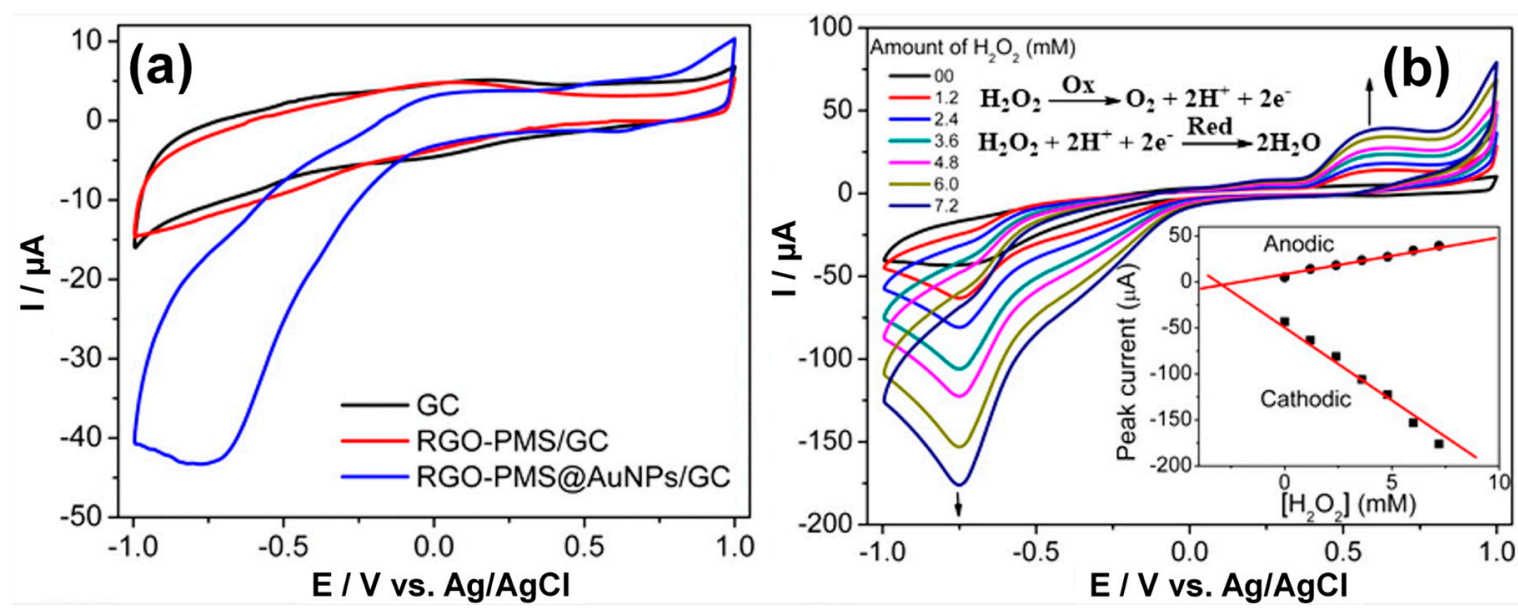

Figure 10. (a) CVs of GC, RGO-PMS/GC, and RGO-PMS@AuNPs/GC electrodes in 0.1 M PBS; (b) CVs of RGO-PMS@AuNPs/GC electrode in the absence and presence of $\mathrm{H}_{2} \mathrm{O}_{2}$ (inset: corresponding calibration plots). Note: the scan rate (in $\mathrm{mV} \cdot \mathrm{s}^{-1}$ ) was not provided, which is extremely disappointing for any comparison with other data within the literature. Reprinted and adapted with permission from Reference [129]. Copyright American Chemical Society, 2014.

\subsubsection{Noble Metal-Based Electrodes}

Due to their high intrinsic electrical conductivity (acting as an effective current collector for the catalyst) and the porous architecture of the open cell (favoring the effective mass transfer of both ionic species and molecules at the catalyst/electrolyte interface), metal nanocages with tunable pore sizes constitute a major part of the state-of-the-art electrocatalysts. Very recently, Li and coworkers introduced an enzyme-free $\mathrm{H}_{2} \mathrm{O}_{2}$ sensor based on quasi-spherical Au nanocages prepared via a galvanic replacement reaction with $\mathrm{HAuCl}_{4}$ in water at room temperature, where mono-dispersed quasi-spherical Ag nanocrystals (AgNCs) are used as sacrificial templates [139]. The principle of the galvanic replacement reactions in aqueous solution is driven by the difference in the electrochemical potential between two metals, herein $\mathrm{Ag}^{+} / \mathrm{Ag}\left(0.80 \mathrm{~V}\right.$ vs. SHE) and $\mathrm{AuCl}_{4}^{-} / \mathrm{Au}(1.00 \mathrm{~V}$ vs. SHE). In general, all metals $\mathrm{M}$ for which $E^{\circ}<1.00 \mathrm{~V}$ vs. SHE can be used as the sacrificial template to synthesize various shapes of AuM bimetallic NCs (the method has been optimized for various 
systems by Xia's group over the last decade [94,140-146]). AgNCs are routinely synthesized via a one-pot synthesis such as polyol before a galvanic replacement reaction between the as-prepared sacrificial template and an aqueous $\mathrm{HAuCl}_{4}$ solution leading to hollow, porous AuNCs and $\mathrm{Au}$ nanocages [139,147]. A typical synthesis of Au nanocages involves $2.5 \mathrm{~mL}$ of the aqueous solution of $\mathrm{HAuCl}_{4}(175 \mu \mathrm{M})$ to be added to $5 \mathrm{~mL} \mathrm{AgNCs}$ solution using a syringe pump at a rate of $250 \mu \mathrm{L} \cdot \mathrm{min}^{-1}$ under magnetic stirring and the final product is centrifuged and then dispersed in water for utilization. Figure 11a depicts the energy dispersion spectroscopy (EDS) mapping profile of Au nanocages, indicating the presence of the remaining Ag since the reaction conditions were manipulated to yield an $\mathrm{Ag} / \mathrm{Au}$ atomic ratio of 33/67 for a better synergic effect between the silver and gold [139]. Typical CV profiles in $0.1 \mathrm{M} \mathrm{PBS}(\mathrm{pH}=7.2)$ are displayed within Figure $11 \mathrm{~b}$, and the reduction current changes gradually with the initial $\mathrm{H}_{2} \mathrm{O}_{2}$ amount (Figure 11c). Amperometric assays at $-0.3 \mathrm{~V}$ vs. $\mathrm{Ag}|\mathrm{AgCl}| \mathrm{KCl}_{\text {sat }}$ indicate that the sensitivity of Au nanocages is much higher than other classes of nanostructures, with $215 \mu \mathrm{A} \cdot \mathrm{mM}^{-1} \cdot \mathrm{cm}^{-2}$ for nanocages compared to $198 \mu \mathrm{A} \cdot \mathrm{mM}^{-1} \cdot \mathrm{cm}^{-2}$ for porous AuNCs and $170 \mu \mathrm{A} \cdot \mathrm{mM}^{-1} \cdot \mathrm{cm}^{-2}$ for hollow AuNCs $\left(158 \mu \mathrm{A} \cdot \mathrm{mM}^{-1} \cdot \mathrm{cm}^{-2}\right.$ is reached for AgNCs). The range of the linear response to the $\mathrm{H}_{2} \mathrm{O}_{2}$ concentration is from 0.2 to $26.5 \mathrm{mM}$ with a LOD of $11 \mu \mathrm{M}$ and no significant interference from ascorbic acid, glucose and uric acid. These outcomes illustrate that due to their large interior and synergic effect, bimetallic nanocages can be integrated into electroanalytical devices for hydrogen peroxide assays.
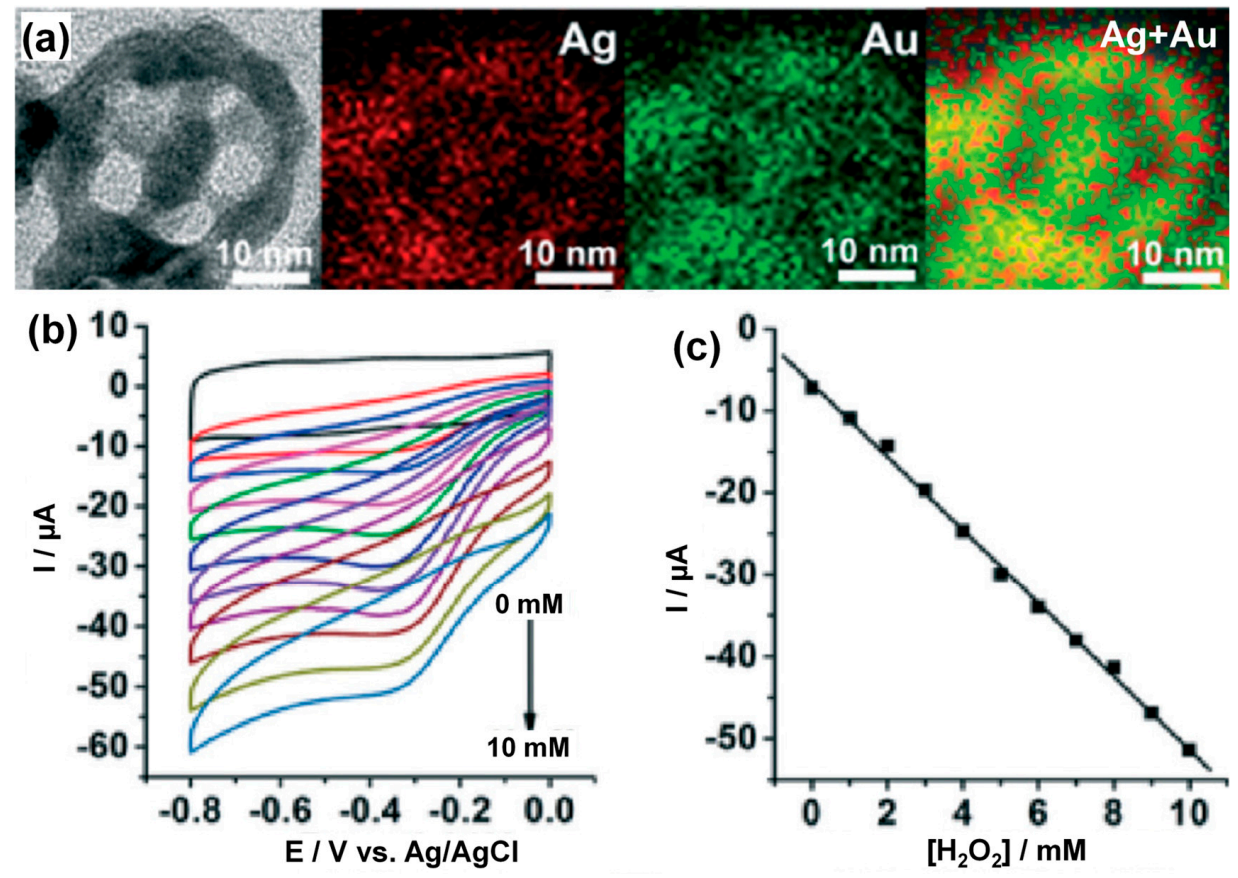

Figure 11. (a) EDS elemental mapping of the as-synthesized quasi-spherical Au nanocages; (b) CVs of Au nanocage-modified GC in $0.1 \mathrm{M}$ PBS (pH 7.2) with the concentration of $\mathrm{H}_{2} \mathrm{O}_{2}$ ranging from 0 to $10 \mathrm{mM}$; (c) Corresponding plots of $I$ vs. $\left[\mathrm{H}_{2} \mathrm{O}_{2}\right]$ at the potential of $-0.3 \mathrm{~V}$ vs. $\mathrm{Ag}|\mathrm{AgCl}| \mathrm{KCl}_{\text {sat }}$. Reprinted and adapted with permission from Reference [139]. Copyright The Royal Society of Chemistry, 2015.

\subsection{Nanomaterials for the Electroanalysis of Species of Biological Interest: DNA, Ascorbic Acid, Dopamine}

The great excitement generated by the above glucose and $\mathrm{H}_{2} \mathrm{O}_{2}$ sensors was mostly motivated by the tunable physical, morphological and catalytic properties of nanoscale materials. To take advantage of the fascinating properties of nanomaterials, such as larger specific surface areas and the higher density of surface active sites, various methods have been developed by different groups to prepare nanostructured materials to trace other substrates within biofluids such as DNA $[8,148,149]$, ascorbic 
acid [12,150,151], dopamine [11,152], acetylsalicylic acid (aspirin) [12,153], and paracetamol [9,10]. At the physiological level, ascorbic acid, commonly known as vitamin $\mathrm{C}$, is a compound of great biomedical interest that plays a very important role in regulating metabolism and central nervous system functions. Ascorbic acid and acetylsalicylic acid (or aspirin) are present in biofluids (plasma, serum and urine). For the electroanalytical detection of ascorbic acid and acetylsalicylic acid within human urine samples, Puangjan et al. [12] developed electrochemical sensors made from heterogeneous nanocomposites composed of manganese dioxide $\left(\mathrm{MnO}_{2}\right)$, antimony trioxide $\left(\mathrm{Sb}_{2} \mathrm{O}_{3}\right)$ and polyaniline (PANI), patterned all together on a fluorine-doped tin oxide (FTO) electrode $\left(\mathrm{MnO}_{2}-\mathrm{Sb}_{2} \mathrm{O}_{3} / \mathrm{PANI} / \mathrm{FTO}\right)$ through a potentiostatic deposition method. Deep electrochemical characterization by EIS demonstrated that the fabricated electrode material displays fast kinetics. Indeed, an $R_{\mathrm{ct}}$ value of $697 \Omega$ was determined for the bare FTO, which is approximately four-fold bigger than the recorded value after modification with PANI $\left(R_{\mathrm{ct}}=179 \Omega\right)$. This set of data indicates that the presence of highly conductive PANI greatly enhances the conductivity of the electrode and facilitates electron transfer between the substrate and electrode surface. Interestingly, the deposition of $\mathrm{MnO}_{2}-\mathrm{Sb}_{2} \mathrm{O}_{3}$ nanocomposites enables the significant improvement of the conductivity of the electrode $\left(R_{\mathrm{ct}}=36 \Omega\right)$. It should be noted that the lowest value of $R_{\mathrm{ct}}$ is correlated with high-throughput electron transfer at the electrode/electrolyte interface $\left(R_{\mathrm{ct}}\right.$ is inversely proportional to the rate constant, assuming the electron transfer as a rate-determining step (rds) [154]). Differential pulse voltammetry (DPV) experiments in $50 \mathrm{mmol} \cdot \mathrm{L}^{-1} \mathrm{PBS}$ (pH 7.0), for the simultaneous detection of ascorbic acid and acetylsalicylic acid in a mixture, showed linear relationships between their current intensity and concentration. The linear range was $6-265.4 \mathrm{nmol} \cdot \mathrm{L}^{-1}$ and $1.2-228.7 \mathrm{nmol} \cdot \mathrm{L}^{-1}$ with a low detection limit $(\mathrm{S} / \mathrm{N}=3)$ of $1.05 \mathrm{nmol} \cdot \mathrm{L}^{-1}$ and $0.20 \mathrm{nmol} \cdot \mathrm{L}^{-1}$ for ascorbic acid and acetylsalicylic acid, respectively [12]. The fabricated $\mathrm{MnO}_{2}-\mathrm{Sb}_{2} \mathrm{O}_{3} / \mathrm{PANI} / \mathrm{FTO}$ electrode was also able to selectively sense both analytes within a human urine sample.

Furthermore, DNA sensors based on nucleic acid recognition processes are quickly being developed as economical assays that test various genetic and infectious diseases [155]. To construct DNA sensors, researchers have the ingenious idea to develop electrochemical methods that convert the DNA hybridization from Watson-Crick base-pair recognition events into a readable analytical signal under controlled potential conditions, thereby monitoring the current response that results [155]. Owing to their large interior, NPG electrodes have found numerous applications in surface science and can host relatively large biomolecules for the construction of electrochemical genosensors $[7,148,149]$. Hu et al. [148] fabricated a NPG electrode using the classic dealloying strategy, by which silver is subtly dissolved from silver/gold bulk alloys in nitric acid. The interaction between NPG and DNA was qualitatively characterized by EIS and the fabricated DNA biosensor enables the detection of the DNA target quantitatively, in the range of $8.0 \times 10^{-17}$ to $1.6 \times 10^{-12} \mathrm{~mol} \cdot \mathrm{L}^{-1}$, with a limit of detection as low as $28 \mathrm{aM}$, i.e., $2.8 \times 10^{-17} \mathrm{~mol} \cdot \mathrm{L}^{-1}$.

Overall, the above research was not only aiming to enable the development of practical devices but also, ultimately, to understand and correlate the guiding principles by which the performance of a particular electrode material is achieved and/or preserved. To make electrochemical sensors based on nanomaterials more viable, we still need to integrate methods of physical and electroanalytical chemistry with a new point of view and a set of approaches to interrogate the intricate relationship of surface structure to performance. When possible, studies could also unite various strategies for the development of synthesis methods for nanomaterials with specific applications in energy conversion for powering micro-scale implantable devices.

\section{Nanomaterials as Abiotic Catalysts at Work in Fuel Cells for the Activation of Bio-Devices}

\subsection{From Enzymatically to Abiotically Catalyzed Glucose Fuel Cell for Implantable Targets}

As previously mentioned, one of the motivations for the transition from the enzymatic to abiotic approach comes from the urgent need to improve both the electronic conductivity or interactions 
and high resistance against changes in the environment (stability) by designing efficient electrode materials. Historically, electrodes for glucose electrooxidation have been studied not only because of their great importance in sensing (diabetes management), but also in the context of generating self-sufficient electrical energy through an electrochemical energy converter, the so-called glucose- $\mathrm{O}_{2}$ biofuel cell (BFC). It is worth noting that the recorded signal during electrochemical sensing can be the current, the voltage or the power after suitable calibration. Thus, a BFC can be employed not only to produce energy for use, but also for analytical purposes. Basically, an electrochemical energy converter is a system capable of directly converting/transforming the chemical energy through an electrochemical reaction into electrical energy. Specifically, the three types of electrochemical energy converters are [156-159]: (i) primary: those which deliver electricity from a chemical reaction of oxidation reduction and which are not rechargeable; (ii) secondary: the production of electrical energy relies on reversible redox reactions (batteries), and thus the system can operate as an energy generator (discharge) or as a receiver (load) using an external DC (direct current converter) power source; (iii) tertiary: known as the fuel cell (FC) with the specificity of being able to directly convert the chemical energy of an oxidation reaction of a fuel (dihydrogen, oxide, polyols, etc.) in the presence of an oxidizer (dioxygen) into electrical energy. The concept of FC came from the seminal experiments carried out by W. R. Grove in the mid-19th century [160-162]. According to the seminal works of Yahiro et al. [163] which employed a GOx bioanode and a Pt cathode to construct a BFC (open circuit voltage, OCV of 175-350 mV) and those of Young et al. [164], the definition of an enzymatic biofuel cell is stated as a fuel cell utilizing an enzyme as the electrocatalyst at one of the two electrodes; in this case it is at the anode. It should be noted that there is another class of BFC, namely the microbial fuel cell (MFC) which uses bacteria or microbes as catalysts [165-169]. Historically, this is the first type of BFC to be developed where specific bacteria perform both fuel oxidation and oxygen reduction reactions (ORR). The electronic transfer takes place between the microorganism and the surface of the electrode. In general, these are robust systems that can operate on variable raw materials and are resistant to poisoning, and are capable of oxidizing the substrate completely to carbon dioxide and water. De facto, MFCs will find their main application in the treatment of water and household waste. The following discussions cover only BFCs intended to operate within biofluids. Thus, the acronym of BFC excludes bacteria as catalysts.

As highlighted by Heller, the leading expert in this field, BFCs originally were intended to power cardiac-assisted devices ("artificial hearts"), then cardiac pacemakers, and then to supply electrical power to homes or electrical grids by electrooxidizing glucose in wastes or their derivates [170]. Presently, the observation is that the objectives at the beginning of the "BFC story" were overambitious, since after almost 50 years of intense efforts, there is still not a single BFC in use. To be competitive and attractive against $\mathrm{Li}$ /iodide batteries or $\mathrm{Li}-\mathrm{SOCl}_{2}, \mathrm{BFCs}$ must generate sufficient power $(\geq 3 \mu \mathrm{W})$ and be stable enough for the autonomous power supply of implantable devices [171,172]. Indeed, within biological conditions ([glucose] $=3-7 \mathrm{mM},\left[\mathrm{O}_{2}\right] \leq 0.25 \mathrm{mM}, \mathrm{pH} 7.7$ ), the power density of a glucose BFC is about $10^{4}$-fold below that required for a cardiac-assisted device and about $10^{3}$-fold below that required to competitively supply power to the electrical grid, and most importantly, the operational lifetime of the low power density for cardiac pacemakers is about three orders of magnitude shorter than that required [170,173]. To date, the most stable glucose "BFC" (no enzyme) was constructed by Kerzenmacher et al. [27] in 2008, delivering $3.3 \pm 0.2 \mu \mathrm{W} \cdot \mathrm{cm}^{-2}$ after 10 days of operation and $1.00 \pm 0.05 \mu \mathrm{W} \cdot \mathrm{cm}^{-2}$ after 224 days, but still working in vitro [174]. The great excitement generated by BFCs was to provide a sustainable power supply for medical implants by harvesting energy from body tissues (sugar and oxygen). Various strategies for enzymatic electrode elaboration have been developed by different groups leading to efficient performances in vitro [30,175-181] (from 1 to over $1000 \mu \mathrm{W} \cdot \mathrm{cm}^{-2}$ ) and in those implanted in living organisms [124,182-188]. Aiming to provide larger specific surface areas and a higher density of surface active sites, different methods have been developed to substitute one of the electrodes, mostly the anode, with an abiotic one, leading 
to the concept of the hybrid biofuel cell (hBFC) [180,189-191], and in some cases, all the electrodes are substituted by abiotic catalysts [174,181,192-196].

The first FC for medical implants intended to function with glucose from body fluids was presented in 1967 by Warner and Robinson [197]. Over 20 years of intense experimental high-throughput screening of electrocatalytic materials for glucose electrooxidation, the majority of investigators based their efforts almost exclusively on the use and a thorough understanding of the reaction mechanisms of $\mathrm{Pt}, \mathrm{Au}$ and $\mathrm{Pd}$ catalysts, which are the most capable of performing the reaction at a low anode potential. The first works with metallic nanomaterials go back to the early 2000s, with the aim to increase the active surface and kinetics of electrodes (the use of bulk metals is neither thermodynamically nor economically viable and became obsolete). The primary argument in favor of transitioning from bulk catalysts to those based on nanostructured metals is, indeed, quite self-compelling: the kinetics, the scarcity of noble metals, and their high price make them impractical for global-scale production applications. Therefore, the development of low-cost and high-performance alternative electrode materials that are suitable for activating glucose molecules at a low electrode potential is of paramount importance. Thus, the elegant solution to overcome the aforementioned issues is to develop functional bio-inspired nanocatalysts, which will constitute an important advance to bridge the gap towards good performance and large-scale electrocatalyst production. Hence, inspired by the performances of enzymes such as GOx and GDH, researchers have exploited a series of heterogeneous metallic nanocatalysts. This constitutes a profound achievement in the field of enzyme-free electrocatalysts. Recent research has focused on some alternatives including earth-abundant elements such as $\mathrm{Fe}, \mathrm{Ni}, \mathrm{Mn}, \mathrm{C}$, and $\mathrm{O}$ which could lead to similar or better electrochemical efficiency compared to the state-of-the-art Pt electrocatalysts. Indeed, the most promising strategy for preparing nanoscale materials consists of introducing an earth-abundant element that could reduce the cost without significantly affecting the performance.

The common electrocatalyst preparation methods can be used to synthesize nanocatalysts and inspirations can be drawn from the reported computational high-throughput screening of surface alloys in classical electrocatalysis to identify new electrocatalysts. Several analogues and/or prototypes of abiotically catalyzed glucose fuel cells utilizing nanoscale or microscale materials were presented within the last decade [189,195,196,198-200], in some cases incorporated with enzymes [201,202]. A compilation of recent glucose-based fuel cells operated in either close-biological conditions or alkaline/acidic ones can be found in Reference [203]. The comparison of cell performances is tedious and practically impossible since the experimental conditions vary from one researcher to another. This can be the size of the electrodes, glucose concentration, $\mathrm{pH}$, temperature, the presence or absence of a separation membrane (between the anode and cathode), and the method used for recording the polarization curves; all this information depends on the intended application. For instance, BFC research for implantable devices should not include a separation membrane during the tests since this is in contrast to reality where the fuel (glucose) and oxidizer $\left(\mathrm{O}_{2}\right)$ coexist within the same biofluid. The size of the electrode also plays a crucial role; a high-power-density BFC (expressed in $\mu \mathrm{W} \cdot \mathrm{cm}^{-2}$ ) is not necessarily the best-performing one. If the power is intended to be normalized with the geometric surface area of the electrode in terms of $\mu \mathrm{W} \cdot \mathrm{cm}^{-2}$, the size of the limiting electrode should be at least superior to $0.5-1 \mathrm{~cm}^{2}$ for trustworthiness and to avoid any conflicting comparison. Extremely small surface areas should be avoided during the tests; the conversion of a geometric surface area of $1 \mathrm{~mm}^{2}$ into $1 \mathrm{~cm}^{2}$ induces a factor a $10^{2}$ in normalized parameters. In practice, only the current or power is needed to activate a device, not the normalized values. In conventional FC science, conditions are more regulated (e.g., an electrode size of $5 \mathrm{~cm}^{2}$ is advised). Thus, it is worth noting that the standardization of testing conditions, i.e., establishing standardized tests in order to compare different results obtained by different researchers, and screening the optimal catalysts is very mandatory. The following sections are concentrated on examples of nanoscale materials used to design abiotically catalyzed fuel cells for the activation of bio-devices. 


\subsection{Target-Directed Development of Gold-Based Nanostructures by "Bromide Anion Exchange" Method}

\subsubsection{Preparation of Nanoelectrocatalysts Scheduled to Operate in Membraneless Cells}

Complete glucose electrooxidation involves 24 electrons per molecule and enables an OCV of $1.25 \mathrm{~V}$, which represents a free energy of $2871 \mathrm{~kJ} \cdot \mathrm{mol}^{-1}$, that is, $4.430 \mathrm{kWh} \cdot \mathrm{kg}^{-1}$, while a selective two-electron process affords $\mathrm{OCV}=1.15 \mathrm{~V}$ for $\mathrm{pH}=3.76$ and $\mathrm{OCV}=1.04+0.03 \times \mathrm{pH}$ for $\mathrm{pH}>3.76$, i.e., $\mathrm{OCV}=1.27 \mathrm{~V}$ at $\mathrm{pH} 7.7$ [69]. This represents a good opportunity to be taken for clean energy generation and it is suggested that the glucose BFC could effectively replace Li-based batteries for powering implantable micro-devices. The first demonstration of the ability of abiotically catalyzed fuel cells for the activation of biomedical devices, such as pacemakers, was reported by Kerzenmacher's group which highlighted the necessary conversion of the relatively low fuel cell voltage of $0.2 \mathrm{~V}$ into the $3 \mathrm{~V}$ typically required by implant electronics [204]. However, a membrane was employed to guarantee the selectivity. One of the intelligent cornerstone ways to further moderate electrode selectivity and suppress the use of this membrane, thereafter improving the design towards practical applicability, was recently reported [181,192,205]. It consists of introducing Au-based nanocatalysts coated on two different carbon supports. The surfactant-free nanomaterials were synthesized according to the bromide anion exchange (BAE) method, a soft and simple chemical approach which does not require any organic molecule as a surfactant or capping agent and enables the effective preparation of well-dispersed nanocrystals with a good chemical yield (>90\%) [105,180,205-208]. A typical TEM micrograph of an $\mathrm{Au} / \mathrm{C}$ nanocatalyst is shown in Figure 12a and the average particle size of $5.7 \pm 0.1 \mathrm{~nm}$ is estimated from the histograms presented in Figure 12b. Nanocrystals are deposited randomly onto the carbon support without a well-defined orientation for a total metal loading of 20 wt. \%. The HRTEM micrograph shown in Figure 12c displays a truncated octahedral shape with different degrees of truncation; NPs have facets oriented along the (111) and (200) crystallographic planes [64] instead of the common (111) and (100) planes predicted by Wulff's theorem.
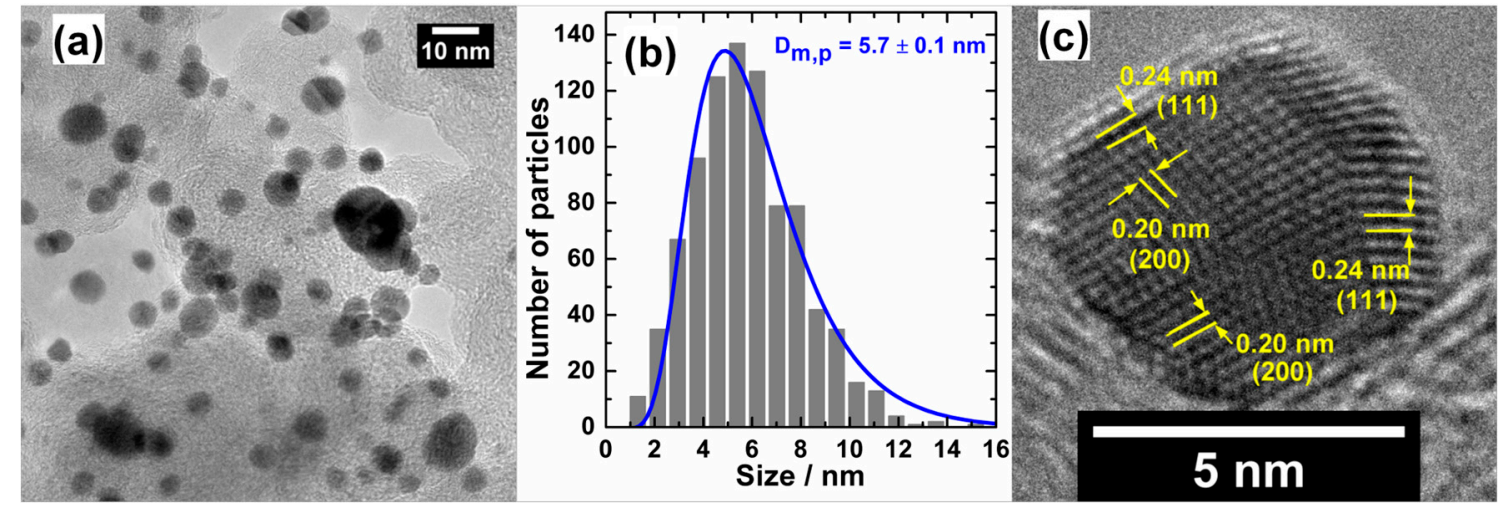

Figure 12. (a) Typical transmission electron microscopy (TEM) image of Au/C synthesized from the bromide anion exchange (BAE) method; (b) The corresponding particle size distribution: histograms were fitted using the log-normal function (blue curve); (c) Typical high resolution transmission electron microscopy (HRTEM) micrograph of Au/C monometallic nanomaterial [64]: the zone axis is [101].

\subsubsection{Design and Fabrication of Electrodes with Improved Selectivity in Human Serum Solution}

After basic and preliminary experiments based on the measurement of the open circuit potential (OCP) in a three-electrode electrochemical cell, buckypaper (BP) and carbon paper (CP) were chosen as the supports for the anode and cathode, respectively $[181,209]$. These basic experiments enabled choosing the best pair of electrodes producing the maximum potential difference $E_{\text {cathode }}-E_{\text {anode }}=E_{\text {cell }}$ (cell voltage). BP is a 3D-matrix composed of hollow nanotubes with a $50 \mathrm{~nm}$ diameter with a porosity of about $0.1-0.3 \mu \mathrm{m}$, while $\mathrm{CP}$ (more graphitic than $\mathrm{BP}$ ) is composed of fibers (filled tubes) with a $7 \mu \mathrm{m}$ diameter and has a much larger porosity $(10-50 \mu \mathrm{m})$ [181]. All these features 
are expected to further modify the diffusion and modulate the reactivity of glucose and oxygen. Aiming to improve the lifetime of pacemakers activated by enzymatic BFCs [124,210], metal NPs supported on Ketjenblack EC-600JD (carbon black) were loaded onto the above 3D carbon substrates towards the objective of $56 \mu \mathrm{g} \cdot \mathrm{cm}^{-2}$ as the metal loading on each electrode. As the implantable energy-harvesting devices are expected to use the fuel (e.g., glucose) and $\mathrm{O}_{2}$ from the biofluid (no external supply of $\mathrm{O}_{2}$ ), the preliminary experiments were performed in a PBS at $\mathrm{pH}$ 7.4 containing glucose and $\mathrm{O}_{2}$ in equilibrium with air. The best candidate for the catalytic anode was Au/C-modified $\mathrm{BP}$ which produced the lowest electrode potential in the presence of glucose and oxygen $(+0.38 \mathrm{vs}$. $\mathrm{RHE}$ ). The best cathode was represented by $\mathrm{Au}_{60} \mathrm{Pt}_{40} / \mathrm{C}$-modified $\mathrm{CP}$, which produced the most positive potential in the presence of oxygen and glucose ( $+0.89 \mathrm{vs.} \mathrm{RHE).} \mathrm{All} \mathrm{this} \mathrm{enables} \mathrm{us} \mathrm{to} \mathrm{expect}$ the best possible cathode-anode OCV of $510 \mathrm{mV}$ [181]. Figure 13a shows the polarization curves of the FC operating in human serum solution containing $5.4 \mathrm{mM}$ (plot (a)) and $20 \mathrm{mM}$ (plot (b)) glucose. The maximum power production achieved on the external load of $250 \Omega$ was ca. $105 \mu \mathrm{W}$ in the presence of the physiologically normal glucose concentration $(5.35 \pm 0.16 \mathrm{mM} ; \mathrm{pH} 7.75)$ and OCV $=0.35 \mathrm{~V}$. With an electrode size of $2 \mathrm{~cm}^{2}, P_{\max }=52 \mu \mathrm{W} \cdot \mathrm{cm}^{-2}$ at $5.4 \mathrm{mM}$ and $96 \mu \mathrm{W} \cdot \mathrm{cm}^{-2}$ at $20 \mathrm{mM}$.

(a)

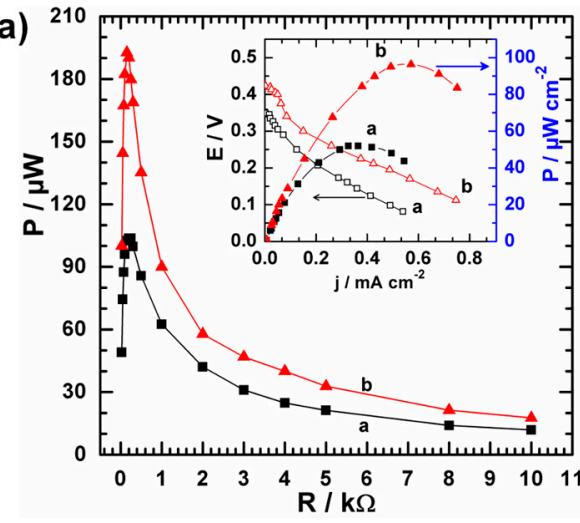

(b)

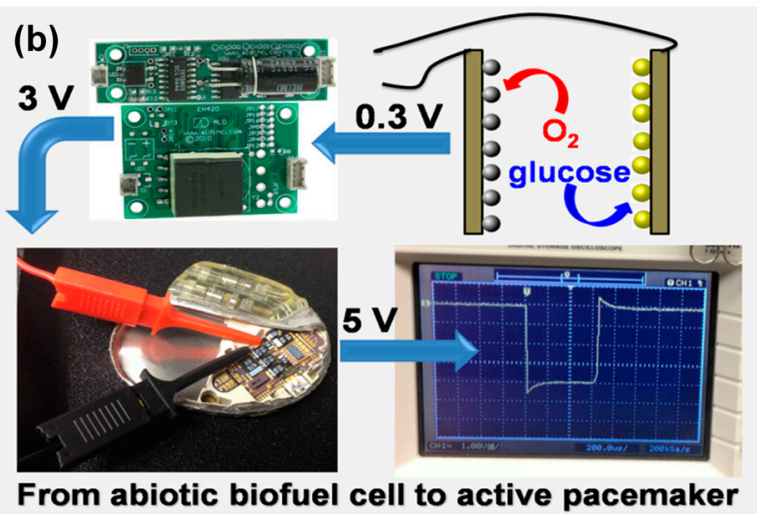

Figure 13. (a) Polarization characteristics of the fuel cell composed of the Au/CB-modified buckypaper anode and the $\mathrm{Au}_{60} \mathrm{Pt}_{40} / \mathrm{C}$-modified carbon paper cathode operating in human serum solution (pH 7.75, room temperature) containing $5.4 \mathrm{mM}$ (i) and $20 \mathrm{mM}$ (ii) glucose: The main panel shows the power released on the external variable resistance $(R)$, the inset shows the cell voltage and the released power as functions of the current density; (b) The scheme of the experimental setup including: a flow FC, an energy-harvesting circuit, a pacemaker, and an oscilloscope for registration of the pacemaker output signals. Reprinted and adapted with permission from Reference [181]. Copyright Wiley-VCH Verlag GmbH \& Co. KGaA, 2014.

Afterwards, a flow cell mimicking the human blood circulatory system filled with human serum solution containing ca. $5.4 \mathrm{mM}$ glucose was used to power a pacemaker, and its operation was monitored with an oscilloscope by registering the pacemaker output signals. It should be noted that the size of the electrodes was small enough $(2 \mathrm{~cm} \times 2 \mathrm{~cm})$ to allow for the accommodation of the fuel cell in a biological tissue together with the energy-harvesting circuit and the pacemaker. The pacemaker used in the study (Affinity DR5330L) operates at a minimum $2.8 \mathrm{~V}$ and a $100 \mu \mathrm{A}$ peak current draw, and to reach this voltage $(\sim 3 \mathrm{~V})$, an energy-harvesting circuit including a DC-DC converter was used to amplify the low voltage of $\sim 0.3 \mathrm{~V}$ [181]. Figure $13 \mathrm{~b}$ shows the characteristic waveform on the oscilloscope and it proves the successful operation of the pacemaker using power generated by the fuel cell in human serum solution employing abiotic electrodes.

For medical uses as an energy source to activate a pacemaker, implanted FCs are required to provide power for many years, as this is the case of batteries that have a lifetime of ca. 10 years $[211,212]$. To date, the two developed prototypes of enzymatic [124,210] and abiotic [180] 
FCs are thus far inefficient and unsustainable over time (only within hours for the lifetime), and are therefore less competitive in the market scope with lithium-based batteries. In order to target high catalytic performances and support high current densities, the active metals, such as those discussed above, need to be dispersed on nanocarbons, for instance graphene and carbon nanotubes, which will provide, in return, either favorable structural supports (e.g., a large surface area) or cooperative electrical effects (e.g., enhanced electron transfer and mass transport) or both. The road towards these high-performance electrocatalysts can consist of an intentional, but tight introduction of some heteroatoms (N, B, O, S, P, F) into the pristine structure of nanocarbons, leading to the creation of defect sites that are readily capable of modulating the physical and chemical properties of the pristine material. More importantly, the process might be accompanied by the addition of reactive sites that efficiently mediate the conversion of glucose. Within the last 20 years, laser ablation, radiolysis, polyol, seed-mediated, water-in-oil, and BAE methods have opened new avenues for the preparation of various kinds of metal NCs in materials science using top-down to bottom-up approaches classified into chemical and physical methods $[205,213]$. The leading approaches should be to eschew the use of organic complexes or molecules of surfactant or capping agents, since any remaining species can drastically alter the electrode material activity and/or selectivity through the control of active sites $[75,213]$. Having demonstrated excellent electroactivity and stability in half-cell experiments, the possibility of designing an energy-harvesting device based on these nanomaterials will certainly add a new dimension to electrical energy generation from biofluids.

\subsubsection{Design and Fabrication of Electrodes to Activate Wireless Information Transmission Systems}

At the present level of BFC technology, their medical use for implantation in the human body is limited by their extremely short lifetime. Thus, an alternative option is supplying the power for sensors used for environmental monitoring, particularly for possible homeland security applications that need a shorter operational time (hours to months) [192,214-220]. Consequently, an elegant way should consist of extracting electrical power from biological sources that might include animals or plants, while the catalytic electrodes could be minimally invasive or even located on their surface, printed as a "tattoo" [192]. A prototype of a wireless information transmission device receiving electrical power from an available fruit has been tested with employing abiotic electrocatalysts [192]. Figure 14a displays the fuel cell polarization curves where the $\mathrm{Pt} / \mathrm{C}$-modified $\mathrm{CP}$ cathode and the $\mathrm{Au}_{80} \mathrm{Pt}_{20} / \mathrm{C}$-modified BP anode are implanted in an orange and red plum. The metal nanomaterials were prepared by the BAE method and the metal loading on the anode and cathode was $56 \mu \mathrm{g} \cdot \mathrm{cm}^{-2}$; a picture of the orange with the implanted electrodes $\left(2 \mathrm{~cm}^{2}\right)$ can be seen in Figure 14b. The maximum power production achieved with the external load of $150 \Omega$ was ca. $182 \mu \mathrm{W}\left(P_{\max }=91 \mu \mathrm{W} \cdot \mathrm{cm}^{-2}\right)$ for the orange and ca. $258 \mu \mathrm{W}\left(P_{\max }=129 \mu \mathrm{W} \cdot \mathrm{cm}^{-2}\right)$ for the red plum while the OCV was 0.35 and $0.43 \mathrm{~V}$ for orange and red plum, respectively. The used orange contained glucose and fructose concentrations of $1.82-1.83$ and $1.98-2.05 \mathrm{~g} / 100 \mathrm{~mL}$, respectively (ca. $100 \mathrm{mM}$ total) [192]. The red plum juice might have a high concentration or better diffusion facilities for reactants which explains the high performance.

Figure $14 \mathrm{~b}$ displays the designed energy-harvesting and wireless transmission units. For proper automatic wireless transmission, the electronic device needs an optimized voltage of $2.3 \mathrm{~V}$. Typically, electronic components charge a super-capacitor from the low voltage generated by the FC, and upon reaching this desired threshold of $2.3 \mathrm{~V}$, the micro-controller powers up the transmitter and messages are sent inside a packet to be received with little interference. The system continues transmitting until it discharges the super-capacitor to below the $1.5 \mathrm{~V}$ before the automatic cyclic activation and wireless information transmission, and it will stop sending data when all the sugar and/or $\mathrm{O}_{2}$ within the juice is exhausted. These preliminary tests with a nanomaterials-based fuel cell extracting electrical energy from biofluids open new prospects in bionanotechnology engineering and could be extended to a large area of the bioelectronics and healthcare industry that is moving toward wearable biomedical devices $[2,219,221-225]$. The outlined effectiveness of nanoscale inorganic materials as 
"abiotic catalysts" is not aiming to replace biocatalysts, but rather to constitute an alternative for the elaboration of efficient systems that harvest energy from biological sources for various sensing and wireless information-processing devices within biomedical, homeland security, and environmental monitoring applications.
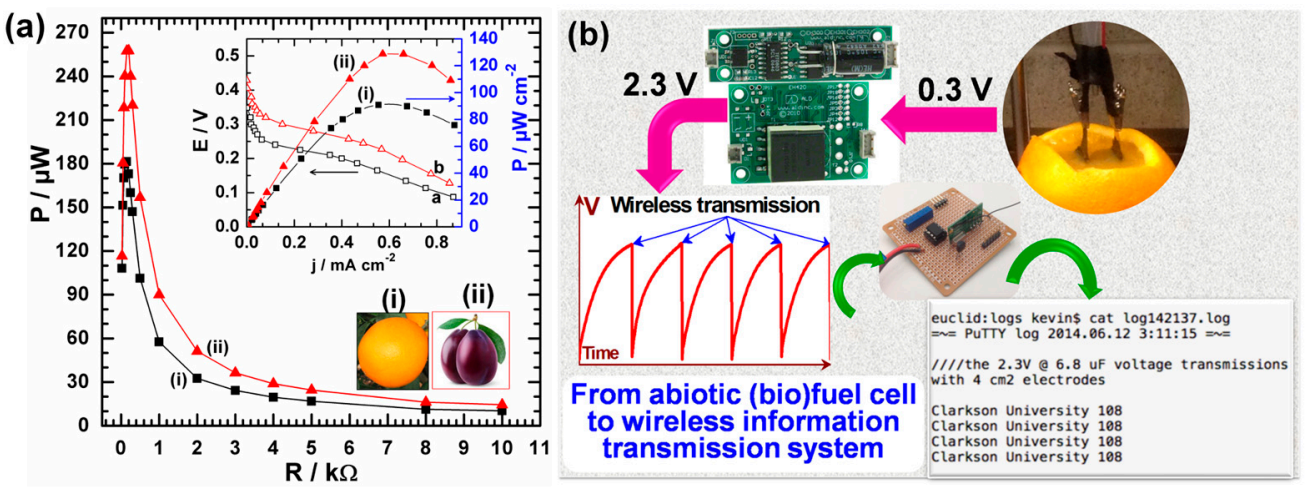

Figure 14. (a) Polarization characteristics of the fuel cell composed of the $\mathrm{Pt} / \mathrm{C}$-modified carbon paper cathode and the $\mathrm{Au}_{80} \mathrm{Pt}_{20} / \mathrm{C}$-modified buckypaper anode implanted in an orange (i) and red plum (ii): The main panel shows the power released on the external variable resistance, the inset shows the cell voltage and the released power as the functions of the current density; (b) The orange with implanted electrodes (close view), the energy-harvesting circuit, the charging-discharging process and the message transmitted wirelessly using the power harvested by the FC from the orange. Reprinted and adapted with permission from Reference [192]. Copyright Wiley-VCH Verlag GmbH \& Co. KGaA, 2015.

\section{Concluding Remarks and Further Outlook}

Within this contribution, we went through both the fundamental and practical aspects of the unavoidable question of introducing nanostructured inorganic materials in electrochemical sensing and biofuel cells. The benefits of inorganic fabrication methods compete favorably against enzymatic fabrication, as the delicate nature of the enzyme need not be considered, thus allowing for more diverse, rapid and lower-cost processes. This offers another advantage to non-enzymatic glucose sensing: the ability to reuse an electrode. Careful analysis of the literature data reveals that either strong corrosive acidic solutions ( $\mathrm{pH}$ about 0 ) or alkaline ones ( $\mathrm{pH}$ about 13) constitute most of the electrolytic solutions used to conduct the non-enzymatic sensing. Then, the conclusions are "extrapolated" to physiological conditions where most of the investigators claim the suitability for blood glucose sensing. Such experimental approaches invalidate most of the data and studies with nanomaterials. The performance descriptors for glucose oxidation have been suggested to be $\mathrm{Cu}$ (III)/Cu(II), $\mathrm{Ni}(\mathrm{III}) / \mathrm{Ni}(\mathrm{II}), \mathrm{Co}(\mathrm{IV}) / \mathrm{Co}(\mathrm{III})$ and $\mathrm{Au}(\mathrm{OH})_{x}$ species for the particular cases of copper-, nickel-, cobaltand gold-based electrodes, respectively. Designed to mimic biological mechanisms, the redox couples thereby mimic the enzymatic electron transfer catalysis by reducing the $\mathrm{M}$ (III) center to $\mathrm{M}$ (II) (where $\mathrm{M}=\mathrm{Ni}$, Fe or $\mathrm{Cu}$ ). Thus, to boost the efficiency of electrodes based on those metals, synthesis methodologies should be guided in order to provide such species at relatively low electrode potentials and make the catalytic cycle as reversible as possible in order to maintain the same performance for a long time. Extensive studies have shown that nanomaterials (gold, carbon, etc.) are promising candidates for modifying electrode surfaces, which can then host a specific bio-recognition layer. This approach introduces many advantages in sensors and biofuel cells, encompassing their ability to provide a friendly and efficient loading platform for immobilizing enzymes and further improve electron transfer between the active site and electrode.

Electrochemical sensing and biofuel cells could, in principle, conveniently provide efficient, powerful tools to detect analytes and harvest electrical energy for the autonomy of implantable devices. However, existing catalytic materials are too inefficient in practice: either weak binding interactions 
between the reaction intermediates and the catalyst give rise to high overpotentials (requiring more energy to make the reaction), or slow electron transfer kinetics lead to low exchange current densities (poor kinetics for drawing high current densities). For instance, higher overpotential or low selectivity lead to the reduction or oxidation reactions of interference chemical species within the sample and the amount of the analyte is overestimated or underestimated. Fundamental multidisciplinary investigations demonstrated that both metrics depend not only on the intrinsic electronic properties of the catalyst, but also on the medium and the nature of the catalyst. The first instruction is to pursue and accentuate the search for both activity and stability descriptors in close-biological conditions. Then, particular attention should be paid to replacing expensive and rare noble metal electrocatalysts with inexpensive and earth-abundant ones. To this end, more options for robust nanocatalysts that work at a $\mathrm{pH}$ of about 7 should be promoted in order to provide more flexibility in terms of cost and applicability. In order to mimic practical applications, strong corrosive acidic and/or alkaline media having extreme $\mathrm{pH}$ values of 0 or 13 should be gradually replaced by electrolytic solutions that reflect the real conditions. In addition, an ultra-small electrode surface (leading to the overestimation of normalized outputs such as the current density $\left(\mu \mathrm{A} \cdot \mathrm{cm}^{-2}\right)$ and power density $\left.\left(\mu \mathrm{W} \cdot \mathrm{cm}^{-2}\right)\right)$ should be substituted by suitable dimensions that are able to deliver the necessary current $(\mu \mathrm{A})$ and power $(\mu \mathrm{W})$ for the activation of a device. One of the important questions that should also be addressed is the biocompatibility of the chemical species involved in the design of the electrodes and the preparation of the electrolytic solutions. Therefore, experimental conditions should be set as close as possible to the real ones. The present work continues the research line where advanced strategies are used to design electrode materials using nanostructured inorganic materials to improve the catalytic kinetics and device durability. The suggested directions could serve as guidelines for future work, offer new strategic approaches for simplifying the design of electrocatalysts, and pave a pathway for breakthroughs in the development of electrochemical sensing and biofuel cell technologies to achieve superior performances.

Acknowledgments: The authors thank all the co-workers, cited in the literature list, École Nationale Supérieure de Chimie de Montpellier (ENSCM), Institut Européen des Membranes (IEM, UMR 5635, ENSCM, CNRS, UM) and the University of Poitiers, France.

Conflicts of Interest: The authors declare no conflict of interest.

\section{References}

1. Willner, I.; Katz, E. Bioelectronics: From Theory to Applications; Wiley-VCH Verlag GmbH \& Co. KGaA: Weinheim, Germany, 2005; p. 492.

2. Katz, E. Implantable Bioelectronics; Wiley-VCH Verlag GmbH \& Co. KGaA: Weinheim, Germany, 2014; p. 450.

3. Gao, W.; Emaminejad, S.; Nyein, H.Y.Y.; Challa, S.; Chen, K.; Peck, A.; Fahad, H.M.; Ota, H.; Shiraki, H.; Kiriya, D.; et al. Fully integrated wearable sensor arrays for multiplexed in situ perspiration analysis. Nature 2016, 529, 509-514. [CrossRef] [PubMed]

4. Nagel, B.; Dellweg, H.; Gierasch, L. Glossary for chemists of terms used in biotechnology (IUPAC recommendations 1992). Pure Appl. Chem. 1992, 64, 143-168. [CrossRef]

5. International Union of Pure and Applied Chemistry. Compendium of Chemical Terminology, 2nd ed.; the "Gold Book"; McNaught, A.D., Wilkinson, A., Eds.; Blackwell Scientific Publications: Oxford, UK, 1997.

6. Wang, L.; Ma, W.; Xu, L.; Chen, W.; Zhu, Y.; Xu, C.; Kotov, N.A. Nanoparticle-based environmental sensors. Mater. Sci. Eng. R Rep. 2010, 70, 265-274. [CrossRef]

7. Zhu, C.; Yang, G.; Li, H.; Du, D.; Lin, Y. Electrochemical sensors and biosensors based on nanomaterials and nanostructures. Anal. Chem. 2015, 87, 230-249. [CrossRef] [PubMed]

8. Das, M.; Sumana, G.; Nagarajan, R.; Malhotra, B.D. Application of nanostructured ZnO films for electrochemical DNA biosensor. Thin Solid Films 2010, 519, 1196-1201. [CrossRef]

9. Kang, X.; Wang, J.; Wu, H.; Liu, J.; Aksay, I.A.; Lin, Y. A graphene-based electrochemical sensor for sensitive detection of paracetamol. Talanta 2010, 81, 754-759. [CrossRef] [PubMed] 
10. Fan, Y.; Liu, J.-H.; Lu, H.-T.; Zhang, Q. Electrochemical behavior and voltammetric determination of paracetamol on Nafion/ $\mathrm{TiO}_{2}$-graphene modified glassy carbon electrode. Colloids Surf. B 2011, 85, 289-292. [CrossRef] [PubMed]

11. Wang, Y.; Zhang, X.; Chen, Y.; Xu, H.; Tan, Y.; Wang, S. Detection of dopamine based on tyrosinase-Fe $\mathrm{F}_{3} \mathrm{O}_{4}$ nanoparticles-chitosan nanocomposite biosensor. Am. J. Biomed. Sci. 2010, 2, 209-216. [CrossRef]

12. Puangjan, A.; Chaiyasith, S.; Wichitpanya, S.; Daengduang, S.; Puttota, S. Electrochemical sensor based on $\mathrm{PANI} / \mathrm{MnO}_{2}-\mathrm{Sb}_{2} \mathrm{O}_{3}$ nanocomposite for selective simultaneous voltammetric determination of ascorbic acid and acetylsalicylic acid. J. Electroanal. Chem. 2016, 782, 192-201. [CrossRef]

13. Van Nguyen, K.; Minteer, S.D. DNA-functionalized Pt nanoparticles as catalysts for chemically powered micromotors: Toward signal-on motion-based DNA biosensor. Chem. Commun. 2015, 51, 4782-4784. [CrossRef] [PubMed]

14. Hickey, D.P.; Milton, R.D.; Rasmussen, M.; Abdellaoui, S.; Nguyen, K.; Minteer, S.D. Fundamentals and applications of bioelectrocatalysis. In Electrochemistry; The Royal Society of Chemistry: London, UK, 2016; Volume 13, pp. 97-132.

15. Clark, L.C.; Wolf, R.; Granger, D.; Taylor, Z. Continuous recording of blood oxygen tensions by polarography. J. Appl. Physiol. 1953, 6, 189-193. [PubMed]

16. Clark, L.C.; Lyons, C. Electrode systems for continuous monitoring in cardiovascular surgery. Ann. N. Y. Acad. Sci. 1962, 102, 29-45. [CrossRef] [PubMed]

17. Leech, D.; Kavanagh, P.; Schuhmann, W. Enzymatic fuel cells: Recent progress. Electrochim. Acta 2012, 84, 223-234. [CrossRef]

18. Ivnitski, D.; Branch, B.; Atanassov, P.; Apblett, C. Glucose oxidase anode for biofuel cell based on direct electron transfer. Electrochem. Commun. 2006, 8, 1204-1210. [CrossRef]

19. Degani, Y.; Heller, A. Direct electrical communication between chemically modified enzymes and metal electrodes. I. Electron transfer from glucose oxidase to metal electrodes via electron relays, bound covalently to the enzyme. J. Phys. Chem. 1987, 91, 1285-1289. [CrossRef]

20. Heller, A. Electrical wiring of redox enzymes. Acc. Chem. Res. 1990, 23, 128-134. [CrossRef]

21. Wilson, R.; Turner, A.P.F. Glucose oxidase: An ideal enzyme. Biosens. Bioelectron. 1992, 7, 165-185. [CrossRef]

22. Wohlfahrt, G.; Witt, S.; Hendle, J.; Schomburg, D.; Kalisz, H.M.; Hecht, H.-J. 1.8 and $1.9 \AA$ resolution structures of the Penicillium amagasakiense and Aspergillus niger glucose oxidases as a basis for modelling substrate complexes. Acta Crystallogr. D Biol. Crystallogr. 1999, 55, 969-977. [CrossRef] [PubMed]

23. Bankar, S.B.; Bule, M.V.; Singhal, R.S.; Ananthanarayan, L. Glucose oxidase-An overview. Biotechnol. Adv. 2009, 27, 489-501. [CrossRef] [PubMed]

24. Wang, J.; Liu, J.; Chen, L.; Lu, F. Highly selective membrane-free, mediator-free glucose biosensor. Anal. Chem. 1994, 66, 3600-3603. [CrossRef]

25. Wang, J.; Romero, E.G.; Reviejo, A.J. Improved alcohol biosensor based on ruthenium-dispersed carbon paste enzyme electrodes. J. Electroanal. Chem. 1993, 353, 113-120. [CrossRef]

26. Weizmann, Y.; Patolsky, F.; Katz, E.; Willner, I. Amplified telomerase analysis by using rotating magnetic particles: The rapid and sensitive detection of cancer cells. ChemBioChem 2004, 5, 943-948. [CrossRef] [PubMed]

27. Baron, R.; Lioubashevski, O.; Katz, E.; Niazov, T.; Willner, I. Two coupled enzymes perform in parallel the 'AND' and 'inhibAND' logic gate operations. Org. Biomol. Chem. 2006, 4, 989-991. [CrossRef] [PubMed]

28. Elouarzaki, K.; Bourourou, M.; Holzinger, M.; Le Goff, A.; Marks, R.S.; Cosnier, S. Freestanding HRP-GOx redox buckypaper as an oxygen-reducing biocathode for biofuel cell applications. Energy Environ. Sci. 2015, 8, 2069-2074. [CrossRef]

29. Kavanagh, P.; Leech, D. Mediated electron transfer in glucose oxidising enzyme electrodes for application to biofuel cells: Recent progress and perspectives. Phys. Chem. Chem. Phys. 2013, 15, 4859-4869. [CrossRef] [PubMed]

30. Katz, E.; Willner, I.; Kotlyar, A.B. A non-compartmentalized glucose $/ \mathrm{O}_{2}$ biofuel cell by bioengineered electrode surfaces. J. Electroanal. Chem. 1999, 479, 64-68. [CrossRef]

31. Schlesinger, M. Applications of Electrochemistry in Medicine; Springer: New York, NY, USA, 2013; Volume 56, p. 452.

32. Toghill, K.E.; Compton, R.G. Electrochemical non-enzymatic glucose sensors: A perspective and an evaluation. Int. J. Electrochem. Sci. 2010, 5, 1246-1301. 
33. Meredith, M.T.; Kao, D.-Y.; Hickey, D.; Schmidtke, D.W.; Glatzhofer, D.T. High current density ferrocene-modified linear poly(ethylenimine) bioanodes and their use in biofuel cells. J. Electrochem. Soc. 2011, 158, B166-B174. [CrossRef]

34. Meredith, M.T.; Minson, M.; Hickey, D.; Artyushkova, K.; Glatzhofer, D.T.; Minteer, S.D. Anthracene-modified multi-walled carbon nanotubes as direct electron transfer scaffolds for enzymatic oxygen reduction. ACS Catal. 2011, 1, 1683-1690. [CrossRef]

35. Reuillard, B.; Le Goff, A.; Agnes, C.; Holzinger, M.; Zebda, A.; Gondran, C.; Elouarzaki, K.; Cosnier, S. High power enzymatic biofuel cell based on naphthoquinone-mediated oxidation of glucose by glucose oxidase in a carbon nanotube 3D matrix. Phys. Chem. Chem. Phys. 2013, 15, 4892-4896. [CrossRef] [PubMed]

36. Jenkins, P.; Tuurala, S.; Vaari, A.; Valkiainen, M.; Smolander, M.; Leech, D. A comparison of glucose oxidase and aldose dehydrogenase as mediated anodes in printed glucose/oxygen enzymatic fuel cells using ABTS/laccase cathodes. Bioelectrochemistry 2012, 87, 172-177. [CrossRef] [PubMed]

37. Mao, F.; Mano, N.; Heller, A. Long tethers binding redox centers to polymer backbones enhance electron transport in enzyme "wiring" hydrogels. J. Am. Chem. Soc. 2003, 125, 4951-4957. [CrossRef] [PubMed]

38. Mano, N.; Mao, F.; Heller, A. Characteristics of a miniature compartment-less glucose- $\mathrm{O}_{2}$ biofuel cell and its operation in a living plant. J. Am. Chem. Soc. 2003, 125, 6588-6594. [CrossRef]

39. Milton, R.D.; Hickey, D.P.; Abdellaoui, S.; Lim, K.; Wu, F.; Tan, B.; Minteer, S.D. Rational design of quinones for high power density biofuel cells. Chem. Sci. 2015, 6, 4867-4875. [CrossRef]

40. Milton, R.D.; Lim, K.; Hickey, D.P.; Minteer, S.D. Employing FAD-dependent glucose dehydrogenase within a glucose/oxygen enzymatic fuel cell operating in human serum. Bioelectrochemistry 2015, 106 Pt A, 56-63. [CrossRef] [PubMed]

41. Zakeeruddin, S.M.; Fraser, D.M.; Nazeeruddin, M.K.; Grätzel, M. Towards mediator design: Characterization of tris-(4,4'-substituted-2,2'-bipyridine) complexes of iron(II), ruthenium(II) and osmium(II) as mediators for glucose oxidase of aspergillus niger and other redox proteins. J. Electroanal. Chem. 1992, 337, $253-283$. [CrossRef]

42. Gallaway, J.W.; Calabrese Barton, S.A. Kinetics of redox polymer-mediated enzyme electrodes. J. Am. Chem. Soc. 2008, 130, 8527-8536. [CrossRef] [PubMed]

43. Takagi, K.; Kano, K.; Ikeda, T. Mediated bioelectrocatalysis based on NAD-related enzymes with reversible characteristics. J. Electroanal. Chem. 1998, 445, 211-219. [CrossRef]

44. Yan, Y.-M.; Tel-Vered, R.; Yehezkeli, O.; Cheglakov, Z.; Willner, I. Biocatalytic growth of Au nanoparticles immobilized on glucose oxidase enhances the ferrocene-mediated bioelectrocatalytic oxidation of glucose. Adv. Mater. 2008, 20, 2365-2370. [CrossRef]

45. Willner, I.; Heleg-Shabtai, V.; Blonder, R.; Katz, E.; Tao, G.; Bückmann, A.F.; Heller, A. Electrical wiring of glucose oxidase by reconstitution of FAD-modified monolayers assembled onto Au-electrodes. J. Am. Chem. Soc. 1996, 118, 10321-10322. [CrossRef]

46. Riklin, A.; Katz, E.; Willner, I.; Stocker, A.; Buckmann, A.F. Improving enzyme-electrode contacts by redox modification of cofactors. Nature 1995, 376, 672-675. [CrossRef] [PubMed]

47. Marcus, R.A.; Sutin, N. Electron transfers in chemistry and biology. Biochim. Biophys. Acta (BBA) Rev. Bioenerg. 1985, 811, 265-322. [CrossRef]

48. Lojou, E. Hydrogenases as catalysts for fuel cells: Strategies for efficient immobilization at electrode interfaces. Electrochim. Acta 2011, 56, 10385-10397. [CrossRef]

49. Vassilyev, Y.B.; Khazova, O.A.; Nikolaeva, N.N. Kinetics and mechanism of glucose electrooxidation on different electrode-catalysts: Part I. Adsorption and oxidation on platinum. J. Electroanal. Chem. Interfacial Electrochem. 1985, 196, 105-125. [CrossRef]

50. Vassilyev, Y.B.; Khazova, O.A.; Nikolaeva, N.N. Kinetics and mechanism of glucose electrooxidation on different electrode-catalysts: Part II. Effect of the nature of the electrode and the electrooxidation mechanism. J. Electroanal. Chem. Interfacial Electrochem. 1985, 196, 127-144. [CrossRef]

51. Zhao, C.; Shao, C.; Li, M.; Jiao, K. Flow-injection analysis of glucose without enzyme based on electrocatalytic oxidation of glucose at a nickel electrode. Talanta 2007, 71, 1769-1773. [CrossRef] [PubMed]

52. Mehmet, S.; Quan, G.; Thomas, S.; Goldsmith, D. Important causes of hypoglycaemia in patients with diabetes on peritoneal dialysis. Diabet. Med. 2001, 18, 679-682. [CrossRef] [PubMed] 
53. Ohara, T.J.; Rajagopalan, R.; Heller, A. "Wired" enzyme electrodes for amperometric determination of glucose or lactate in the presence of interfering substances. Anal. Chem. 1994, 66, 2451-2457. [CrossRef] [PubMed]

54. Lei, H.-W.; Wu, B.; Cha, C.-S.; Kita, H. Electro-oxidation of glucose on platinum in alkaline solution and selective oxidation in the presence of additives. J. Electroanal. Chem. 1995, 382, 103-110. [CrossRef]

55. Guerrieri, A.; Ciriello, R.; Centonze, D. Permselective and enzyme-entrapping behaviours of an electropolymerized, non-conducting, poly(o-aminophenol) thin film-modified electrode: A critical study. Biosens. Bioelectron. 2009, 24, 1550-1556. [CrossRef] [PubMed]

56. Ndamanisha, J.C.; Guo, L. Nonenzymatic glucose detection at ordered mesoporous carbon modified electrode. Bioelectrochemistry 2009, 77, 60-63. [CrossRef] [PubMed]

57. Yeo, I.-H.; Johnson, D.C. Electrochemical response of small organic molecules at nickel-copper alloy electrodes. J. Electroanal. Chem. 2001, 495, 110-119. [CrossRef]

58. Holade, Y.; Hickey, D.P.; Minteer, S.D. Halide-regulated growth of electrocatalytic metal nanoparticles directly onto a carbon paper electrode. J. Mater. Chem. A 2016, 4, 17154-17162. [CrossRef]

59. Alloyeau, D.; Mottet, C.; Ricolleau, C. Nanoalloys: Synthesis, Structure and Properties; Springer: London, UK, 2012; p. 420.

60. Wieckowski, A.; Savinova, E.R.; Vayenas, C.G. Catalysis and Electrocatalysis at Nanoparticle Surfaces; Marcel Dekker, Inc.: New York, NY, USA, 2003; p. 970.

61. Lahmani, M.; Bréchignac, C.; Houdy, P. Les Nanosciences: 2. Nanomatériaux et Nanochimie, 2nd ed.; Belin: Paris, France, 2012; p. 732.

62. Doherty, R.P.; Krafft, J.-M.; Methivier, C.; Casale, S.; Remita, H.; Louis, C.; Thomas, C. On the promoting effect of $\mathrm{Au}$ on $\mathrm{CO}$ oxidation kinetics of $\mathrm{Au}-\mathrm{Pt}$ bimetallic nanoparticles supported on $\mathrm{SiO}_{2}: \mathrm{An}$ electronic effect? J. Catal. 2012, 287, 102-113. [CrossRef]

63. Pedersen, M.Ø.; Helveg, S.; Ruban, A.; Stensgaard, I.; Lægsgaard, E.; Nørskov, J.K.; Besenbacher, F. How a gold substrate can increase the reactivity of a Pt overlayer. Surf. Sci. 1999, 426, 395-409. [CrossRef]

64. Holade, Y.; Servat, K.; Rousseau, J.; Canaff, C.; Poulin, S.; Napporn, T.W.; Kokoh, K.B. Electrochemical and physicochemical characterizations of gold-based nanomaterials: Correlation between surface composition and electrocatalytic activity. J. Electrochem. Soc. 2015, 162, H929-H937. [CrossRef]

65. Sing, K.; Everett, D.; Haul, R.; Moscou, L.; Pierotti, R.; Rouquerol, J.; Siemieniewska, T. Reporting physisorption data for gas/solid systems. Pure Appl. Chem. 1982, 54, 2201.

66. Sing, K.; Everett, D.; Haul, R.; Moscou, L.; Pierotti, R.; Rouquerol, J.; Siemieniewska, T. Reporting physisorption data for gas/solid systems with special reference to the determination of surface area and porosity. Pure Appl. Chem. 1985, 57, 603-619. [CrossRef]

67. Aoun, S.B.; Bang, G.S.; Koga, T.; Nonaka, Y.; Sotomura, T.; Taniguchi, I. Electrocatalytic oxidation of sugars on silver-UPD single crystal gold electrodes in alkaline solutions. Electrochem. Commun. 2003, 5, 317-320. [CrossRef]

68. Aoun, S.B.; Dursun, Z.; Koga, T.; Bang, G.S.; Sotomura, T.; Taniguchi, I. Effect of metal ad-layers on Au(111) electrodes on electrocatalytic oxidation of glucose in an alkaline solution. J. Electroanal. Chem. 2004, 567, 175-183. [CrossRef]

69. Holade, Y.; Servat, K.; Napporn, T.W.; Morais, C.; Berjeaud, J.-M.; Kokoh, K.B. Highly selective oxidation of carbohydrates in an efficient electrochemical energy converter: Cogenerating organic electrosynthesis. ChemSusChem 2016, 9, 252-263. [CrossRef] [PubMed]

70. Garcia, S.; Salinas, D.; Mayer, C.; Schmidt, E.; Staikov, G.; Lorenz, W.J. Ag UPD on Au(100) and Au(111). Electrochim. Acta 1998, 43, 3007-3019. [CrossRef]

71. Hebié, S.; Napporn, T.W.; Morais, C.; Kokoh, K.B. Size-dependent electrocatalytic activity of free gold nanoparticles for the glucose oxidation reaction. ChemPhysChem 2016, 17, 1454-1462. [CrossRef] [PubMed]

72. Wang, J.; Gong, J.; Xiong, Y.; Yang, J.; Gao, Y.; Liu, Y.; Lu, X.; Tang, Z. Shape-dependent electrocatalytic activity of monodispersed gold nanocrystals toward glucose oxidation. Chem. Commun. 2011, 47, 6894-6896. [CrossRef] [PubMed]

73. Hebié, S.; Kokoh, K.B.; Servat, K.; Napporn, T. Shape-dependent electrocatalytic activity of free gold nanoparticles toward glucose oxidation. Gold Bull. 2013, 46, 311-318. [CrossRef]

74. Hebié, S.; Cornu, L.; Napporn, T.W.; Rousseau, J.; Kokoh, B.K. Insight on the surface structure effect of free gold nanorods on glucose electrooxidation. J. Phys. Chem. C 2013, 117, 9872-9880. [CrossRef] 
75. Hebié, S.; Holade, Y.; Maximova, K.; Sentis, M.; Delaporte, P.; Kokoh, K.B.; Napporn, T.W.; Kabashin, A.V. Advanced electrocatalysts on the basis of bare Au nanomaterials for biofuel cell applications. ACS Catal. 2015, 5, 6489-6496. [CrossRef]

76. Wang, J.; Thomas, D.F.; Chen, A. Nonenzymatic electrochemical glucose sensor based on nanoporous PtPb networks. Anal. Chem. 2008, 80, 997-1004. [CrossRef] [PubMed]

77. Ding, Y.; Liu, Y.; Parisi, J.; Zhang, L.; Lei, Y. A novel Ni-Au hybrid nanobelts based sensor for sensitive and selective glucose detection. Biosens. Bioelectron. 2011, 28, 393-398. [CrossRef] [PubMed]

78. Xiao, X.; Wang, M.; Li, H.; Pan, Y.; Si, P. Non-enzymatic glucose sensors based on controllable nanoporous gold/copper oxide nanohybrids. Talanta 2014, 125, 366-371. [CrossRef] [PubMed]

79. Dong, C.; Zhong, H.; Kou, T.; Frenzel, J.; Eggeler, G.; Zhang, Z. Three-dimensional cu foam-supported single crystalline mesoporous $\mathrm{Cu}_{2} \mathrm{O}$ nanothorn arrays for ultra-highly sensitive and efficient nonenzymatic detection of glucose. ACS Appl. Mater. Interfaces 2015, 7, 20215-20223. [CrossRef] [PubMed]

80. Li, Y.; Wei, Y.; Shi, G.; Xian, Y.; Jin, L. Facile synthesis of leaf-like CuO nanoparticles and their application on glucose biosensor. Electroanalysis 2011, 23, 497-502. [CrossRef]

81. Dong, J.; Ren, L.; Zhang, Y.; Cui, X.; Hu, P.; Xu, J. Direct electrodeposition of cable-like Cu@Cu nanowires array for non-enzymatic sensing. Talanta 2015, 132, 719-726. [CrossRef] [PubMed]

82. Kong, C.; Tang, L.; Zhang, X.; Sun, S.; Yang, S.; Song, X.; Yang, Z. Templating synthesis of hollow CuO polyhedron and its application for nonenzymatic glucose detection. J. Mater. Chem. A 2014, 2, 7306-7312. [CrossRef]

83. Song, M.-J.; Lee, S.-K.; Kim, J.-H.; Lim, D.-S. Non-enzymatic glucose sensor based on cu electrode modified with CuO nanoflowers. J. Electrochem. Soc. 2013, 160, B43-B46. [CrossRef]

84. Zhuang, Z.; Su, X.; Yuan, H.; Sun, Q.; Xiao, D.; Choi, M.M.F. An improved sensitivity non-enzymatic glucose sensor based on a $\mathrm{CuO}$ nanowire modified Cu electrode. Analyst 2008, 133, 126-132. [CrossRef] [PubMed]

85. Wang, J.; Chen, G.; Wang, M.; Chatrathi, M.P. Carbon-nanotube/copper composite electrodes for capillary electrophoresis microchip detection of carbohydrates. Analyst 2004, 129, 512-515. [CrossRef] [PubMed]

86. Xu, Q.; Zhao, Y.; Xu, J.Z.; Zhu, J.-J. Preparation of functionalized copper nanoparticles and fabrication of a glucose sensor. Sens. Actuators B 2006, 114, 379-386. [CrossRef]

87. Burke, L.D.; Bruton, G.M.; Collins, J.A. The redox properties of active sites and the importance of the latter in electrocatalysis at copper in base. Electrochim. Acta 1998, 44, 1467-1479. [CrossRef]

88. Wu, Z.; Zhang, Z.; Liu, L. Electrochemical studies of a $\mathrm{Cu}(\mathrm{II})-\mathrm{Cu}(\mathrm{III})$ couple: Cyclic voltammetry and chronoamperometry in a strong alkaline medium and in the presence of periodate anions. Electrochim. Acta 1997, 42, 2719-2723. [CrossRef]

89. Ogorevc, B.; Tavčar, G.; Hudnik, V.; Pejovnik, S. Electrochemical behaviour of a Cu(II)-Cu(III) couple: Cyclic voltammetry and kinetic parameters at a platinum electrode in a strong alkaline medium and in the presence of tellurate anions. J. Electroanal. Chem. 1993, 351, 81-90. [CrossRef]

90. Kang, X.; Mai, Z.; Zou, X.; Cai, P.; Mo, J. A sensitive nonenzymatic glucose sensor in alkaline media with a copper nanocluster/multiwall carbon nanotube-modified glassy carbon electrode. Anal. Biochem. 2007, 363, 143-150. [CrossRef] [PubMed]

91. Wu, H.-X.; Cao, W.-M.; Li, Y.; Liu, G.; Wen, Y.; Yang, H.-F.; Yang, S.-P. In situ growth of copper nanoparticles on multiwalled carbon nanotubes and their application as non-enzymatic glucose sensor materials. Electrochim. Acta 2010, 55, 3734-3740. [CrossRef]

92. Li, Z.; Xin, Y.; Zhang, Z.; Wu, H.; Wang, P. Rational design of binder-free noble metal/metal oxide arrays with nanocauliflower structure for wide linear range nonenzymatic glucose detection. Sci. Rep. 2015, 5, 10617. [CrossRef] [PubMed]

93. Su, Y.; Luo, B.; Zhang, J.Z. Controllable cobalt oxide/Au hierarchically nanostructured electrode for nonenzymatic glucose sensing. Anal. Chem. 2016, 88, 1617-1624. [CrossRef] [PubMed]

94. Sun, Y.; Mayers, B.T.; Xia, Y. Template-engaged replacement reaction: A one-step approach to the large-scale synthesis of metal nanostructures with hollow interiors. Nano Lett. 2002, 2, 481-485. [CrossRef]

95. Lu, X.; Au, L.; McLellan, J.; Li, Z.-Y.; Marquez, M.; Xia, Y. Fabrication of cubic nanocages and nanoframes by dealloying $\mathrm{Au} / \mathrm{Ag}$ alloy nanoboxes with an aqueous etchant based on $\mathrm{Fe}\left(\mathrm{NO}_{3}\right)_{3}$ or $\mathrm{NH}_{4} \mathrm{OH}$. Nano Lett. 2007, 7, 1764-1769. [CrossRef] [PubMed]

96. Xia, Y.; Xia, X.; Peng, H.-C. Shape-controlled synthesis of colloidal metal nanocrystals: Thermodynamic versus kinetic products. J. Am. Chem. Soc. 2015, 137, 7947-7966. [CrossRef] [PubMed] 
97. Liang, H.-P.; Wan, L.-J.; Bai, C.-L.; Jiang, L. Gold hollow nanospheres: Tunable surface plasmon resonance controlled by interior-cavity sizes. J. Phys. Chem. B 2005, 109, 7795-7800. [CrossRef] [PubMed]

98. Fan, Y.; Yang, Z.; Cao, X.; Liu, P.; Chen, S.; Cao, Z. Hierarchical macro-mesoporous $\mathrm{Ni}(\mathrm{OH})_{2}$ for nonenzymatic electrochemical sensing of glucose. J. Electrochem. Soc. 2014, 161, B201-B206. [CrossRef]

99. Zhan, B.; Liu, C.; Chen, H.; Shi, H.; Wang, L.; Chen, P.; Huang, W.; Dong, X. Free-standing electrochemical electrode based on $\mathrm{Ni}(\mathrm{OH})_{2} / 3 \mathrm{D}$ graphene foam for nonenzymatic glucose detection. Nanoscale 2014, 6 , 7424-7429. [CrossRef] [PubMed]

100. Li, G.; Huo, H.; Xu, C. $\mathrm{Ni}_{0.31} \mathrm{Co}_{0.69} \mathrm{~S}_{2}$ nanoparticles uniformly anchored on a porous reduced graphene oxide framework for a high-performance non-enzymatic glucose sensor. J. Mater. Chem. A 2015, 3, 4922-4930. [CrossRef]

101. Zhao, B.; Wang, T.; Jiang, L.; Zhang, K.; Yuen, M.M.F.; Xu, J.-B.; Fu, X.-Z.; Sun, R.; Wong, C.-P. NiO mesoporous nanowalls grown on RGO coated nickel foam as high performance electrodes for supercapacitors and biosensors. Electrochim. Acta 2016, 192, 205-215. [CrossRef]

102. Rengaraj, A.; Haldorai, Y.; Kwak, C.H.; Ahn, S.; Jeon, K.-J.; Park, S.H.; Han, Y.-K.; Huh, Y.S. Electrodeposition of flower-like nickel oxide on CVD-grown graphene to develop an electrochemical non-enzymatic biosensor. J. Mater. Chem. B 2015, 3, 6301-6309. [CrossRef]

103. Marimuthu, T.; Mohamad, S.; Alias, Y. Needle-like polypyrrole-NiO composite for non-enzymatic detection of glucose. Synth. Met. 2015, 207, 35-41. [CrossRef]

104. Zhao, X.; Muench, F.; Schaefer, S.; Brötz, J.; Duerrschnabel, M.; Molina-Luna, L.; Kleebe, H.-J.; Liu, S.; Tan, J.; Ensinger, W. Electroless decoration of macroscale foam with nickel nano-spikes: A scalable route toward efficient catalyst electrodes. Electrochem. Commun. 2016, 65, 39-43. [CrossRef]

105. Holade, Y.; Morais, C.; Arrii-Clacens, S.; Servat, K.; Napporn, T.W.; Kokoh, K.B. New preparation of PdNi/C and $\mathrm{PdAg} / \mathrm{C}$ nanocatalysts for glycerol electrooxidation in alkaline medium. Electrocatalysis 2013, 4, 167-178. [CrossRef]

106. Oliveira, V.L.; Morais, C.; Servat, K.; Napporn, T.W.; Tremiliosi-Filho, G.; Kokoh, K.B. Glycerol oxidation on nickel based nanocatalysts in alkaline medium-Identification of the reaction products. J. Electroanal. Chem. 2013, 703, 56-62. [CrossRef]

107. Ye, J.-S.; Wen, Y.; De Zhang, W.; Ming Gan, L.; Xu, G.Q.; Sheu, F.-S. Nonenzymatic glucose detection using multi-walled carbon nanotube electrodes. Electrochem. Commun. 2004, 6, 66-70. [CrossRef]

108. Wang, S.G.; Zhang, Q.; Wang, R.; Yoon, S.F. A novel multi-walled carbon nanotube-based biosensor for glucose detection. Biochem. Biophys. Res. Commun. 2003, 311, 572-576. [CrossRef] [PubMed]

109. Premlatha, S.; Sivasakthi, P.; Ramesh Bapu, G.N.K. Electrodeposition of a 3D hierarchical porous flower-like cobalt-MWCNT nanocomposite electrode for non-enzymatic glucose sensing. RSC Adv. 2015, 5, 74374-74380. [CrossRef]

110. Ci, S.; Mao, S.; Huang, T.; Wen, Z.; Steeber, D.A.; Chen, J. Enzymeless glucose detection based on $\mathrm{CoO} /$ graphene microsphere hybrids. Electroanalysis 2014, 26, 1326-1334. [CrossRef]

111. Wang, Y.; Zhang, S.; Bai, W.; Zheng, J. Layer-by-layer assembly of copper nanoparticles and manganese dioxide-multiwalled carbon nanotubes film: A new nonenzymatic electrochemical sensor for glucose. Talanta 2016, 149, 211-216. [CrossRef] [PubMed]

112. Ramachandran, K.; Raj kumar, T.; Babu, K.J.; Gnana kumar, G. Ni-Co bimetal nanowires filled multiwalled carbon nanotubes for the highly sensitive and selective non-enzymatic glucose sensor applications. Sci. Rep. 2016, 6, 36583. [CrossRef] [PubMed]

113. Min, H.; Wu, W.; Wu, H.; Wang, S.; Feng, C.; Ding, Y. Synthesis of $\mathrm{Pt}_{x} \mathrm{Sn} / \mathrm{MWCNTS}$ and their application in non-enzymatic glucose and hydrogen peroxide sensors. Electroanalysis 2016. [CrossRef]

114. Guo, C.; Li, H.; Zhang, X.; Huo, H.; Xu, C. 3D porous $\mathrm{CNT} / \mathrm{MnO}_{2}$ composite electrode for high-performance enzymeless glucose detection and supercapacitor application. Sens. Actuators B 2015, 206, 407-414. [CrossRef]

115. Masoomi-Godarzi, S.; Khodadadi, A.A.; Vesali-Naseh, M.; Mortazavi, Y. Highly stable and selective non-enzymatic glucose biosensor using carbon nanotubes decorated by $\mathrm{Fe}_{3} \mathrm{O}_{4}$ nanoparticles. J. Electrochem. Soc. 2014, 161, B19-B25. [CrossRef]

116. Rong, L.-Q.; Yang, C.; Qian, Q.-Y.; Xia, X.-H. Study of the nonenzymatic glucose sensor based on highly dispersed Pt nanoparticles supported on carbon nanotubes. Talanta 2007, 72, 819-824. [CrossRef] [PubMed] 
117. Nana, C.; Hongjuan, W.; Xiaomeng, L.; Liande, Z. Amperometric glucose biosensor based on integration of glucose oxidase with palladium nanoparticles/reduced graphene oxide nanocomposite. Am. J. Anal. Chem. 2012, 3, 312-319.

118. Xu, C.; Liu, Y.; Su, F.; Liu, A.; Qiu, H. Nanoporous ptag and PtCu alloys with hollow ligaments for enhanced electrocatalysis and glucose biosensing. Biosens. Bioelectron. 2011, 27, 160-166. [CrossRef] [PubMed]

119. Hossain, M.F.; Park, J.Y. Amperometric glucose biosensor based on Pt-Pd nanoparticles supported by reduced graphene oxide and integrated with glucose oxidase. Electroanalysis 2014, 26, 940-951. [CrossRef]

120. Putzbach, W.; Ronkainen, N. Immobilization techniques in the fabrication of nanomaterial-based electrochemical biosensors: A review. Sensors 2013, 13, 4811-4840. [CrossRef] [PubMed]

121. Gao, F.; Viry, L.; Maugey, M.; Poulin, P.; Mano, N. Engineering hybrid nanotube wires for high-power biofuel cells. Nat. Commun. 2010, 1. [CrossRef] [PubMed]

122. Giroud, F.; Milton, R.D.; Tan, B.-X.; Minteer, S.D. Simplifying enzymatic biofuel cells: Immobilized naphthoquinone as a biocathodic orientational moiety and bioanodic electron mediator. ACS Catal. 2015, 5, 1240-1244. [CrossRef]

123. Narváez Villarrubia, C.W.; Artyushkova, K.; Garcia, S.O.; Atanassov, P. NAD ${ }^{+} / \mathrm{NADH}$ tethering on mwnts-bucky papers for glucose dehydrogenase-based anodes. J. Electrochem. Soc. 2014, 161, H3020-H3028. [CrossRef]

124. MacVittie, K.; Halamek, J.; Halamkova, L.; Southcott, M.; Jemison, W.D.; Lobel, R.; Katz, E. From "cyborg" lobsters to a pacemaker powered by implantable biofuel cells. Energy Environ. Sci. 2013, 6, 81-86. [CrossRef]

125. Halámková, L.; Halámek, J.; Bocharova, V.; Szczupak, A.; Alfonta, L.; Katz, E. Implanted biofuel cell operating in a living snail. J. Am. Chem. Soc. 2012, 134, 5040-5043. [CrossRef] [PubMed]

126. Ciaccafava, A.; De Poulpiquet, A.; Techer, V.; Giudici-Orticoni, M.T.; Tingry, S.; Innocent, C.; Lojou, E. An innovative powerful and mediatorless $\mathrm{H}_{2} / \mathrm{O}_{2}$ biofuel cell based on an outstanding bioanode. Electrochem. Commun. 2012, 23, 25-28. [CrossRef]

127. Poulpiquet, A.d.; Marques-Knopf, H.; Wernert, V.; Giudici-Orticoni, M.T.; Gadiou, R.; Lojou, E. Carbon nanofiber mesoporous films: Efficient platforms for bio-hydrogen oxidation in biofuel cells. Phys. Chem. Chem. Phys. 2014, 16, 1366-1378. [CrossRef] [PubMed]

128. Wu, P.; Cai, Z.; Chen, J.; Zhang, H.; Cai, C. Electrochemical measurement of the flux of hydrogen peroxide releasing from RAW 264.7 macrophage cells based on enzyme-attapulgite clay nanohybrids. Biosens. Bioelectron. 2011, 26, 4012-4017. [CrossRef] [PubMed]

129. Maji, S.K.; Sreejith, S.; Mandal, A.K.; Ma, X.; Zhao, Y. Immobilizing gold nanoparticles in mesoporous silica covered reduced graphene oxide: A hybrid material for cancer cell detection through hydrogen peroxide sensing. ACS Appl. Mater. Interfaces. 2014, 6, 13648-13656. [CrossRef] [PubMed]

130. Miller, E.W.; Albers, A.E.; Pralle, A.; Isacoff, E.Y.; Chang, C.J. Boronate-based fluorescent probes for imaging cellular hydrogen peroxide. J. Am. Chem. Soc. 2005, 127, 16652-16659. [CrossRef] [PubMed]

131. Maruyama, W.; Dostert, P.; Matsubara, K.; Naoi, M. N-methyl(r)salsolinol produces hydroxyl radicals: Involvement to neurotoxicity. Free Radic. Biol. Med. 1995, 19, 67-75. [CrossRef]

132. Chang, M.C.Y.; Pralle, A.; Isacoff, E.Y.; Chang, C.J. A selective, cell-permeable optical probe for hydrogen peroxide in living cells. J. Am. Chem. Soc. 2004, 126, 15392-15393. [CrossRef] [PubMed]

133. Ohshima, H.; Tatemichi, M.; Sawa, T. Chemical basis of inflammation-induced carcinogenesis. Arch. Biochem. Biophys. 2003, 417, 3-11. [CrossRef]

134. Devadoss, A.; Han, H.; Song, T.; Kim, Y.-P.; Paik, U. Gold nanoparticle-composite nanofibers for enzymatic electrochemical sensing of hydrogen peroxide. Analyst 2013, 138, 5025-5030. [CrossRef] [PubMed]

135. Gao, L.; Zhuang, J.; Nie, L.; Zhang, J.; Zhang, Y.; Gu, N.; Wang, T.; Feng, J.; Yang, D.; Perrett, S.; et al. Intrinsic peroxidase-like activity of ferromagnetic nanoparticles. Nat. Nano 2007, 2, 577-583. [CrossRef] [PubMed]

136. He, W.; Wu, X.; Liu, J.; Hu, X.; Zhang, K.; Hou, S.; Zhou, W.; Xie, S. Design of AgM bimetallic alloy nanostructures $(\mathrm{M}=\mathrm{Au}, \mathrm{Pd}, \mathrm{Pt})$ with tunable morphology and peroxidase-like activity. Chem. Mater. 2010, 22, 2988-2994. [CrossRef]

137. Li, W.; Kuai, L.; Qin, Q.; Geng, B. Ag-Au bimetallic nanostructures: Co-reduction synthesis and their component-dependent performance for enzyme-free $\mathrm{H}_{2} \mathrm{O}_{2}$ sensing. J. Mater. Chem. A 2013, 1, 7111-7117. [CrossRef]

138. Lee, Y.; Loew, A.; Sun, S. Surface- and structure-dependent catalytic activity of Au nanoparticles for oxygen reduction reaction. Chem. Mater. 2010, 22, 755-761. [CrossRef] 
139. Li, H.; Li, Y.; Wang, S. Water-soluble Au nanocages for enzyme-free $\mathrm{H}_{2} \mathrm{O}_{2}$ sensor and 4-nitrophenol reduction. CrystEngComm 2015, 17, 2368-2375. [CrossRef]

140. Sun, Y.; Xia, Y. Shape-controlled synthesis of gold and silver nanoparticles. Science 2002, 298, $2176-2179$. [CrossRef] [PubMed]

141. Sun, Y.; Xia, Y. Mechanistic study on the replacement reaction between silver nanostructures and chloroauric acid in aqueous medium. J. Am. Chem. Soc. 2004, 126, 3892-3901. [CrossRef] [PubMed]

142. Yavuz, M.S.; Cheng, Y.; Chen, J.; Cobley, C.M.; Zhang, Q.; Rycenga, M.; Xie, J.; Kim, C.; Song, K.H.; Schwartz, A.G.; et al. Gold nanocages covered by smart polymers for controlled release with near-infrared light. Nat. Mater. 2009, 8, 935-939. [CrossRef] [PubMed]

143. Chen, J.; Yang, M.; Zhang, Q.; Cho, E.C.; Cobley, C.M.; Kim, C.; Glaus, C.; Wang, L.V.; Welch, M.J.; Xia, Y. Gold nanocages: A novel class of multifunctional nanomaterials for theranostic applications. Adv. Funct. Mater. 2010, 20, 3684-3694. [CrossRef]

144. Zhang, L.; Roling, L.T.; Wang, X.; Vara, M.; Chi, M.; Liu, J.; Choi, S.-I.; Park, J.; Herron, J.A.; Xie, Z.; et al. Platinum-based nanocages with subnanometer-thick walls and well-defined, controllable facets. Science 2015, 349, 412-416. [CrossRef] [PubMed]

145. Skrabalak, S.E.; Au, L.; Li, X.; Xia, Y. Facile synthesis of Ag nanocubes and Au nanocages. Nat. Protoc. 2007, 2, 2182-2190. [CrossRef] [PubMed]

146. Cobley, C.M.; Campbell, D.J.; Xia, Y. Tailoring the optical and catalytic properties of gold-silver nanoboxes and nanocages by introducing palladium. Adv. Mater. 2008, 20, 748-752. [CrossRef] [PubMed]

147. Yang, L.-C.; Lai, Y.-S.; Tsai, C.-M.; Kong, Y.-T.; Lee, C.-I.; Huang, C.-L. One-pot synthesis of monodispersed silver nanodecahedra with optimal sers activities using seedless photo-assisted citrate reduction method. J. Phys. Chem. C 2012, 116, 24292-24300. [CrossRef]

148. Hu, K.; Lan, D.; Li, X.; Zhang, S. Electrochemical DNA biosensor based on nanoporous gold electrode and multifunctional encoded DNA-Au bio bar codes. Anal. Chem. 2008, 80, 9124-9130. [CrossRef] [PubMed]

149. Daggumati, P.; Matharu, Z.; Seker, E. Effect of nanoporous gold thin film morphology on electrochemical DNA sensing. Anal. Chem. 2015, 87, 8149-8156. [CrossRef] [PubMed]

150. Jin, L.; Zhang, Z.; Zhuang, Z.; Meng, Z.; Li, C.; Shen, Y. PdPt bimetallic alloy nanowires-based electrochemical sensor for sensitive detection of ascorbic acid. RSC Adv. 2016, 6, 42008-42013. [CrossRef]

151. Satheesh Babu, T.G.; Varadarajan, D.; Murugan, G.; Ramachandran, T.; Nair, B.G. Gold nanoparticle-polypyrrole composite modified $\mathrm{TiO}_{2}$ nanotube array electrode for the amperometric sensing of ascorbic acid. J. Appl. Electrochem. 2012, 42, 427-434. [CrossRef]

152. Nancy, T.E.M.; Kumary, V.A. Synergistic electrocatalytic effect of graphene/nickel hydroxide composite for the simultaneous electrochemical determination of ascorbic acid, dopamine and uric acid. Electrochim. Acta 2014, 133, 233-240. [CrossRef]

153. Sanghavi, B.J.; Srivastava, A.K. Simultaneous voltammetric determination of acetaminophen, aspirin and caffeine using an in situ surfactant-modified multiwalled carbon nanotube paste electrode. Electrochim. Acta 2010, 55, 8638-8648. [CrossRef]

154. Bard, A.J.; Faulkner, L.R. Electrochemical Methods: Fundamentals and Applications, 2nd ed.; John Wiley \& Sons, Inc.: Hoboken, NJ, USA, 2001; p. 850.

155. Chen, A.; Chatterjee, S. Nanomaterials based electrochemical sensors for biomedical applications. Chem. Soc. Rev. 2013, 42, 5425-5438. [CrossRef] [PubMed]

156. Tarascon, J.M.; Armand, M. Issues and challenges facing rechargeable lithium batteries. Nature 2001, 414, 359-367. [CrossRef] [PubMed]

157. Whittingham, M.S. Electrical energy storage and intercalation chemistry. Science 1976, 192, $1126-1127$. [CrossRef] [PubMed]

158. Winter, M.; Brodd, R.J. What are batteries, fuel cells, and supercapacitors? Chem. Rev. 2004, 104, 4245-4270. [CrossRef] [PubMed]

159. Steele, B.C.H.; Heinzel, A. Materials for fuel-cell technologies. Nature 2001, 414, 345-352. [CrossRef] [PubMed]

160. Grove, W.R. On voltaic series and the combination of gases by platinum. Philos. Mag. 1839, 14, 127-130. [CrossRef]

161. Grove, W.R. On a small voltaic battery of great energy; some observations on voltaic combinations and forms of arrangement; and on the inactivity of a copper positive electrode in nitro-sulphuric acid. Philos. Mag. 1839, 15, 287-293. [CrossRef] 
162. Grove, W.R. On a gaseous voltaic battery. Philos. Mag. 1842, 21, 417-420.

163. Yahiro, A.T.; Lee, S.M.; Kimble, D.O. Bioelectrochemistry: I. Enzyme utilizing bio-fuel cell studies. Biochim. Biophys. Acta 1964, 88, 375-383. [CrossRef]

164. Young, T.G.; Hadjipetrou, L.; Lilly, M.D. The theoretical aspects of biochemical fuel cells. Biotechnol. Bioeng. 1966, 8, 581-593. [CrossRef]

165. Zhao, F.; Slade, R.C.T.; Varcoe, J.R. Techniques for the study and development of microbial fuel cells: An electrochemical perspective. Chem. Soc. Rev. 2009, 38, 1926-1939. [CrossRef] [PubMed]

166. Davis, J.B.; Yarbrough, H.F. Preliminary experiments on a microbial fuel cell. Science 1962, 137, $615-616$. [CrossRef]

167. Higgins, S.R.; Lau, C.; Atanassov, P.; Minteer, S.D.; Cooney, M.J. Standardized characterization of a flow through microbial fuel cell. Electroanalysis 2011, 23, 2174-2181. [CrossRef]

168. Liu, H.; Ramnarayanan, R.; Logan, B.E. Production of electricity during wastewater treatment using a single chamber microbial fuel cell. Environ. Sci. Technol. 2004, 38, 2281-2285. [CrossRef] [PubMed]

169. Logan, B.E.; Hamelers, B.; Rozendal, R.; Schröder, U.; Keller, J.; Freguia, S.; Aelterman, P.; Verstraete, W.; Rabaey, K. Microbial fuel cells: Methodology and technology. Environ. Sci. Technol. 2006, 40, 5181-5192. [CrossRef] [PubMed]

170. Heller, A.; Feldman, B. Electrochemical glucose sensors and their application in diabetes management. In Applications of Electrochemistry in Medicine; Schlesinger, M., Ed.; Springer: New York, NY, USA, 2013; Volume 56, pp. 121-187.

171. Heller, A. Integrated medical feedback systems for drug delivery. AIChE J. 2005, 51, 1054-1066. [CrossRef]

172. Holmes, C.F. Electrochemical power sources and the treatment of human illness. Electrochem. Soc. Interface 2003, 12, 26-29.

173. Heller, A. Potentially implantable miniature batteries. Anal. Bioanal. Chem. 2006, 385, 469-473. [CrossRef] [PubMed]

174. Kerzenmacher, S.; Ducrée, J.; Zengerle, R.; von Stetten, F. An abiotically catalyzed glucose fuel cell for powering medical implants: Reconstructed manufacturing protocol and analysis of performance. J. Power Sources 2008, 182, 66-75. [CrossRef]

175. Kwon, C.H.; Lee, S.-H.; Choi, Y.-B.; Lee, J.A.; Kim, S.H.; Kim, H.-H.; Spinks, G.M.; Wallace, G.G.; Lima, M.D.; Kozlov, M.E.; et al. High-power biofuel cell textiles from woven biscrolled carbon nanotube yarns. Nat. Commun. 2014, 5, 3928. [CrossRef] [PubMed]

176. Katz, E.; Filanovsky, B.; Willner, I. A biofuel cell based on two immiscible solvents and glucose oxidase and microperoxidase-11 monolayer-functionalized electrodes. New J. Chem. 1999, 23, 481-487. [CrossRef]

177. Katz, E.; Willner, I. A biofuel cell with electrochemically switchable and tunable power output. J. Am. Chem. Soc. 2003, 125, 6803-6813. [CrossRef]

178. Zebda, A.; Gondran, C.; Le Goff, A.; Holzinger, M.; Cinquin, P.; Cosnier, S. Mediatorless high-power glucose biofuel cells based on compressed carbon nanotube-enzyme electrodes. Nat. Commun. 2011, 2, 370. [CrossRef] [PubMed]

179. $\mathrm{Xu}, \mathrm{S}$.; Minteer, S.D. Enzymatic biofuel cell for oxidation of glucose to $\mathrm{CO}_{2}$. ACS Catal. 2012, 2, 91-94. [CrossRef]

180. Holade, Y.; Both Engel, A.; Tingry, S.; Cherifi, A.; Cornu, D.; Servat, K.; Napporn, T.W.; Kokoh, K.B. Insights on hybrid glucose biofuel cell based on bilirubin oxidase cathode and gold-based nanomaterials anode. ChemElectroChem 2014, 1, 1976-1987. [CrossRef]

181. Holade, Y.; MacVittie, K.; Conlon, T.; Guz, N.; Servat, K.; Napporn, T.W.; Kokoh, K.B.; Katz, E. Pacemaker activated by an abiotic biofuel cell operated in human serum solution. Electroanalysis 2014, 26, 2445-2457. [CrossRef]

182. Cinquin, P.; Gondran, C.; Giroud, F.; Mazabrard, S.; Pellissier, A.; Boucher, F.; Alcaraz, J.-P.; Gorgy, K.; Lenouvel, F.; Mathé, S.; et al. A glucose biofuel cell implanted in rats. PLoS ONE 2010, 5, e10476. [CrossRef] [PubMed]

183. Rasmussen, M.; Ritzmann, R.E.; Lee, I.; Pollack, A.J.; Scherson, D. An implantable biofuel cell for a live insect. J. Am. Chem. Soc. 2012, 134, 1458-1460. [CrossRef] [PubMed]

184. Szczupak, A.; Halamek, J.; Halamkova, L.; Bocharova, V.; Alfonta, L.; Katz, E. Living battery-Biofuel cells operating in vivo in clams. Energy Environ. Sci. 2012, 5, 8891-8895. [CrossRef] 
185. Andoralov, V.; Falk, M.; Suyatin, D.B.; Granmo, M.; Sotres, J.; Ludwig, R.; Popov, V.O.; Schouenborg, J.; Blum, Z.; Shleev, S. Biofuel cell based on microscale nanostructured electrodes with inductive coupling to rat brain neurons. Sci. Rep. 2013, 3, 3270. [CrossRef] [PubMed]

186. Castorena-Gonzalez, J.A.; Foote, C.; MacVittie, K.; Halámek, J.; Halámková, L.; Martinez-Lemus, L.A.; Katz, E. Biofuel cell operating in vivo in rat. Electroanalysis 2013, 25, 1579-1584. [CrossRef]

187. Katz, E.; MacVittie, K. Implanted biofuel cells operating in vivo-Methods, applications and perspectives-Feature article. Energy Environ. Sci. 2013, 6, 2791-2803. [CrossRef]

188. Zebda, A.; Cosnier, S.; Alcaraz, J.P.; Holzinger, M.; Le Goff, A.; Gondran, C.; Boucher, F.; Giroud, F.; Gorgy, K.; Lamraoui, H.; et al. Single glucose biofuel cells implanted in rats power electronic devices. Sci. Rep. 2013, 3, 1516. [CrossRef] [PubMed]

189. Habrioux, A.; Servat, K.; Tingry, S.; Kokoh, K.B. Enhancement of the performances of a single concentric glucose $/ \mathrm{O}_{2}$ biofuel cell by combination of bilirubin oxidase/Nafion cathode and Au-Pt anode. Electrochem. Commun. 2009, 11, 111-113. [CrossRef]

190. Habrioux, A.; Sibert, E.; Servat, K.; Vogel, W.; Kokoh, K.B.; Alonso-Vante, N. Activity of platinum-gold alloys for glucose electrooxidation in biofuel cells. J. Phys. Chem. B 2007, 111, 10329-10333. [CrossRef] [PubMed]

191. Both Engel, A.; Bechelany, M.; Fontaine, O.; Cherifi, A.; Cornu, D.; Tingry, S. One-pot route to gold nanoparticles embedded in electrospun carbon fibers as an efficient catalyst material for hybrid alkaline glucose biofuel cells. ChemElectroChem 2016, 3, 629-637. [CrossRef]

192. Holade, Y.; MacVittie, K.; Conlon, T.; Guz, N.; Servat, K.; Napporn, T.W.; Kokoh, K.B.; Katz, E. Wireless information transmission system powered by an abiotic biofuel cell implanted in an orange. Electroanalysis 2015, 27, 276-280. [CrossRef]

193. Kerzenmacher, S.; Ducrée, J.; Zengerle, R.; von Stetten, F. Energy harvesting by implantable abiotically catalyzed glucose fuel cells. J. Power Sources 2008, 182, 1-17. [CrossRef]

194. Kloke, A.; Biller, B.; Kräling, U.; Kerzenmacher, S.; Zengerle, R.; von Stetten, F. A single layer glucose fuel cell intended as power supplying coating for medical implants. Fuel Cells 2011, 11, 316-326. [CrossRef]

195. Yang, L.; Zhang, Y.; Chu, M.; Deng, W.; Tan, Y.; Ma, M.; Su, X.; Xie, Q.; Yao, S. Facile fabrication of network film electrodes with ultrathin Au nanowires for nonenzymatic glucose sensing and glucose $/ \mathrm{O}_{2}$ fuel cell. Biosens. Bioelectron. 2014, 52, 105-110. [CrossRef] [PubMed]

196. Zhao, Y.; Fan, L.; Hong, B.; Zhang, Y.; Zhang, M.; Que, Q.; Ji, J. Three-dimensional porous palladium foam-like nanostructures as electrocatalysts for glucose biofuel cells. Energy Technol. 2016, 4, 249-255. [CrossRef]

197. Werner, H.; Robinson, B.W. A glucose cell. In Proceedings of the Digest of the 7th International Conference on Medical and Biological Engineering, Stockholm, Sweden, 14-19 August 1967; Jacobson, B., Ed.; The Royal Academy of Engineering Sciences: Stockholm, Sweden, 1967; p. 520.

198. Kloke, A.; Köhler, C.; Zengerle, R.; Kerzenmacher, S. Porous platinum electrodes fabricated by cyclic electrodeposition of PtCu alloy: Application to implantable glucose fuel cells. J. Phys. Chem. C 2012, 116, 19689-19698. [CrossRef]

199. Slaughter, G.; Sunday, J. A membraneless single compartment abiotic glucose fuel cell. J. Power Sources 2014, 261, 332-336. [CrossRef]

200. Oncescu, V.; Erickson, D. A microfabricated low cost enzyme-free glucose fuel cell for powering low-power implantable devices. J. Power Sources 2011, 196, 9169-9175. [CrossRef]

201. Zhang, J.; Zhu, Y.; Chen, C.; Yang, X.; Li, C. Carbon nanotubes coated with platinum nanoparticles as anode of biofuel cell. Particuology 2012, 10, 450-455. [CrossRef]

202. Wen, D.; Liu, W.; Herrmann, A.-K.; Eychmüller, A. A membraneless glucose $/ \mathrm{O}_{2}$ biofuel cell based on Pd aerogels. Chem. Eur. J. 2014, 20, 4380-4385. [CrossRef] [PubMed]

203. Santiago, Ó.; Navarro, E.; Raso, M.A.; Leo, T.J. Review of implantable and external abiotically catalysed glucose fuel cells and the differences between their membranes and catalysts. Appl. Energy 2016, 179, 497-522. [CrossRef]

204. Kerzenmacher, S.; Zehnle, S.; Volk, T.; Jansen, D.; von Stetten, F.; Zengerle, R. An efficient low-power DC-DC converter enables operation of a cardiac pacemaker by an integrated glucose fuel cell. In Proceedings of the PowerMEMS 2008, Sendai, Japan, 9-12 November 2008; pp. 189-192.

205. Holade, Y.; Napporn, T.W.; Kokoh, B.K. Advanced surfactant-free nanomaterials for electrochemical energy conversion systems: From electrocatalysis to bionanotechnology. In Advanced Electrode Materials; Tiwari, A., Kuralay, F., Uzun, L., Eds.; John Wiley \& Sons, Inc.: Hoboken, NJ, USA, 2016; pp. 103-146. 
206. Both Engel, A.; Holade, Y.; Tingry, S.; Cherifi, A.; Cornu, D.; Servat, K.; Napporn, T.W.; Kokoh, K.B. Electrospun carbon fibers: Promising electrode material for abiotic and enzymatic catalysis. J. Phys. Chem. C 2015, 119, 16724-16733. [CrossRef]

207. Holade, Y.; Sahin, N.; Servat, K.; Napporn, T.; Kokoh, K. Recent advances in carbon supported metal nanoparticles preparation for oxygen reduction reaction in low temperature fuel cells. Catalysts 2015, 5, 310-348. [CrossRef]

208. Holade, Y.; Servat, K.; Napporn, T.W.; Kokoh, K.B. Electrocatalytic properties of nanomaterials synthesized from "bromide anion exchange" method-Investigations of glucose and glycerol oxidation. Electrochim. Acta 2015, 162, 205-214. [CrossRef]

209. Holade, Y. Powering implantable micro-devices: Towards a new joker? L'Act. Chim. 2016, 412, $23-31$.

210. Southcott, M.; MacVittie, K.; Halamek, J.; Halamkova, L.; Jemison, W.D.; Lobel, R.; Katz, E. A pacemaker powered by an implantable biofuel cell operating under conditions mimicking the human blood circulatory system-Battery not included. Phys. Chem. Chem. Phys. 2013, 15, 6278-6283. [CrossRef] [PubMed]

211. Pistoia, G. Batteries for Portable Devices; Elsevier Science B.V.: Amsterdam, The Netherlands, 2005.

212. Szczesny, S.; Jetzki, S.; Leonhardt, S. Review of Current Actuator Suitability for Use in Medical Implants. In Proceedings of the 28th Annual International Conference of the IEEE Engineering in Medicine and Biology Society (EMBS '06), New York City, NY, USA, 30 August 2006-3 September 2006; pp. 5956-5959.

213. Hebié, S.; Holade, Y.; Servat, K.; Kokoh, B.K.; Napporn, T.W. Electrochemical reactivity at free and supported gold nanocatalysts surface. In Catalytic Application of Nano-Gold Catalysts; Mishra, N.K., Ed.; Intech: Rijeka, Croatia, 2016; pp. 101-130.

214. Gellett, W.; Kesmez, M.; Schumacher, J.; Akers, N.; Minteer, S.D. Biofuel cells for portable power. Electroanalysis 2010, 22, 727-731. [CrossRef]

215. Katz, E. Implantable biofuel cells operating in vivo-Potential power sources for bioelectronic devices. Bioelectron. Med. 2015, 2, 1-12.

216. MacVittie, K.; Conlon, T.; Katz, E. A wireless transmission system powered by an enzyme biofuel cell implanted in an orange. Bioelectrochemistry 2015, 106, 28-33. [CrossRef] [PubMed]

217. Schröder, U. From in vitro to in vivo-Biofuel cells are maturing. Angew. Chem. Int. Ed. 2012, 51, 7370-7372. [CrossRef] [PubMed]

218. Schwefel, J.; Ritzmann, R.E.; Lee, I.N.; Pollack, A.; Weeman, W.; Garverick, S.; Willis, M.; Rasmussen, M.; Scherson, D. Wireless communication by an autonomous self-powered cyborg insect. J. Electrochem. Soc. 2015, 161, H3113-H3116. [CrossRef]

219. Falk, M.; Alcalde, M.; Bartlett, P.N.; De Lacey, A.L.; Gorton, L.; Gutierrez-Sanchez, C.; Haddad, R.; Kilburn, J.; Leech, D.; Ludwig, R.; et al. Self-powered wireless carbohydrate/oxygen sensitive biodevice based on radio signal transmission. PLoS ONE 2014, 9, e109104. [CrossRef] [PubMed]

220. Falk, M.; Shleev, S.; Narváez Villarrubia, C.W.; Babanova, S.; Atanassov, P. Biological fuel cells for biomedical applications. In Enzymatic Fuel Cells: From Fundamentals to Applications; Luckarift, H.R., Atanassov, P., Johnson, G.R., Eds.; John Wiley \& Sons, Inc.: Hoboken, NJ, USA, 2014; pp. 422-450.

221. Jia, W.; Valdés-Ramírez, G.; Bandodkar, A.J.; Windmiller, J.R.; Wang, J. Epidermal biofuel cells: Energy harvesting from human perspiration. Angew. Chem. Int. Ed. 2013, 52, 7233-7236. [CrossRef] [PubMed]

222. Jia, W.; Bandodkar, A.J.; Valdés-Ramírez, G.; Windmiller, J.R.; Yang, Z.; Ramírez, J.; Chan, G.; Wang, J. Electrochemical tattoo biosensors for real-time noninvasive lactate monitoring in human perspiration. Anal. Chem. 2013, 85, 6553-6560. [CrossRef] [PubMed]

223. Diamond, D.; Coyle, S.; Scarmagnani, S.; Hayes, J. Wireless sensor networks and chemo-/biosensing. Chem. Rev. 2008, 108, 652-679. [CrossRef] [PubMed]

224. Windmiller, J.R.; Wang, J. Wearable electrochemical sensors and biosensors: A review. Electroanalysis 2013, 25, 29-46. [CrossRef]

225. Luckarift, H.R.; Atanassov, P.; Johnson, G.R. Enzymatic Fuel Cells: From Fundamentals to Applications, 1st ed.; John Wiley \& Sons, Inc.: Hoboken, NJ, USA, 2014; p. 496.

(C) 2017 by the authors; licensee MDPI, Basel, Switzerland. This article is an open access article distributed under the terms and conditions of the Creative Commons Attribution (CC-BY) license (http://creativecommons.org/licenses/by/4.0/). 